\author{
UnB - UNIVERSIDADE DE BRASÍLIA \\ FGA - FACULDADE GAMA \\ PROGRAMA DE PÓS-GRADUAÇÃO EM ENGENHARIA \\ BIOMÉDICA
}

\title{
ESTUDO ESTATÍSTICO DA RESPOSTA DA FREQUÊNCIA CARDÍACA DE AMPUTADOS DURANTE TESTE CARDIOPULMONAR
}

ELISÂNGELA DE ANDRADE AOYAMA

ORIENTADORA: Dra. Vera Regina Fernandes da Silva Marães CO-ORIENTADORA: Dra. Dra. Marília Miranda Forte Gomes

DISSERTAÇÃO DE MESTRADO EM ENGENHARIA BIOMÉDICA

PUBLICAÇÃO: 059A/2017

BRASÍLIA/DF: JANEIRO - 2017 


\section{UnB - UNIVERSIDADE DE BRASÍLIA}

FGA - FACULDADE GAMA

\section{PROGRAMA DE PÓS-GRADUAÇÃO EM ENGENHARIA} BIOMÉDICA

\section{ESTUDO ESTATÍSTICO DA RESPOSTA DA FREQUÊNCIA CARDÍACA DE AMPUTADOS DURANTE TESTE CARDIOPULMONAR}

\section{ELISÂNGELA DE ANDRADE AOYAMA}

DiSSERTAÇÃO DE MESTRAdO SUBMETIDA AO PROGRAMA DE PÓSGRADUAÇÃ̃O EM ENGENHARIA BIOMÉDICA DA FACULDADE GAMA DA UNIVERSIDADE DE BRASÍLIA, COMO PARTE DOS REQUISITOS NECESSÁRIOS PARA A OBTENÇÃO DO GRAU DE MESTRE EM ENGENHARIA BIOMÉDICA.

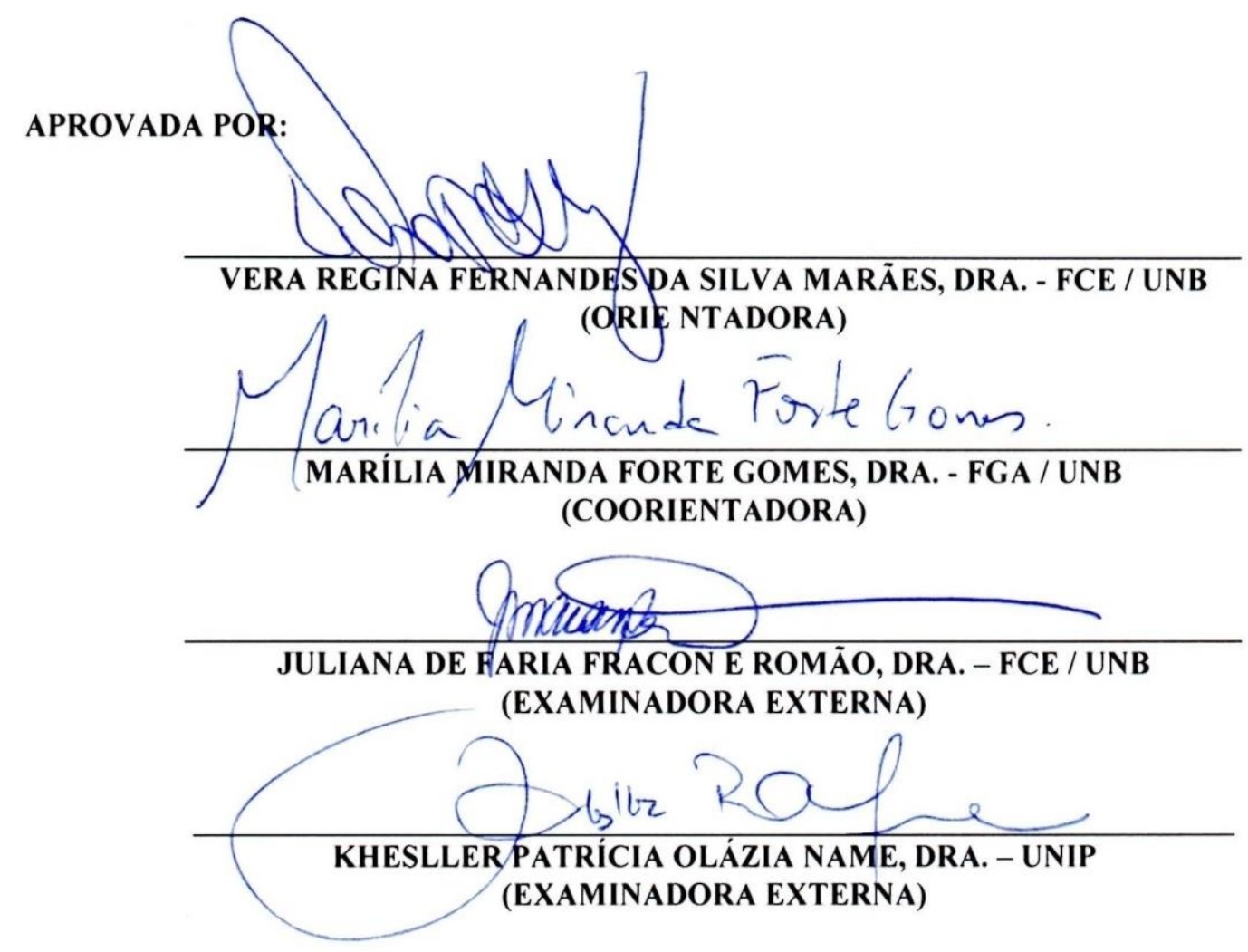

BRASÍLIA/DF, 25 DE JANEIRO DE 2017. 


\section{FICHA CATALOGRÁFICA}

ELISÂNGELA DE ANDRADE AOYAMA

ESTUDO ESTATÍSTICO DA RESPOSTA DA FREQUÊNCIA CARDÍACA DE AMPUTADOS DURANTE TESTE CARDIOPULMONAR, [Distrito Federal] 2017.

77 p., 210 x 297 mm (FGA/UnB Gama, Mestre, Engenharia Biomédica, 2017). Dissertação de Mestrado - Universidade de Brasília. Faculdade Gama. Programa de Pós-Graduação em Engenharia Biomédica.

1. EXERCÍCIO FÍSICO

2. FREQUÊNCIA CARDÍACA

3. LIMIAR ANAERÓBIO

I. FGA UnB Gama/ UnB.

II. Título (série)

\section{REFERÊNCIA BIBLIOGRÁFICA}

AOYAMA, E. A. (2017). ESTUDO ESTATÍSTICO DA RESPOSTA DA FREQUÊNCIA CARDÍACA DE AMPUTADOS DURANTE TESTE CARDIOPULMONAR. Dissertação de Mestrado em Engenharia Biomédica, Publicação 059A/2017, Programa de PósGraduação em Engenharia Biomédica, Faculdade Gama, Universidade de Brasília, Brasília, DF, 77 p.

\section{CESSÃO DE DIREITOS}

AUTORA: ELISÂNGELA DE ANDRADE AOYAMA

TÍTULO: ESTUDO ESTATÍSTICO DA RESPOSTA DA FREQUÊNCIA CARDÍACA DE AMPUTADOS DURANTE TESTE CARDIOPULMONAR

GRAU: Mestre

ANO: 2017

É concedida à Universidade de Brasília permissão para reproduzir cópias desta dissertação de mestrado e para emprestar ou vender tais cópias somente para propósitos acadêmicos e científicos. $\mathrm{O}$ autor reserva outros direitos de publicação e nenhuma parte desta dissertação de mestrado pode ser reproduzida sem a autorização por escrito do autor.

2017

QUADRA 20 CASA 83 SETOR LESTE GAMA.

CEP 72.460-200 Brasília, DF - Brasil. 


\section{DEDICATÓRIA}

Para ..., com amor.

"Treine enquanto eles dormem, estude enquanto eles se divertem, persista enquanto eles descansam, e então, viva o que eles sonham".

Provérbio japonês. 


\section{AGRADECIMENTOS}

Assim como tudo é possível para quem tem fé e acredita, porque sem Deus nada é possível, meu primeiro agradecimento é para Ele, por me guiar, dar saúde, força e sabedoria para superar os obstáculos e concluir mais uma etapa da minha vida.

Em especial ao meu esposo Hélio por apreender a importância dessa conquista e apoio incondicional em todos os momentos desta significativa etapa em minha vida e aos meus filhos Igor, Laís e Vítor, que sabem se amor e educação são critérios para ser mãe, é porque imaginei os filhos que eu queria ter.

Aos meus pais, João e Marilúzia, mesmo diante de todas as dificuldades que enfrentaram ao longo de suas vidas, sempre fizeram questão de nos proporcionar uma criação baseada no respeito, humildade e muito amor. Aos meus irmãos Edson (in memoriam), Edgelson e Elizany e seus familiares, por compreenderem a minha ausência em muitos momentos.

A professora Dra. Vera Marães, por ter concedido a honra de sua orientação, por todos os "anseios intelectuais" provocados a cada reunião e por mostrar que uma pesquisadora deve estar além da fisiologia. Espero suprir as expectativas quanto orientanda.

A professora e co-orientadora Dra. Marília Gomes que de maneira muito agradável e com maestria prestou relevantes contribuições à minha formação acadêmica.

Não poderia esquecer a aplicada Bruna Sousa por seu empenho e colaboração quando mais precisei, a bendita e complexa análise estatística.

Ao apoio financeiro para realização dos testes e exames viabilizados pelo CNPq e FAPDF.

Aos voluntários da pesquisa e aos técnicos do Laboratório de Biofísica e de Fisiologia do Exercício (FCE - UnB), que sempre deram todo o suporte necessário para a realização do presente trabalho.

Sem mestres, amigos, família e fé eu não seria nada e não iria a lugar algum. Todos tiveram importância ímpar neste processo e serei eternamente grata por isso. 


\title{
RESUMO
}

\section{ESTUDO ESTATÍSTICO DA RESPOSTA DA FREQUÊNCIA CARDÍACA DE AMPUTADOS DURANTE TESTE CARDIOPULMONAR}

\author{
Autor: ELISÂNGELA DE ANDRADE AOYAMA \\ Orientadora: Profa. Dra. Vera Regina Fernandes da Silva Marães \\ Co-orientadora: Profa. Dra. Marília Miranda Forte Gomes \\ Programa de Pós-Graduação em Engenharia Biomédica \\ Brasília, Janeiro de 2017.
}

A resposta da frequência cardíaca é considerada o melhor parâmetro para monitorar a intensidade do trabalho do coração tornando-se ferramenta indispensável na prescrição individualizada do exercício físico e para a clínica, com intuito de elucidar as causas e os riscos de morbimortalidade desencadeados por sua oscilação caracterizada por arritmias fatais. O teste de exercício máximo ou teste ergométrico é utilizado para avaliar possíveis alterações cardiovasculares e identificar vários marcadores metabólicos. Este teste associado a um ergoespirômetro permite coletar e analisar os gases inspirados e expirados e obter importantes marcadores metabólicos como o limiar anaeróbio e o ponto de compensação ventilatória. Estes limiares podem ser identificados também por meio da análise da resposta da frequência cardíaca durante o exercício físico tornando-se um método mais prático e menos dispendioso comparativamente a ergoespirometria. Este trabalho apresenta como objetivos identificar mudanças na curva de resposta da frequência cardíaca de amputados durante teste cardiopulmonar e identificar o limiar anaeróbio empregando ferramenta estatística. Os dados para análise foram obtidos por meio da aplicação do teste cardiopulmonar, realizado em três indivíduos do sexo masculino, com amputação transfemoral, na faixa etária entre 27 e 32 anos. Todos os voluntários apresentaram teste sem risco para quedas e esforço submáximo, tendo como causa o desacoplamento da prótese. Exibiram maiores valores de frequência cardíaca em menores potências, sugerindo que amputados transfemorais apresentem ajustes mitocondriais e cardiovasculares ocasionados pela perda parcial do membro. A elevação da frequência cardíaca acompanhando o acréscimo de carga, sendo que os voluntários alcançaram em torno de $90 \%$ da frequência cardíaca máxima prevista no método matemático Heteroscedástico e no método ARIMA, demonstraram boa atividade musculoesquelética, metabólica e cardiorrespiratória e condicionamento aeróbio obtido pelas atividades físicas regulares. A determinação do limiar de anaerobiose é de extrema importância para evitar exercícios acima dos valores mensurados.

Palavras-chaves: Exercício físico, Frequência cardíaca, Limiar anaeróbio e Teste de esforço. 


\title{
ABSTRACT \\ STATISTICAL STUDY OF AMPUTEE CARDIAC FREQUENCY DURING CARDIOPULMONARY TEST
}

\author{
Author: ELISÂNGELA DE ANDRADE AOYAMA \\ Supervisor: Dra. Vera Regina Fernandes da Silva Marães \\ Co-supervisor: Dra. Marília Miranda Forte Gomes \\ Post-Graduation Program in Biomedical Engineering \\ Brasília, January of 2017.
}

The heart rate response is considered the best parameter to monitor heart work intensity, making it an indispensable tool in individualized exercise and clinical prescription, in order to elucidate the causes and risks of morbimortality triggered by its oscillation characterized by fatal arrhythmias. The maximal exercise test or exercise test is used to evaluate possible cardiovascular changes and to identify various metabolic markers. This test associated with an ergospirometer allows collecting and analyzing the inspired and expired gases and obtaining important metabolic markers such as the anaerobic threshold and the point of ventilatory compensation. These thresholds can also be identified by analyzing heart rate response during exercise, making it a more practical and less expensive method compared to ergospirometry. This work presents as objectives to identify changes in the heart rate response curve of amputees during cardiopulmonary test and to identify the anaerobic threshold using a statistical tool. The data for analysis were obtained through the application of the cardiopulmonary test, performed in three males, with transfemoral amputation, between the ages of 27 and 32 years. All the volunteers presented a test without risk for falls and submaximal effort, due to the decoupling of the prosthesis. They exhibited higher heart rate values at lower potencies, suggesting that transfemoral amputees present mitochondrial and cardiovascular adjustments caused by partial limb loss. The increase in heart rate accompanied by an increase in load, and the volunteers reached around $90 \%$ of the maximum heart rate predicted in the Heteroscedastic mathematical method and the ARIMA method, demonstrated good musculoskeletal, metabolic and cardiorespiratory activity and aerobic conditioning obtained through physical activities Regular. The determination of the anaerobic threshold is of extreme importance to avoid exercises above the measured values.

Key-words: Physical exercise, Heart rate, Anaerobic threshold and Stress test. 


\section{SUMÁRIO}

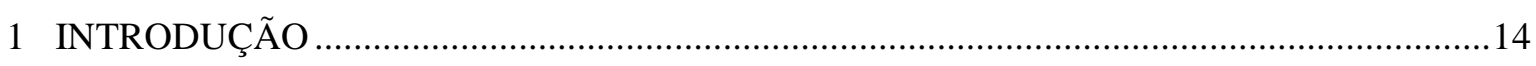

1.1 CONTEXTUALIZAÇÃO E FORMULAÇÃO DO PROBLEMA ……................................... 14

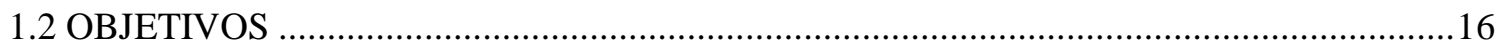

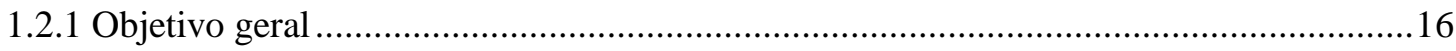

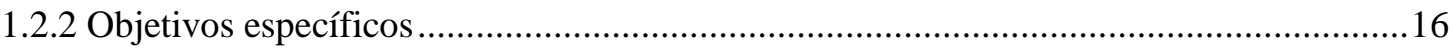

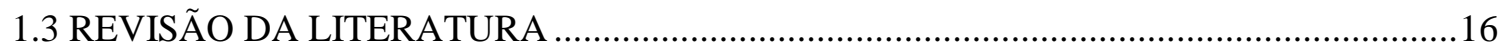

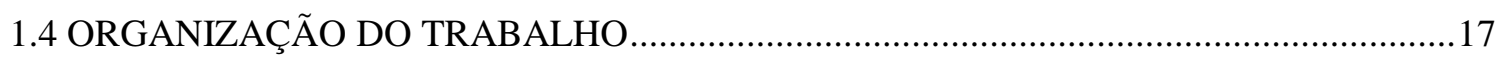

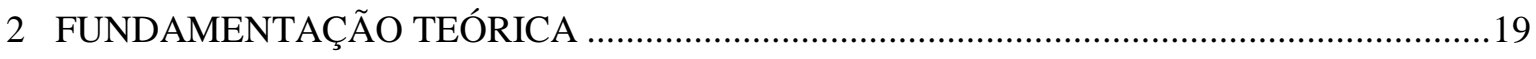

2.1 ANATOMIA E FIOSIOLOGIA CARDIOVASCULAR....................................................... 19

2.2 MECANISMOS DE CONTROLE DA FREQUÊNCIA CARDÍACA ...................................20

2.3 FREQUÊNCIA CARDÍACA EM CONDIÇÕES ESPECÍFICAS ........................................21

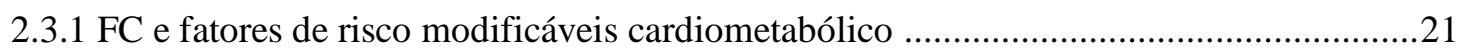

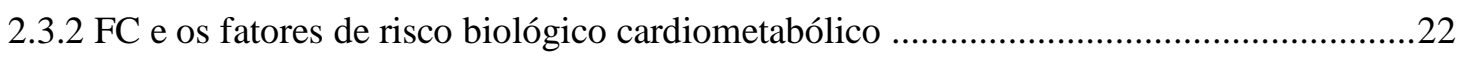

2.3.3 FC e os fatores de estilo de vida de risco cardiometabólico ..........................................22

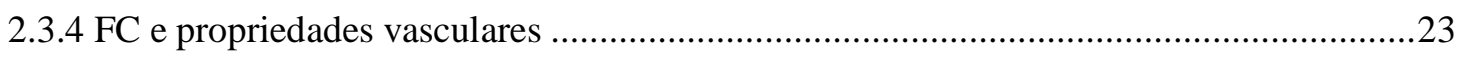

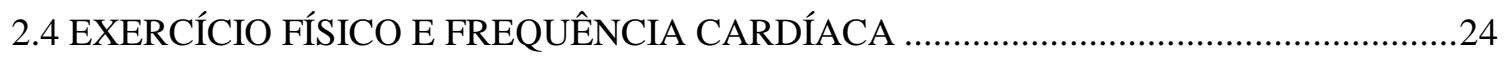

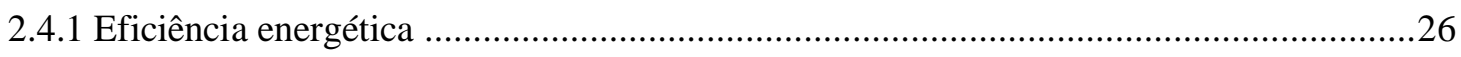

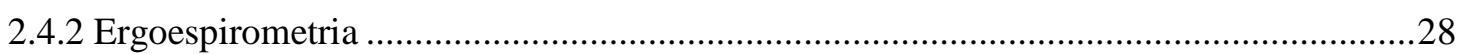

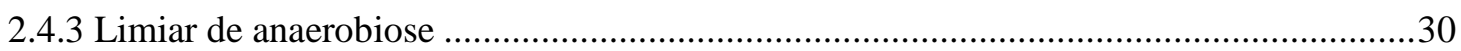

2.5 ANÁLISE DAS IMPLICAÇÕES CLÍNICAS DA FREQUÊNCIA CARDÍACA ..................31

2.6 ATIVIDADE FÍSICA PRATICADA POR INDIVÍDUOS AMPUTADOS ............................33

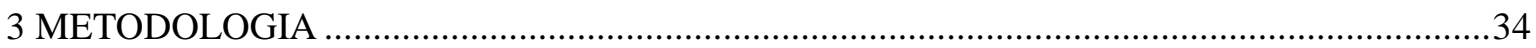

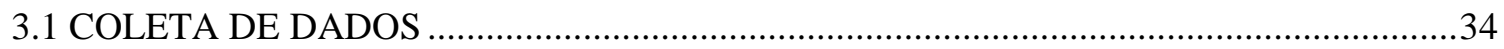

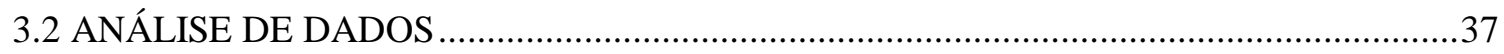

4 RESULTADOS

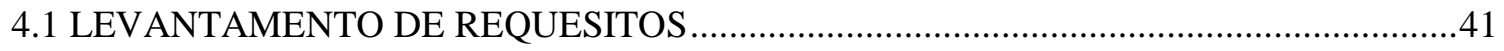

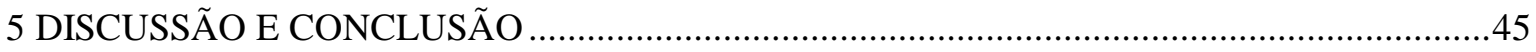

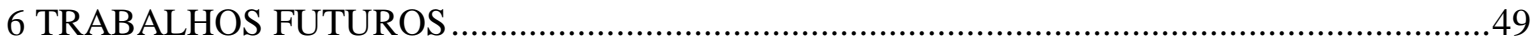

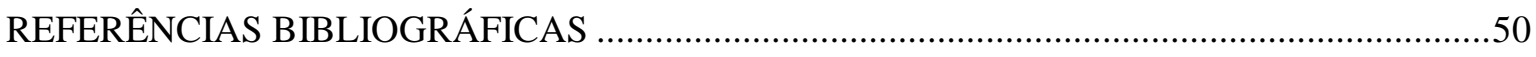

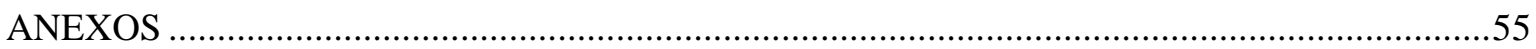

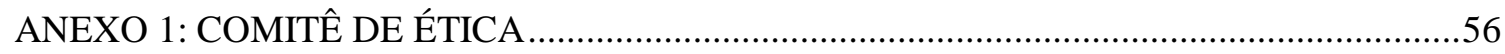

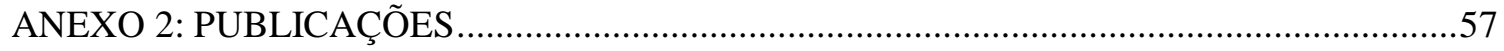

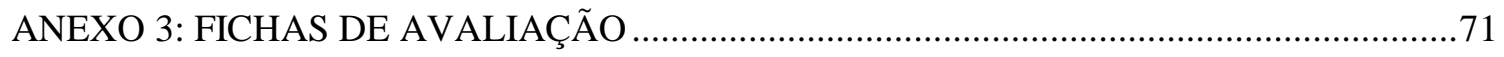

ANEXO 4: TERMO DE CONSENTIMENTO LIVRE E ESCLARECIDO (TCLE) ..................76 


\section{LISTA DE TABELAS}

Tabela 1: Características da amostra. Dados antropométricos descritivos de pacientes amputados transfemorais $(\mathrm{n}=3)$

Tabela 2: Valores detalhados de RMSSD, FC método heteroscedástico e ARIMA no momento do limiar de anaerobiose . .44 Tabela 3: Valores médios de RMSSD, FC método heteroscedástico e ARIMA no momento do limiar de anaerobiose 44 


\section{LISTA DE FIGURAS}

Figura 1: Escala de Borg - percepção de esforço para adultos em cicloergômetro.

Figura 2: Coleta de dados da frequência cardíaca durante o teste cardiopulmonar em bicicleta

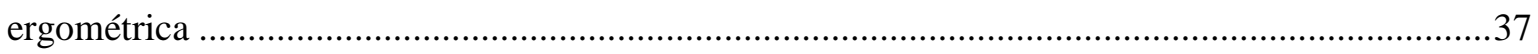

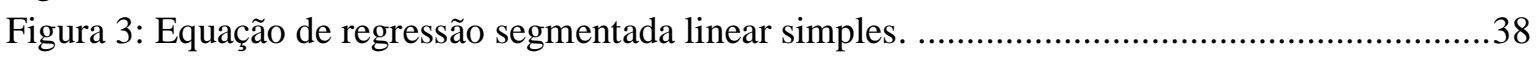

Figura 4: Sequência de atividades propostas para obtenção dos resultados......................................39

Figura 5: Dados coletados dos intervalos RR (inverso da frequência cardíaca) durante teste cardiopulmonar de um voluntário estudado ................................................................................. 40

Figura 6: Frequência cardíaca expresso em batimentos por minutos, em função do tempo total de exercício (s), com análise por método matemático Heteroscedástico do voluntário COL .................41 Figura 7: Frequência cardíaca expresso em batimentos por minutos, em função do tempo total de exercício (s), com análise por método matemático Heteroscedástico do voluntário FBF . .42

Figura 8: Frequência cardíaca expresso em batimentos por minutos, em função do tempo total de exercício (s), com análise por método matemático Heteroscedástico do voluntário HSB ................42 Figura 9: Representação do ajuste do modelo autoregressivo (ARIMA) aos dados de frequência cardíaca em batimentos por minuto em função do espaço de descrição do software, obtidos durante o teste de exercício físico do voluntário COL . .43

Figura 10: Representação do ajuste do modelo autoregressivo (ARIMA) aos dados de frequência cardíaca em batimentos por minuto em função do espaço de descrição do software, obtidos durante o teste de exercício físico do voluntário FBF

Figura 11: Representação do ajuste do modelo autoregressivo (ARIMA) aos dados de frequência cardíaca em batimentos por minuto em função do espaço de descrição do software, obtidos durante o teste de exercício físico do voluntário HSB. . .44 


\section{LISTA DE SÍMBOLOS, NOMENCLATURAS E ABREVIAÇÕES}

ADP - Adenosina Difosfato

ARIMA - Autoregressivos-Integrados-Médias Móveis

ATP - Adenosina Trifosfato

ATS - Avaliação da Tecnologia em Saúde

ATPase - Miosina Muscular

BPM - Batimentos Por Minuto

$\mathrm{CaO}_{2}-$ Perióxido de Cálcio

$\mathrm{CH}-$ Carboidratos

$\mathrm{cm}-$ Centímetro

$\mathrm{CO}_{2}-$ Dióxido de Carbono

ECA - Enzima Conversora de Angiotensina

ECG - Eletrocardiograma

FAD+ - Dinucleótido de Flavina e Adenina

FC - Frequência Cardíaca

$\mathrm{FC}_{\text {máx }}-$ Frequência Cardíaca Máxima

FCV - Frequência Cardiorespiratória

$\mathrm{H}_{2} \mathrm{O}-$ Água

IBGE - Instituto Brasileiro de Geografia e Estatística

IMC - Índice de Massa Corpórea

IPAQ - Questionário Internacional de Atividade Física

Kcal - Quilocaloria

kPa - kilopascal (unidade padrão de pressão e tensão no Sistema Internacional de Unidades)

LA - Limiar Aeróbio 
LAn - Limiar Anaeróbio

LS - Lipídios

LV - Limiar Ventilatório

MEEM - Mini Exame do Estado Mental

mmHg - Milímetros de Mercúrio

NAD + - Nicotinamida Adenina Dinucleotídeo

ne - Eficiência do Acoplamento Contrátil

nm - Eficiência Muscular Total

$n p$ - Eficiência do Acoplamento Fosforilativo

OMS - Organização Mundial da Saúde

$\mathrm{O}_{2}$ - Oxigênio

PA - Pressão Arterial

$\mathrm{PaCO}_{2}-$ Pressão Parcial de Dióxido de Carbono

PCr - Reação da cadeia Polimerase

Q $\mathrm{CO}_{2}-$ Produção Periférica de Dióxido de Carbono

$\grave{Q} O_{2}$ - Consumo Periférico de Oxigênio

Q - Calor

QR - Quociente Respiratório

RMSSD - Raiz quadrada média das diferenças sucessivas

RR - Intervalo do Inverso da Frequência Cardíaca

SciELO - Scientific Electronic Library Online

SPPB - Short Physical Performance Battery

SPSS - Statistical Package for Social Science for Windows

SRAA - Sistema Regulador Renina-Angiotensina-Aldosterona

SNA - Sistema Nervoso Autônomo 
TCP - Teste Cardiopulmonar

TECP - Teste de Esforço Cardiopulmonar

TUG - Timed Up and Go

U - Potencial e Cinética

UnB - Universidade de Brasília

VFC - Variabilidade da Frequência Cardíaca

$\dot{V} \mathrm{CO}_{2}-$ Produção de Dióxido de Carbono

$\dot{V} \mathrm{O}_{2}-$ Consumo de Oxigênio

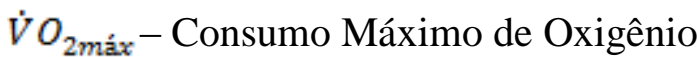

W - Trabalho Muscular

$\Delta \mathrm{G}-$ Energia Livre

$\Delta \mathrm{p}$ - Força Prótonmotiva 


\section{INTRODUÇÃO}

\subsection{CONTEXTUALIZAÇÃO E FORMULAÇÃO DO PROBLEMA}

As necessidades corporais são reguladas pelos neurônios do centro vasomotor, adaptados por atividade dos neurônios do simpático, assim, se a pressão arterial aumenta, receptores específicos (barorreceptores) enviam sinais ao centro cardiorregulador e ao vasomotor. Segundo Marães (2010) a pressão nas artérias depende de parâmetros físicos, tais como: distensibilidade, resistência ao fluxo por parte dos vasos, viscosidade do sangue e ejeção da frequência cardíaca, e cada uma destas variáveis serão diretamente influenciadas pelo sistema nervoso autônomo (SNA).

A frequência cardíaca (FC) é caracterizada pelo número de vezes que o coração contrai e relaxa, ou seja, os batimentos por minuto. Reconhecidamente, é o melhor parâmetro de monitoramento da atividade física para determinar o limiar anaeróbio (LAn) (CARUSO, et al., 2012). A FC é uma informação importante sobre o estado de saúde de uma pessoa, e um excelente indicador sobre o nível de intensidade de trabalho do coração segundo Sandoval (2005), principalmente para avaliar diferentes variáveis fisiológicas. O músculo cardíaco responde às necessidades de oxigênio e fluxo sanguíneo do organismo em diferentes momentos.

Ao iniciar o exercício físico a FC aumenta de acordo a intensidade do exercício e a capacidade física atual do indivíduo. Há correlação direta entre a frequência cardíaca máxima $\left(\mathrm{FC}_{\text {máx }}\right)$ e o consumo máximo de oxigênio $\left(\dot{V} O_{2 \text { máx。 }}\right)$ durante o exercício, tanto para a população em geral quanto para esportista (SANDOVAL, 2005). Muitos fatores afetam a FC durante o exercício, sendo os principais: temperatura, umidade, horário, posição, ingestão de alimentos e uso de medicamentos. Para Caruso et al. (2012) aplicando-se modelos estatísticos tanto aos dados da produção de dióxido de carbono $\left(\mathrm{VCO}_{2}\right)$ quanto aos dados da $\mathrm{FC}$, é possível configurar importantes estratégias de avaliação e capacidade funcional.

Quando se pedala ou anda a pé o corpo promove movimentos complexos e afetam todos os sistemas do organismo. Enquanto se faz exercício várias vezes semanalmente o corpo adapta-se, fazendo de forma mais eficiente. Polito e Ferinatti (2003) afirmam que durante a prática de exercício o coração pode atingir 150 batimentos por minuto (bpm) ou 
mais duplicando o valor habitual em repouso. Esse valor, para a maioria das pessoas, situase em torno de 60 a 80 bpm. Este aumento permite ao coração bombear até 20 litros de sangue por minuto quadruplicando o habitual em repouso.

Para Gomes (2015) o mecanismo que gera energia durante o exercício físico provém da complexa e sofisticada integração entre os sistemas cardiovascular, respiratório e muscular. O limiar de anaerobiose ou limiar anaeróbio é considerado um importante marcador metabólico e é um índice para mensurar o desempenho aeróbio durante o exercício físico. Em teste cardiopulmonar (TCP) é possível analisar as respostas ventilatórias e metabólicas sendo refletidas, mesmo com atraso, na respiração celular dos músculos periféricos. Existem vários fatores de risco cardiovasculares e utilizar a frequência cardíaca como valiosa ferramenta possibilita ampliar perspectivas para a aplicação clínica. Diversos estudos apresentam a modificação da FC durante exercício físico e a alteração do balanço simpático-vagal cardíaco (MARÃES, 2010; MCARDLE et al., 2013; GUYTON, 2006).

A prática da atividade física regular e sistematizada influencia no desempenho funcional preservando a independência e autonomia das pessoas. Brasil (2009) afirma que as tecnologias em saúde incluem os equipamentos, medicamentos, procedimentos e sistemas organizacionais e de suporte, com intuito de promover os cuidados com a saúde. Primariamente a tecnologia biomédica, avaliada senso comum, oferece tecnologia aos equipamentos e medicamentos, interatuando diretamente com os pacientes (SECOLI, et al., 2010).

Geralmente cirúrgica a amputação é definida como a retirada total ou parcial de um membro, realizada entre a desarticulação do joelho e a de quadril a amputação transfemoral é dividida em terço proximal, médio e distal. Ao sofrer uma amputação, seja por problemas vasculares ou trauma, o corpo da pessoa deverá adaptar-se à assimetria de massa e força muscular para reduzir a carga assimétrica e a instabilidade lateral. Independente do tempo de amputação os pacientes afirmam que a dor crônica é prevalente (BRASILEIRO E ARAÚJO, 2013).

Para determinar o LAn utiliza-se o método ventilatório, de caráter não invasivo e consideravelmente prático, mas que infelizmente possui acesso restrito por envolver equipamentos caros, ainda que seja em laboratórios específicos, como os de fisiologia do esforço, afirma Marães (2010). Para o desenvolvimento de novos aparelhos criados por 
engenheiros biomédicos, os dados da pesquisa iniciam uma discussão sobre as possibilidades de aprimoramento, já que muitas vezes as análises da variável frequência cardíaca na identificação do limiar de anaerobiose e do ponto de compensação ventilatória, são feitas visualmente. Agregada ao estudo estatístico, essa inovação tecnológica possibilitará encontrar pontos de mudança na curva da FC correspondente ao limiar anaeróbio do indivíduo, ferramenta importante para a prescrição adequada de exercício físico tanto para o aprimoramento cardiorrespiratório quanto para reabilitação cardiovascular (MARÃES, 2010).

\subsection{OBJETIVOS}

\subsubsection{Objetivo geral}

Identificar padrões de mudanças da curva de frequência cardíaca de amputados durante teste cardiopulmonar para identificação do limiar de anaerobiose, utilizando ferramenta estatística.

\subsubsection{Objetivos específicos}

- Aplicar o teste cardiopulmonar (ergoespirométrico) em indivíduos amputados;

- Analisar a curva de frequência cardíaca (intervalos RR) de adultos submetidos ao teste cardiopulmonar;

- Identificar o limiar de anaerobiose a partir da análise estatística da frequência cardíaca (intervalos RR);

- Comparar os dados obtidos com a aplicação do teste cardiopulmonar e a literatura.

\subsection{REVISÃO DA LITERATURA}

Como base bibliográfica para a construção deste trabalho foram feitas buscas por artigos científicos, dissertações, livros e teses, em fontes especializadas como: PubMed, SciELO e repositório da UnB (Universidade de Brasília). A pesquisa foi realizada com a aplicação das palavras-chave: exercício físico, frequência cardíaca, limiar anaeróbio e teste de esforço e seus correspondentes na língua inglesa, para buscar os textos, com retorno de inúmeros trabalhos. Entretanto, foram selecionados apenas os trabalhos que possuíam 
maior relevância ao tema estudado. Os mesmos parâmetros foram utilizados para as buscas em todo o meio eletrônico e livros físicos.

O PubMed é uma base de dados de literatura biomédica para publicação de periódicos sobre ciências da vida e livros on-line, é um recurso livre desenvolvido e mantido pelo National Center for Biotechnology Information (NCBI) na Biblioteca Nacional EUA de Medicina (NLM), localizado no National Institutes of Health (NIH). A pesquisa realizada com a palavra-chave "Frequência Cardíaca" retornou 296.951 trabalhos (realizada em 09/08/15, às 20h17min), dos quais apenas um foi relevante para o trabalho. Utilizando a palavra-chave "Exercício Físico" surgiram 322.627 artigos (realizada em 10/08/15, às 23h20min) e um destes foi relevante. Ao buscar pelas palavras-chave "Limiar Anaeróbio" e "Teste de Esforço" foi encontrado apenas um trabalho (realizada em 11/08/15, às 23h26min), mas sem relevância ao tema em estudo.

SciELO (Scientific Electronic Library Online) é uma biblioteca científica eletrônica para publicação de periódicos científicos na internet. A pesquisa com a palavra-chave "Exercício Físico" retornou 790 trabalhos (realizada em 08/08/15, às 12h41min) e três foram importantes. Utilizando "Limiar Anaeróbio" como palavra-chave (realizada em 08/08/15, às 16h18min) o retorno foi de 97 artigos, sendo quatro consideráveis a este trabalho. Ao realizar pesquisa com a palavra-chave "Frequência Cardíaca" obteve-se retorno de 1.305 artigos (realizada em 09/08/15, às 9h04min) dos quais apenas três foram relevantes ao tema investigado.

Uma instituição comprometida com a excelência acadêmica, científica e tecnológica, a UnB (Universidade de Brasília), é considerada uma das melhores universidades brasileiras. Pesquisas realizadas no repositório institucional com as palavras-chave "Frequência Cardíaca", "Exercício Físico", "Limiar Anaeróbio" e "Teste de Esforço” retornaram 1.285 trabalhos (realizada em 03/07/15, às 08h54min) dos quais apenas um trabalho foi relevante ao tema em estudo.

\subsection{ORGANIZAÇÃO DO TRABALHO}

Este trabalho está organizado em cinco capítulos, incluindo este capítulo que contextualiza sobre a frequência cardíaca, a importância de se determinar o limiar de anaerobiose, os 
benefícios do exercício físico para pessoas amputadas, apresenta os objetivos, a revisão da literatura e sua organização.

No segundo capítulo apresenta-se uma visão geral do trabalho através do referencial teórico apresentando toda a alteração fisiológica durante o exercício e a relação com o limiar anaeróbio.

O terceiro capítulo trata-se da metodologia utilizada no estudo, de forma detalhada contendo os diferentes métodos utilizados para verificação do limiar durante o teste cardiopulmonar. Sendo que o quarto capítulo descreve os resultados obtidos sob o olhar dos três métodos e o plano de procedimentos detalha a metodologia utilizada no estudo.

O quarto capítulo apresenta uma discussão baseada em evidências comparando os resultados deste estudo com os artigos mais relevantes para o tema, apresentando as conclusões finais do trabalho.

Por fim, o quinto e último capítulo apresenta os trabalhos futuros que podem ser desenvolvidos a partir das ideias apresentadas neste documento. 


\section{FUNDAMENTAÇÃO TEÓRICA}

\subsection{ANATOMIA E FIOSIOLOGIA CARDIOVASCULAR}

O coração é um órgão formado por tecido muscular e sua estrutura confere ao músculo cardíaco ou miocárdio características eletroquímicas singulares. Desempenha a propulsão sanguínea sempre em atividade alternando fases de diástole (relaxamento) e de sístole (contração), sendo que um adulto, mesmo em repouso, efetua 70 contrações por minuto (YUE, 2009, p. 153). Entender a anatomia cardíaca facilita a compreensão da fisiologia cardíaca e consequências funcionais da doença.

A base do coração é composta pela superfície posterior formada pelo átrio esquerdo e uma pequena seção do átrio e do ventrículo direitos (MCARDLE et al., 2013). A parte apical do septo interventricular é composta por uma pequena porção da parte inferior do ventrículo esquerdo, estendida anteriormente, formando uma ponta obtusa. O ponto de impulso máximo se deve à inclinação do coração para frente e ao movimento dessa porção apical do ventrículo esquerdo durante a contração cardíaca. Yue (2009) afirma que ao visualizar o coração de frente, parece estar deitado de lado, voltado para frente e para a esquerda, com o lado direito à frente.

Para McArdle et al. (2013) o tamanho e o peso do coração são influenciados pela idade, constituição corporal, frequência de exercícios físicos e as doenças cardíacas. O coração de uma pessoa adulta comum tem aproximadamente $12 \mathrm{~cm}$ de comprimento da base ao ápice ventricular esquerdo, transversalmente de 8 a $9 \mathrm{~cm}$ de largura (na parte mais larga) e $6 \mathrm{~cm}$ de espessura anteroposterior. Corresponde a aproximadamente 0,43\% do peso corporal, de $280 \mathrm{~g}$ a $350 \mathrm{~g}$, com média de $300 \mathrm{~g}$, em homens adultos. Nas mulheres adultas aproximadamente $0,40 \%$ do peso corporal, 230 a $300 \mathrm{~g}$ de peso, com média de $250 \mathrm{~g}$ (YUE, 2009).

O sangue é impulsionado para o corpo por meio de contrações através do circuito pulmonar e do circuito sistêmico para fornecer nutrientes e remover resíduos dos órgãos. Segundo Gartner e Hiatt (2003) o coração é envolvido pelo pericárdio, membrana mucosa, e repousa no compartimento mediastinal mediano do tórax, entre duas cavidades pleurais.

É constituído por quatro câmaras musculares: dois átrios e dois ventrículos e estruturas associadas. O átrio e ventrículo direitos recebem sangue das demais partes do corpo e bombeiam para o sistema arterial pulmonar (baixa pressão) e o átrio e ventrículo esquerdos 
recebem sangue dos pulmões e bombeiam para o sistema arterial sistêmico (alta pressão). Os átrios e ventrículos direitos são separados dos átrios e ventrículos esquerdos por septos interatrial e interventricular (YUE, 2009).

A pressão não é constante no sistema arterial e oscila entre dois valores de pressão instantânea e dois valores matemáticos, que são descritos por McArdle et al. (2013), como: Pressão sistólica (máxima): influenciada pela idade e estado emocional do indivíduo, é medida no momento da sístole ventricular esquerda. A média em adulto sadio é de 12-17, 3 kPa (90-130 mmHg); Pressão diastólica (mínima): pressão que as paredes das artérias suportam durante o ciclo cardíaco, é medida no momento da diástole ventricular. A média em adulto sadio é de $8-11,3 \mathrm{kPa}(60-85 \mathrm{mmHg})$; Pressão de pulso: um adulto sadio tem a média com valores de $4-6 \mathrm{kPa}(30-45 \mathrm{mmHg})$ e é obtida pela diferença entre a pressão sistólica e a diastólica; Pressão média: obtém-se integrando a área da curva da pressão arterial em função do tempo, a média em um adulto sadio é de 10, 7-13, 3 kPa (80-100 $\mathrm{mmHg}$.

Obliquamente o eixo longo do coração está orientado para a esquerda, para baixo e para frente. Fatores que alterem a forma do tórax podem mudar a posição do coração e modificar este eixo. Para McArdle et al. (2013) a respiração na altura do diafragma e a expansão da caixa torácica podem mudar o eixo cardíaco, logo, quando a respiração é profunda o coração desce e adota posição vertical. Os fatores que causam variações no eixo, em pessoas saudáveis, incluem idade, peso, gravidez, forma do corpo e do tórax. A direção do eixo cardíaco também é influenciada por condições patológicas do coração, pulmões, órgãos abdominais e outras estruturas.

\subsection{MECANISMOS DE CONTROLE DA FREQUÊNCIA CARDÍACA}

A função primordial dos sistemas respiratório e cardiovascular é manter a troca gasosa celular dentro dos limites compatíveis com as demandas energético-metabólicas e o equilíbrio ácido-básico. Neder e Nery (2002) afirmam que durante o esforço físico o aumento da atividade contrátil do músculo estriado induz, consideravelmente, incrementos no consumo periférico de oxigênio $\left(\mathrm{Q}_{2}\right)$ e na liberação celular de dióxido de carbono $\left(\mathrm{CO}_{2}\right)$ e, por conseguinte, a sobrecarga dos sistemas de suporte ao exercício. A deficiência local de oxigênio ou a limitação enzimática é notada na transição repouso-exercício 
quando há necessidade de energia imediata para a progressão dos processos mitocondriais aeróbios, com variações inter e intra-individual aeróbio para gerar energia aeróbia.

Imprescindível para saúde humana a atividade física auxilia na estabilidade de peso corporal e previne ou retarda doenças cardíacas. A Organização Mundial de Saúde (OMS) recomenda aos adultos 150 minutos de atividade física moderada a vigorosa, por semana. Para Moore et al. (2012) a preocupação com pessoas inativas faz com que pesquisadores e profissionais de diversas áreas direcionem estudos, em países desenvolvidos e em desenvolvimento, para maximizar os benefícios da atividade física na promoção da qualidade de vida, mesmo não resultando em perda de peso, os benefícios propiciam o aumento da longevidade.

É notória e acelerada a transição demográfica, nutricional e epidemiológica enfrentada pelas populações nas últimas décadas. A transição demográfica deve-se ao ritmo veloz do crescimento da população idosa em consequência principalmente pela redução da taxa de natalidade e controle de doenças infectocontagiosas, graças aos avanços tecnológicos (UENO, 2012). Nutricionalmente é possível constatar a transição de desnutrição para obesidade, formas complexas desse indicador que coexistem. Segundo Alexandre (2012) a transição epidemiológica é marcada pela redução de doenças infecciosas e aumento gradativo de doenças e agravos não transmissíveis, como as doenças cardiovasculares.

De acordo Hallal e Knuth (2011) a agenda de saúde pública e internacional prioriza a atividade física para a modificação do perfil de morbimortalidade e aumento da expectativa de vida, mas a mudança comportamental da população é intrincada devida principalmente a aspectos ambientais, culturais e socioeconômicos.

\subsection{FREQUÊNCIA CARDÍACA EM CONDIÇÕES ESPECÍFICAS}

\subsubsection{FC e fatores de risco modificáveis cardiometabólico}

A frequência cardíaca estabelece prioridade de avaliação por incidência e prevalência de morbimortalidade e o grande número de pacientes afetados potencializando a redução do risco para a saúde através de uma metodológica atividade física, diz Ueno (2012). 
Marocolo et al. (2012) afirmam que internacionalmente o melhor parâmetro fisiológico para mensurar o consumo máximo de oxigênio (V $O_{2 m a ́ x}$ ) é significativo para equacionar a capacidade funcional do sistema cardiorespiratório com propósito de alcançar excelente saúde. Em laboratórios experimentais pode-se avaliar durante o exercício a potência aeróbia utilizando bicicleta ergonômetra e as medidas diretas, em espirômetros. A potência aeróbia máxima sofre variações conforme hábitos de atividade física, idade, peso corporal e sexo. O treinamento físico aeróbio tem efeito fisiológico direto à estimulação do sistema nervoso parassimpático, em repouso, aumentando a modulação autonômica e a variabilidade da frequência cardíaca (VFC). Ainda segundo o autor a VFC é a variação que ocorre entre batimentos cardíacos sucessivos em ritmo sinusal.

\subsubsection{FC e os fatores de risco biológico cardiometabólico}

O aumento da expectativa de vida com o envelhecimento da população e a mudança do perfil de morbimortalidade que acompanham o desenvolvimento dos países geram resultados que calculam riscos aos quais as pessoas estão sujeitas. Alexandre (2012) define risco como o grau de probabilidade da ocorrência de determinado evento e não é igual para cada pessoa. A epidemiologia pode mostrar, por meio de estudos estatísticos e interpretação epidemiológica, se uma população é mais doente ou mais saudável (BELLUSCI, 1995).

O movimento físico é caracterizado pelo fornecimento consecutivo de energia definida e mensurada pelos efeitos em definidos processos, afirmam Neder e Nery (2002). As leis básicas da termodinâmica possuem, no contexto biológico, energia química (potencial) dos alimentos e energia mecânica (cinética) da taxa do trabalho muscular (W), expressados fisicamente como calor $(\mathrm{Q})$. Constituído na $1^{\mathrm{a}}$ lei da termodinâmica o princípio universal de conservação de energia, ou seja, a energia não é criada, nem destruída e sim transformada. Onde U é formado pelo potencial e a cinética e representa a energia interna total de um corpo:

$$
\mathrm{U}=\mathrm{Q}-\mathrm{W}
$$

\subsubsection{FC e os fatores de estilo de vida de risco cardiometabólico}

Vários pesquisadores consideram que as atividades físicas adicionam expectativa de vida e geram benefícios aumentando em até sete anos na longevidade de uma pessoa. Estudos 
recentes, de acordo com Moore et al. (2012), mostram que o nível mínimo de atividade física que é necessário para aumentar a longevidade é o acréscimo de 75 minutos de caminhada rápida (ou outra atividade moderada) por semana. Os níveis recomendados pelas autoridades de saúde são de 150 minutos por semana para elevar em 3,4 anos a longevidade de uma pessoa. $\mathrm{O}$ aumento pode chegar a 4,5 anos se praticado durante 450 minutos semanais.

Ao longo dos anos a população brasileira vem apresentando uma expectativa de vida maior, conforme mostram dados do IBGE (2015), a expectativa de vida ao nascer subiu de 74,9 anos de idade para 75,2 - de 2013 para 2014. Os aumentos nas esperanças de vida preservam estreitas relações com o lento acréscimo da longevidade humana.

A Organização Mundial da Saúde (OMS) incluiu a atividade física na agenda mundial de saúde pública lançando a Estratégia Global de Alimentação, Atividade Física e Saúde, afirmam Hallal et al. (2007), após estudos epidemiológicos indicarem que grande parcela da população não atinge as recomendações atuais quanto à prática de atividades físicas. Os estudos comprovam a importância da atividade física para a manutenção da capacidade funcional e da autonomia no processo de envelhecimento, mas é primordial que a população se conscientize de todos os benefícios tanto para o estado físico quanto para o mental e o psicológico. Segundo Craig et al. (2003) a participação em atividades físicas leves e moderadas pode retardar os declínios funcionais.

\subsubsection{FC e propriedades vasculares}

O aumento da pressão arterial se deve a vasoconstrição das arteríolas e a redução do fluxo de sangue nos capilares. De acordo Nogueira et al. (2012) o metabolismo celular possui alta concentração de dióxido de carbono, o que sensibiliza as arteríolas e aumenta o fluxo sanguíneo, devido à intensa atividade metabólica nos tecidos.

A volemia, volume do sangue circulante em limites precisos, também auxilia no controle da pressão arterial por meio do sistema regulador renina-angiotensina-aldosterona (SRAA), hormônios vinculados à atividade renal, ativados pelas variáveis de volemia (MCARDLE et al., 2013). A variação da volemia ativa a produção de renina, uma glicoproteína que produz angiotensina I, encontrada no fígado, em angiotensina II, o mais potente vasoconstritor, após ser ativada pela enzima conversora de angiotensina (ECA), concentrada nos pulmões. 
A atividade muscular possui condições que influenciam na pressão arterial. No início de um exercício físico a pressão sistólica pode chegar a 180-200 mmHg, enquanto a diastólica possui pouco aumento $(90-100 \mathrm{mmHg}$ ), com o treinamento as diferenças diminuem, segundo Neder e Nery (2002). A idade é outra condição que influencia por reduzir a distensibilidade das artérias, perda fisiológica ou patológica de elasticidade das artérias, aumentando gradativamente a pressão diferencial.

\subsection{EXERCÍCIO FÍSICO E FREQUÊNCIA CARDÍACA}

Para analisar a frequência cardíaca é necessário ponderar o registro realizado das condições fisiológicas que podem variar em curta, quando durar entre 5 a 30 minutos, ou de longa duração (24 horas) e também se foram obtidos durante o repouso ou exercício físico. Para análise linear são indispensáveis 256 intervalos inversos a frequência cardíaca (RR) e para análise não-linear a recomendação varia em torno de 1.000 intervalos $\mathrm{RR}$, cada intervalo RR corresponde a um batimento cardíaco (MARÃES, 2010).

Fundamentados na frequência cardíaca em repouso é possível determinar a intensidade do exercício físico. O coração de um indivíduo saudável, em repouso, bate continuamente entre 70 e 80 vezes por minuto, logo valores muito inferiores e superiores a esta frequência cardíaca, em geral, possuem correlação a distúrbios funcionais e risco cardiovascular (MARÃES, 2010). Sabe-se que a frequência cardíaca pode ser modificada dependendo das condições fisiológicas como repouso, exercício físico, posição de decúbio, vigília, sono e muitas outras.

A variabilidade da frequência cardíaca é estimulada pelos nervos parassimpáticos associados à redução dos valores de frequência cardíaca e os efeitos da estimulação para aumento desses valores provêm de nervos simpáticos, afirma Polito (2003). A postura envolve importantes modificações das variáveis cardiovasculares correspondente aos desvios hidrostáticos e respostas reflexas adaptativas.

A intensidade do exercício físico promove modulação entre os sistemas simpático e parassimpático apresentados por crescimento linear. Vários mecanismos fisiológicos regulam a frequência cardíaca durante o exercício físico, como os fatores humorais e o SNA, promovendo mudanças nos valores absolutos e na variabilidade, atuando sobre o coração (LEITE et al., 2010). 
Após o primeiro minuto de esforço físico a taquicardia tardia é mantida por fatores humorais. O marcante aumento da frequência cardíaca se deve ao período de latência, logo no início do esforço, independente da intensidade de potência aplicada, estimulando o nódulo sinoatrial devido à diminuição da estimulação parassimpática (MARÃES, 2010). Influenciado parcialmente pela atividade física o crescimento da frequência cardíaca é mais lenta após 60 a 90 segundos do período inicial devido à remoção lenta do tônus vagal.

Posteriormente ao pico da frequência cardíaca os valores desta variável serão equilibrados entre 1,8 a 3,7 minutos, em esforços de baixa potência. Para Leite et al. (2010) as potências elevadas da frequência cardíaca aumentam pela predominância da atividade simpática que impede, enquanto durar o exercício físico, a estabilidade da variável, denominada elevação lenta da frequência cardíaca.

O mecanismo anaeróbio de formação de ATP é ativado a nível muscular na potência submáxima durante o exercício físico resultando em produção de ácido láctico, denominado limiar anaeróbio (MARÃES, 2010; POLITO E FARINATTI, 2003). Considerado um essencial marcador fisiológico o limiar anaeróbio comprova episódio de alterações metabólicas e humorais e sobre as variáveis do sistema nervoso central e periférico e ainda do cardiorrespiratório.

$\mathrm{O}$ déficit de $\mathrm{O}_{2}$ existe pelo atraso do metabolismo aeróbio, entre o repouso e o exercício, para gerar energia em uma atividade. Durante esse período de déficit de oxigênio o início do exercício é suprido localmente pela ATP armazenada, o depósito de $\mathrm{O}_{2}$, glicose anaeróbia e metabolismo da PCr. A presença de alguma glicose anaeróbia, até em exercícios leves, gera temporariamente, ácido lático (BENETTI et al., 2000). Os exercícios moderados, sem acúmulo de ácido lático, possuem déficit alático muito maiores, dependendo crucialmente dos ajustes cardiorrespiratórios.

A atividade enzimática local e o desempenho muscular sofrem efeitos após a desestabilização provocada pela formação de ácido lático $\left(\mathrm{C}_{3} \mathrm{H}_{6} \mathrm{O}_{3}\right)$ produzido no ânion lactato e no próton $\mathrm{H}+$. A falta de $\mathrm{O}_{2}$ na cadeia de transporte de elétrons impossibilita a regeneração de nicotinamida adenina dinucleotídeo $(\mathrm{NAD}+)$ ou dinucleótido de flavina e adenina $(\mathrm{FAD}+)$ e o piruvato assume como aceptor, catalisando lactato desidrogenase (LDH), permitindo assim a continuação da glicose, após regenerar o NAD+, (SADAVA et al., 2009). O lactato é uma importante fonte de energia quando revertido para piruvato caso 
a oferta local de $\mathrm{O}_{2}$ aumente, metabolizado no fígado ou ativamente captado por fibras musculares adjacentes ao sítio de liberação e/ou fibras miocárdicas.

Para Polito e Farinatti (2003) à medida que o corpo inicia o exercício físico os músculos utilizam elevados índices de oxigênio e o coração passa a bombear mais sangue oxigenado para atender a demanda e o coração é capaz de adaptar-se a esse aumento por múltiplos mecanismos. A frequência cardíaca apresenta adaptação gradativa à elevada carga de exercício, estabilizando-se após dois ou três minutos (PRENTICE E VOIGHT, 2007).

\subsubsection{Eficiência energética}

Na matriz mitocondrial está vinculada a síntese de ATP cuja função é bombear os prótons para fora da mitocôndria, receptados por NAD+ ou FAD+, oxidados pelo $\mathrm{O}_{2}$ na cadeia de transporte. Fora da mitocôndria criam os gradientes $\Delta \mathrm{p}$ (força prótonmotiva) para transportar os prótons de volta para a mitocôndria criando energia livre para a síntese de ATP. Na sequência de reações de oxidação-redução é liberada $\Delta \mathrm{G}$ empregada para bombear prótons, por meio da membrana mitocondrial, dando continuidade ao metabolismo oxidativo. Ao final da cadeia são liberados $\mathrm{CO}_{2}$ e $\mathrm{H}_{2} \mathrm{O}$, agindo como oxidantes, após um átomo de oxigênio reagir a um par de prótons e elétrons e formarem água. Nesta via o ganho líquido é de 37 ou 36 ATP para glicólise aeróbia e 3 ou 2 ATP para glicólise anaeróbia (SADAVA et al., 2009).

A energia química potencial provém dos alimentos pelo metabolismo dos substratos energéticos. Esta energia é armazenada na porção terminal da molécula de ATP (adenosina trifosfato) constituindo a moeda energética orgânica, ou seja, para gerar ATP utiliza-se glicose, afirma Benetti (2000). É através de sua hidrólise, por um complexo enzimático disponível na miosina muscular (ATPase), que suficiente energia livre $\Delta \mathrm{G}$ é fornecida para a concentração. O exercício intenso realizado por alguns segundos é mantido pela ATP armazenada, sendo esta regenerada sucessivamente pela atividade mitocondrial.

A regeneração da ATP durante o exercício utiliza três grupos de substratos, descritos abaixo, segundo UNESCO (2013):

I. Carboidratos $(\mathrm{CH})$ ou sacarídeos são fontes fundamentais de energia química potencial, compartilham da estrutura de suporte das plantas (celulose) e crustáceos. São 
classificadas em monossacarídeo, dissacarídeo e polissacarídeo, sendo os dois primeiros mais conhecidos por açúcares. No corpo de um indivíduo o carboidrato aparece na forma de glicogênio no músculo esquelético e no fígado apresentando acesso limitado do $\mathrm{CH}$ corporal total durante o exercício físico, causando custo ventilatório.

II. Os lipídios (LS), subdivididos em saponificáveis e não-saponificáveis, são caracterizados por apresentarem propriedade física comum, solubilidade em solventes não polares e insolubilidade na água. Quanto à relevância biológica compõem a segunda fonte energética e mais eficiente, se comparado aos carboidratos, em liberar energia por grama de substrato oxidado. A oferta periférica de $\mathrm{O}_{2}$ decorre do metabolismo rico em LS originando custo cardiovascular.

III. As proteínas possuem fonte energética terciária, em exercício físico moderado, empregadas para preencher as necessidades energéticas musculares.

A energia muscular gasta durante o exercício depende essencialmente do substrato utilizado. Para Sadava et al. (2009) o impacto dos substratos reflete em diferentes exigências para a taxa celular de intercambio, inspiração e expiração, de oxigênio $\left(Q_{Q} O_{2}\right)$ e dióxido de carbono $\left(\hat{Q} \mathrm{CO}_{2}\right)$, consequentes do metabolismo de carboidratos, gorduras e proteínas. Os carboidratos são considerados mais eficientes por gastar menos $\mathrm{O}_{2}$, em contrapartida, o metabolismo dos ácidos graxos são eficientes por liberar menos $\mathrm{CO}_{2}$.

A eficiência energética muscular, que gera trabalho, é analisada pelo fornecimento de energia adquirida pelos alimentos. Para a bioquímica apenas $50-55 \%$ da energia (livre do substrato) se transforma em ATP, chamada eficiência do acoplamento fosforilativo (np) e a contração muscular depende da eficiência do acoplamento contrátil (ne). Logo, a eficiência muscular total (nm) é de 25-30\%. A fosfocreatina possui concentração muscular superior, 4 a 6 vezes, à ATP (GUYTON, 2006). O metabolismo energético compreendido pela reação de fornecimento de ATP nas situações de alta demanda pode ser regenerado com gasto maior de ADP. Essa regeneração de ATP é controlada exatamente pelas necessidades celulares.

A aptidão do indivíduo depende das reservas energéticas quando é aplicada a potência na realização do trabalho. A transição da fase inicial repouso-exercício, atividades intensas ou súbitas, utilizam as fontes energéticas imediatamente produzidas pela glicose anaeróbia. 
Para sustentar atividades prolongadas, leves ou moderadas, utilizam-se fontes energéticas que provém do metabolismo oxidativo. A glicose obtida pela ação das fosforilases tem o ganho de 1 ATP, mas quando provém da glicogenólise muscular o ganho líquido é de 3 moléculas ou 2 ATP quando decorrer da glicose livre (MCARDLE et al., 2013).

O metabolismo celular unifica-se ao meio ambiente, devido à extensa cadeia anatomofuncional, tornando o maior desafio da fisiologia e homeostase sistêmica para o exercício físico. Qualquer gasto energético acima do repouso é definido como exercício, por consequência, atividade física. Para Neder e Nery (2002) um dos ramos do conhecimento biomédico é a fisiologia clínica do exercício definido como abordagem multidisciplinar, dedica-se ao estudo e avaliação integrados dos mecanismos sistêmicos de tolerância ao esforço, buscando respostas objetivas para a melhora no desempenho de indivíduos saudáveis ou recuperação funcional de pacientes.

A fisiologia clínica do exercício avalia pacientes quanto o desempenho físico e a tolerância ao esforço, fornecendo respostas para o entendimento, paliação ou cura da incapacidade funcional, após investigar o funcionamento sistêmico e as condições cardiorrespiratórias. De acordo McArdle et al. (2013) o exercício físico é avaliado, nas atividades dinâmicas (ciclismo, marcha e caminhada) por substanciais incrementos energéticos musculares, por aumentar $\dot{Q} \mathrm{O}_{2}$ e $\dot{Q} \mathrm{CO}_{2}$. O aumento dessas taxas exige complexos e integrados ajustes sistêmicos, logo a avaliação metabólica ventilatória e cardiovascular tornam-se importantes ferramentas para o diagnóstico e prognóstico.

\subsubsection{Ergoespirometria}

Para a fisiologia do exercício surgiram impressionantes avanços técnicos sobre coleta de ar expirado, emprego de bolsa de borracha para coleta e posterior análise do ar, e a espiroergometria (espirógrafo aliado a um dinamoergometro). Neder e Nery (2002) afirmam que David Bruce Dill foi, incontestavelmente, o nome mais importante nas atividades lideradas por 20 anos em Harvard, Nova Iorque, em áreas diversas como o consumo máximo de oxigênio, respostas cardiovasculares e hemodinâmicas e cinética do consumo de oxigênio.

O intercâmbio e o transporte gasoso sanguíneo, inclusive sob condições de estresse, foram destacados em minuciosas descrições e avaliações. A fisiologia muscular, investigada por muitos pesquisadores possibilitou o uso do termo quociente respiratório 
$(\mathrm{QR})$, definido pela taxa de captação periférica de $O_{2}\left(\dot{Q} O_{2}\right)$, dependendo apenas da diferenciação entre pressão gasosa capilar-tissular e não do conteúdo arterial de $O_{2}$ e peróxido de cálcio $\left(\mathrm{CaO}_{2}\right)$. O organismo é eficiente ao transformar energia química em mecânica sem perda em forma de calor. Para Medina e Nisenbaum (2009) o auge para a fisiologia se deu pela inter-conversão entre calor, metabolismo e energia, calculados em forma de calorimetria direta, que mede a produção de calor, e indireta por troca gasosa, comprovando a aplicabilidade da conservação de energia de seres vivos, pela lei da termodinâmica.

A espirometria foi desenvolvida para detectar males respiratórios após testes pulmonares utilizando o termo eletrocardiografia (ECG) para aparelhos relativamente portáteis, afirmam Neder e Nery (2002). Atualmente, poucos conceitos foram alterados para, o agora, eletrocardiograma. O nascimento da fisiologia e da atividade física se deve a Edward Hitchcock e E. Hitchcock Jr. após mensurações metabólicas durante o exercício e os efeitos da atividade no funcionamento cardiovascular e pulmonar (SANDOVAL, 2005).

Para Forjaz e Tricoli (2011) o século XX presenciou controvérsias na fisiologia respiratória sobre a troca pulmonar de oxigênio. Alguns grupos defendiam a difusão e outros a secreção pulmonar de $O_{2}$ durante o exercício e em elevadas altitudes. Em 1920 August Krogh recebeu o prêmio Nobel de Fisiologia e Medicina por elucidar os mecanismos de controle do fluxo capilar muscular demonstrando que em qualquer circunstância a difusão era suficiente, tanto no repouso, quanto no exercício. Sua esposa, Marie Krogh, demonstrou durante o exercício, o aumento da capacidade de difusão pulmonar. Foram obtidos grandes avanços que impulsionaram a mecânica respiratória após o desenvolvimento de sofisticados algoritmos e nomografias, utilizados até meados dos $\operatorname{anos} 60$.

Há vários tipos de ergômetros utilizados em teste de esforço para mensurar a potência e o trabalho durante o exercício físico, mas para o presente estudo foi utilizada a bicicleta ergométrica ou cicloergômetro. As vantagens apresentadas por esse tipo de ergômetro, segundo Parreiras (2010) incluem principalmente: manter o tórax imóvel, não sofre influência do peso da pessoa, tem baixo custo, ocupa pouco espaço e gera menos ansiedade por ser estável. Os cicloergômetros podem ser eletromagnéticos, quando necessitam de luz elétrica, são de complexa portabilidade e calibração, ou mecânicos identificados pela fácil portabilidade e calibração, no qual o trabalho é determinado pela frequência de pedalagem. 
Segundo Gomes et al. (2013) a aptidão aeróbica ou cardiorrespiratória é utilizada como índice para definir o desempenho esportivo e depende diretamente da capacidade máxima que pulmões, coração e sangue têm para fornecer e transportar oxigênio, e os tecidos e órgãos de extrair e utilizá-lo para produção de energia durante o esforço físico. $\mathrm{O}$ teste de esforço é utilizado para analisar variáveis fisiológicas que influenciam nas respostas metabólicas e apontam a condição cardiorrespiratória de uma pessoa, afirmam Tavares et al. (2016).

Confirmada a acurácia do ergoespirômetro e o limiar anaeróbio para mensurar, com qualidade, a integração dos sistemas pulmonar, cardiovascular e musculoesquelético, depois de aplicados em grupos de cardiopatas e pneumopatas, antes de procedimentos caros e invasivos, afirmam Nogueira e Pompeu (2010). Para Parreiras (2010) a ergoespirometria viabiliza a medida com o volume de oxigênio máximo $\left(\dot{V} O_{2 \text { máx。 }}\right.$ ) enquanto a ergometria estima o volume de oxigênio $\left(\dot{V} \mathrm{O}_{2}\right)$.

\subsubsection{Limiar de anaerobiose}

Segundo Neder e Nery (2002) estudos comprovaram que o aumento da concentração de lactato somente era determinado após a intensidade do exercício. Hollmann descreveu, em 1959, o ponto de ótima eficiência da respiração, depois sendo chamado de limiar de lactato. Entre as décadas de 60 e 70 foram desenvolvidos métodos não invasivos conhecidos por limiar anaeróbio ou também limiar ventilatório (LV). O laboratório do pesquisador Wasserman validou algoritmos que possibilitaram fazer análises computadorizadas e métodos para as correções das mudanças nos reservatórios pulmonares gasosos. A fisiologia clínica do exercício foi solidificada e popularizada no final do século XX e no início do século XXI trouxe perspectivas para o incremento da fisiologia humana aplicada.

A atividade abaixo do limiar de lactato determina o déficit de $O_{2}$ e apenas os exercícios não associados ao acúmulo de lactato poderá quantificar este acontecimento. Para Benetti et al. (2000) os débitos lático (atividade acima do limiar) e alático (atividade abaixo do limiar) dependem do acúmulo ou não sustentado de lactato e quanto maior a intensidade do esforço físico, maior a concentração de lactato, sendo liberado na musculatura ácido lático. $\mathrm{O}$ déficit ou débito de $\mathrm{O}_{2}$ dependerá do condicionamento físico 
do indivíduo, quanto mais for condicionado, mais rápida será a oferta de $O_{2}$ e/ou da maquinaria enzimática muscular.

Utilizado na prática clínica tanto para avaliação quanto para treinamento o LAn é a transição entre o metabolismo aeróbio para o anaeróbio, sinalizando a aptidão física. Júnior et al. (2006) afirmam que quando caracterizado apenas em função das trocas respiratórias o limiar anaeróbio é denominado limiar ventilatório, estabelecido pela intensidade de esforço, superando a remoção de ácido láctico, que acarreta na hiperventilação. Em concordância à análise de gases expirados, variáveis respiratórias e oximetria, a ergoespirometria é um procedimento não invasivo que avalia o desempenho físico e a capacidade funcional da pessoa. Ainda segundo os autores o método é útil para determinar os fatores que indicam o desempenho.

De acordo com Nogueira (2010) o LAn é crucial nas ciências do exercício por indicar o condicionamento em vários grupos de indivíduos, a princípio recomendado como índice de intolerância ao exercício, principalmente para pessoas cardiopatas, durante teste ergométrico, empregando medidas de trocas gasosas e ventilatória. Algoritmos matemáticos e cálculos estatísticos auxiliam na automatização e/ou semiautomatização do procedimento de ajuste entre o $\stackrel{\mathrm{V}}{\mathrm{O}_{2}}$ e o $\dot{\mathrm{V}} \mathrm{CO}_{2}$.

Muitas das investigações sobre limiares ventilatório e anaeróbio sugerem que não existe relação entre os fenômenos causa e efeito, ou seja, entre o $\stackrel{\mathrm{V}}{\mathrm{O}_{2}}$, W e FC, sendo considerada controversa por Okano et al. (2006). O limiar ventilatório é identificado pela mudança da ventilação pulmonar e seus equivalentes, $\mathrm{O}_{2}$ e $\mathrm{CO}_{2}$, produzindo valores

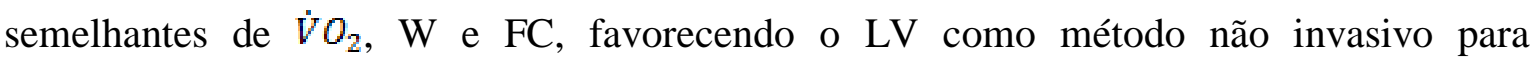
determinar o LAn.

\subsection{ANÁLISE DAS IMPLICAÇÕES CLÍNICAS DA FREQUÊNCIA CARDÍACA}

Primeiramente deve-se realizar um estudo dos aspectos físico, psíquico e socioafetivo, para caracterização da saúde do indivíduo avaliado. Uma boa e adequada alimentação está relacionada a resultados positivos para a atividade física e também os motivos que impulsionam a inicialização de atividade física. Segundo Nogueira et al. (2012) a atividade física deve ser "planejada, estruturada e repetitiva" com o propósito de melhorar 
ou aumentar a aptidão física, proporcionando benefícios para a saúde, além de reduzir os fatores de riscos cardiovasculares, logo, a morbimortalidade.

As variáveis como sexo, idade, grau de condicionamento ou massa corporal não influenciam o $\mathrm{V}_{2}$ em indivíduos normais, mas se comparados a indivíduos com sobrepeso o custo de $\mathrm{O}_{2}$ irá depender da massa corporal (STEIN, 2006). Amplamente investigada a FC possui diferença significativa entre indivíduos treinados e não treinados, além disso, índices verificam a influência destes fatores sobre o controle autonômico, baseados em métodos lineares, apresentados por Vanderlei et al. (2009) em dois grupos: análise no domínio do tempo, realizadas por índices estatísticos e geométricos e da análise no domínio da frequência.

A FC tem implicações importantes na orientação diagnóstica e terapêutica do indivíduo. Pessoas adequadamente treinadas próximas à exaustão apresentam aumento superior a 50 vezes na potência mecânica basal da bomba ventilatória, 8 vezes na taxa metabólica cardíaca e, em determinadas circunstâncias, até 100 vezes na taxa oxidativa muscular (ARAÚJO, 2010). Os pacientes com intolerância ao esforço oferecem demandas fisiológicas inferiores manifestadas no repouso.

A predominância parassimpática em repouso é progressivamente inibida à intensidade do exercício físico. Segundo Vanderlei et al. (2009) na transição repouso-exercício a retirada do tônus parassimpático eleva a FC intimamente ligada ao controle neural enquanto na recuperação participa conjuntamente com o SNA. A FC é utilizada para avaliar o controle autonômico no repouso e exercício como meio não invasivo do controle neural do coração. O elevado índice de morbimortalidade cardiovascular aguça investigações das respostas da FC utilizando o sistema nervoso simpático e parassimpático (MARÃES, 2010).

Gomes (2015) afirma que o aumento inicial da FC é mediado pela redução da atividade parassimpática e depois pelo aumento gradual no tônus simpático sobre o coração. A redução gradual da FC acontece após o exercício ser interrompido, desta forma, haverá reativação vagal, considerada mecanismo primário da FC após realizar estímulos intensos e a desativação simpática.

Consensualmente a literatura admite o SNA como contribuinte primário da variável FC apesar de discussões sobre colaborações dos ramos simpático e parassimpático acerca 
do decremento da FC, após teste de esforço, é compreendido como indicador de disfunção autonômica cardíaca. A recuperação lenta da FC está associada a prognósticos negativos, em indivíduos aparentemente saudáveis, mas com doença pulmonar crônica, diabetes, síndrome metabólica e doença coronariana. Evidências publicadas nos últimos anos sustentam o valor prognóstico da FC, após esforço, em diferentes condições clínicas (GOMES, 2015).

\subsection{ATIVIDADE FÍSICA PRATICADA POR INDIVÍDUOS AMPUTADOS}

Amputação é a retirada de uma extremidade de um órgão ou parte e pode ocorrer em qualquer membro de continuidade óssea. As amputações devem-se principalmente a problemas vasculares, seguindo-se por traumas e acometem jovens e adultos. Para Rodrigues, Mussi e Almeida (2014) a reabilitação dessas pessoas requer demanda de equipe multiprofissional na recuperação da autonomia físico-motora e restauração da saúde, com o intuito de melhorar a qualidade de vida do amputado.

Considerada problema de saúde pública, a reabilitação destes indivíduos apresenta prevalência no sexo masculino, entre 10 e 39 anos e pessoas com menor renda. O impacto econômico é estabelecido pelo alto percentual de internações, custos hospitalares, perdas materiais, consternação da vítima e seus familiares, de baixas na população financeiramente ativa, além das despesas previdenciárias (MATEUS, 2012).

Com a reabilitação espera-se o restabelecimento satisfatório do estado físico, mental e social, após a lesão física que impediria as atividades normais, permitindo a reinserção do lesionado às atividades diárias. Este processo de reabilitação demanda programa organizado e coordenado por equipe multidisciplinar para evolução do paciente (RODRIGUES, MUSSI E ALMEIDA, 2014).

A atividade física aeróbia regular eleva a habilidade no exercício e desempenha papel essencial na prevenção primária e secundária das doenças cardiovasculares, reduzindo o sedentarismo que é um dos principais fatores de risco para a mortalidade da população em geral (MATEUS, 2012). O treinamento de força durante a reabilitação dos amputados transfemorais favorece a recuperação acelerada da força muscular original, assim o exercício físico pode controlar a redução da dor musculoesquelética, prevenir ou evitar deformidades e ainda aumentar a resistência pulmonar e cardiovascular, afirmam Rodrigues, Mussi e Almeida (2014). 


\section{METODOLOGIA}

Esta pesquisa é de natureza analítica, observacional, transversal e prospectiva. O estudo foi realizado no laboratório de Biofísica e de Fisiologia do Exercício da Universidade de Brasília (UnB) - Faculdade de Ceilândia (FCE), em laboratório climatizado artificialmente, para controle da temperatura e umidade.

Após serem encontrados somente 09 indivíduos com amputação transfemoral em Brasília que utilizam prótese e aceitaram participar do estudo, apenas três voluntários foram selecionados por conveniência. Os critérios de inclusão foram: amputação transfemoral unilateral, de origem traumática, sexo masculino, fazer uso de prótese, ter entre 18 e 50 anos e não apresentar alterações cardiovasculares ou neurológicas. Os critérios de exclusão: não apresentar prótese, ser do sexo feminino, ter doenças cardiovasculares e/ou neurológicas ou fazer uso de drogas.

Repassadas orientações sobre a participação no estudo, aos três voluntários, com idades entre 27 e 32 anos, de não ingerir bebidas alcoólicas, café e/ou outras bebidas estimulantes, não praticar atividade física 24 horas antes do teste ergoespirométrico e tão pouco realizarem o teste em jejum, estes assinaram o Termo de Consentimento Livre e Esclarecido, aprovado pelo Comitê de Ética em Pesquisa (Parecer $n^{\circ} 1.446 .986$ ).

Previamente foram apresentadas todas as informações relativas ao teste e orientações para que os voluntários respirassem espontaneamente e não conversassem durante o teste cardiopulmonar. Os voluntários foram treinados para utilização da Escala de Borg com indicação de sua percepção de esforço físico.

\subsection{COLETA DE DADOS}

Depois de selecionados os três pacientes do sexo masculino com amputação transfemoral, fazendo uso de suas respectivas próteses, foram submetidos na primeira etapa a anamnese e avaliação com aferição da frequência cardíaca (FC), da pressão arterial (PA) em repouso, das medidas da massa corporal e estatura, do cálculo do índice de massa corpórea (IMC) e ainda dos seguintes instrumentos: Questionário Internacional de Atividade Física (IPAQ), Escala de Borg, Mini Exame do Estado Mental (MEEM), Timed Up and Go (TUG). Estes testes objetivaram triar os pacientes para minimizar risco de acidentes durante o protocolo experimental. 
Hallal et al. (2007) descrevem o Questionário Internacional de Atividade Física (IPAQ) como um método utilizado para comparar dados de atividade física em diversos contextos. Apesar de o Brasil figurar na lista de países responsáveis pela validação deste método, pesquisadores brasileiros contestaram a análise do estudo afirmando a necessidade de novos dados de validade e repetibilidade. Nos estudos brasileiros são utilizados acelerômetros e pedômetros como métodos fundamentais de mensuração dos níveis de atividade física como padrão-ouro. Apesar das limitações o IPAQ ainda domina como principal método de comparação.

Desenvolvida por Gunnar Borg para mensurar a percepção da intensidade do exercício, a Escala de Borg foi modificada em 1982 com o objetivo de aumentar sua praticidade, desenhando uma escala com valores numéricos de 0 a 10, como se observa na figura 1 (SILVA et al., 2011). É considerada de fácil utilização e deve ser aplicada após esclarecer os indivíduos sobre a percepção do esforço como método quantitativo da intensidade, incômodo ou fadiga, durante o exercício físico. Pode justificar o uso da Escala de Borg por manter uma elevada correlação com os indicadores de intensidade do exercício, FC e $\dot{V} \mathrm{O}_{2}$, e determinar a zona de trabalho (VILLALBA E GIL, 2007).

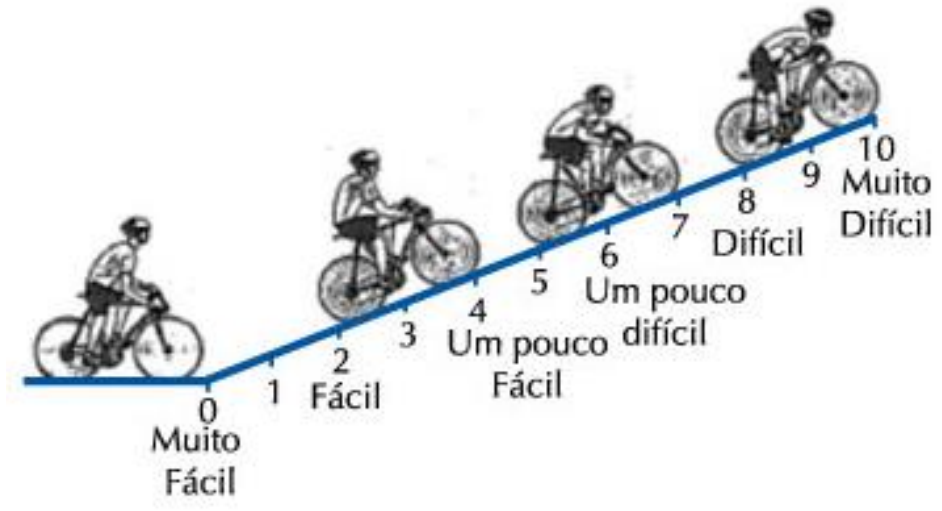

Figura 1: Escala de Borg - percepção de esforço para adultos em cicloergômetro (SILVA et al., 2011).

O Mini Exame do Estado Mental (MEEM) é um dos testes mais empregados e estudados no mundo, utilizado isoladamente ou incorporado a instrumentos amplos, muito utilizado em clínicas por permitir avaliar a função cognitiva e também rastrear os quadros demenciais (LOURENÇO E VERAS, 2006). É parte de testes neuropsicológicos, para avaliação em atividades clínicas e de investigação científica no Brasil. Desde sua criação, em 1975, as características psicométricas avaliam a capacidade de discriminação de indivíduos cognitivamente alterados. 
O teste Timed Up and Go (TUG) inicia o primeiro momento quando o indivíduo recebe a instrução "vá", realizado primariamente para familiarização, mas na segunda vez o tempo é cronometrado e deverá levantar-se da cadeira, sem auxílio dos braços, caminhar por três metros usando a prótese, retornar e sentar-se novamente, encostando o dorso no encosto da cadeira (BRETAN et al., 2013). Para o tempo inferior a 20 segundos de realização corresponde a baixo risco para quedas. O risco médio é considerado entre 20 a 29 segundos e acima de 30 segundos os estudos apontam alto risco para quedas. Outros estudos indicam alto risco de sofrerem quedas, os indivíduos que superaram 14 segundos a partir da tomada do tempo.

A coleta dos dados ocorreu por meio da cinta do cardiofrequencímetro (POLAR WearlinkWind), com armazenamento dos dados através do software Polar Protrainer $5^{\circledR}$ análise por meio do software Kubios (release 2.1 Kubios HRV), sendo utilizado os valores basais de RMSSD (raiz quadrada da média do quadrado das diferenças entre intervalos RR normais adjacentes, em um intervalo de tempo, expresso em ms) obtidos antes, durante e após o exercício associados à frequência cardíaca, para determinação do momento do limiar de anaerobiose dos voluntários.

$\mathrm{Na}$ segunda etapa foi realizado um eletrocardiograma (ECG) e um teste cardiopulmonar (Vmax CareFusion) utilizando bicicleta ergométrica para registro da variabilidade da frequência cardíaca (intervalos RR) durante o exercício físico.

O eletrocardiograma (ECG) é um exame que avalia a atividade cardíaca, em potenciais elétricos e sua condução com eletrodos fixados na superfície da pele. Registrados em gráficos para comparar a normalidade ou alteração dos músculos e nervos do coração monitorando objetivamente a FC durante o exercício (MCARDLE et al., 2013). Tal exame foi realizado para excluir os voluntários que por ventura apresentassem arritmias cardíacas inviabilizando a coleta e análise dos intervalos inverso da frequência cardíaca (RR).

O teste cardiopulmonar é uma ferramenta indispensável para tomada de decisão em situações clínicas, para Stein (2006) é a combinação do teste ergométrico, saturação de $O_{2}$ e medidas das trocas ventilatórias. Associado a oximetria de pulso para quantificar a saturação das hemoglobinas e a bicicleta ergométrica, por possuir vantagens, independente do peso do indivíduo, fornece ampla gama de aplicações para exames de exercícios 
detectando os valores iniciais e de pico, o que melhora e reduz o tempo de processamento de relatórios.

Todos esses exames foram realizados para garantir a segurança dos voluntários que seriam submetidos a coleta da variável de interesse, intervalo RR. O eletrocardiograma e a coleta das variáveis ventilatórias durante o exercício físico garantiram a segurança e diagnóstico cardiopulmonar dos voluntários envolvidos na pesquisa.

As ferramentas essenciais utilizadas para a coleta de dados e mensuração dos intervalos RR são respectivamente o monitor cardíaco e conversor analógico e um cardiofrequencímetro, mostrados na figura 2. O transmissor Polar WearLink - W.I.N.D. é constituído por uma cinta de eletrodo e um conector. Seu mecanismo de clip-on garante colocar e retirar o cinto facilmente, após os dados serem transferidos para o computador, via DataLink, conectado a uma porta USB. Arakelian (2015) e Marães (2010) afirmam que em estudos comparativos realizados o cardiofrequencímetro oferece precisão e bons resultados, principalmente em exercício físico e também em repouso.

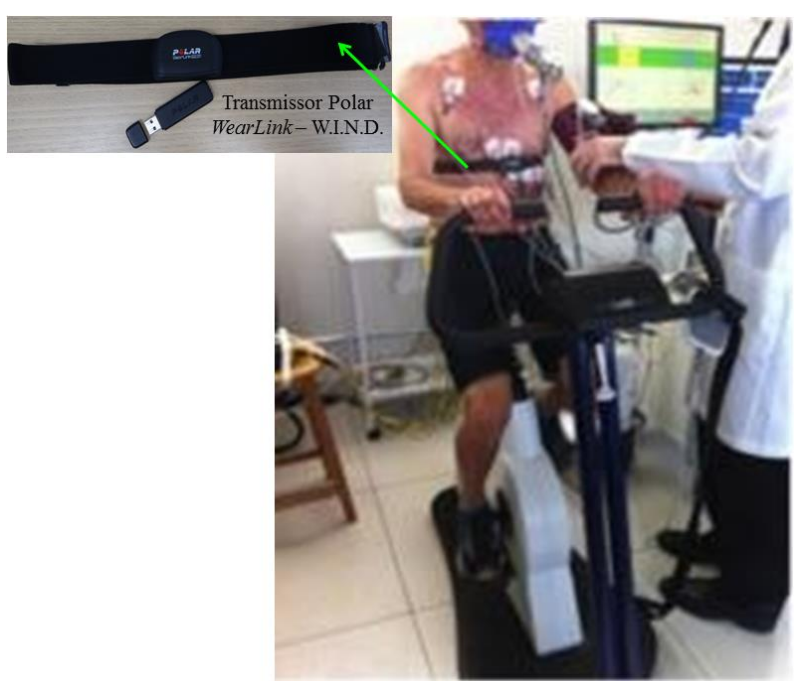

Figura 2: Coleta de dados da frequência cardíaca durante o teste cardiopulmonar em bicicleta ergométrica.

\subsection{ANÁLISE DE DADOS}

Os métodos de análise da frequência cardíaca podem ser realizados nos domínios do tempo, da frequência e ainda com aplicação de modelos estatísticos que podem descrever o comportamento da frequência cardíaca ao longo do tempo e do exercício realizado (GOMES, 2015; MARÃES, 2010). Os modelos estatísticos dos dados possibilitam traçar o ponto de mudança da frequência cardíaca e do ponto de compensação ventilatória para 
analisar o comportamento da FC ou dos intervalos RR utilizando índices temporais estatísticos paramétricos e não paramétricos, afirma Marães (2010), empregando média, mediana, desvio padrão, quartis e diferença entre os intervalos RR máximo e RR mínimo. O estudo do padrão de resposta da frequência cardíaca pode trazer informações fisiológicas e metabólicas relevantes do indivíduo submetido a um estresse físico.

Para análise dos dados foram utilizados os métodos ARIMA (autoregressivosintegrados-médias móveis), modelo matemático Heteroscedástico e a variabilidade da frequência cardíaca (VFC).

O método não invasivo utilizado para detecção do LAn foi analisado pela mudança no padrão das curvas ventilatórias durante o exercício físico contínuo e incremental, baseado na resposta da FC por meio da aplicação do modelo ARIMA que consiste em modelos de séries temporais para análise de mudança dos padrões de respostas, onde acontece a perda de estacionaridade em intervalos de tempo com espaçamentos iguais, como abordagem matemática e estatística (MARÃES, 1999).

Tendo em vista que o método trata-se de um modelo autoregressivo, criaram-se comandos específicos por meio do software MATLAB 8.3, 2014 (Mathworks, Natick), que fizessem os ajustes da frequência cardíaca reduzindo os erros de captação do Polar, e determinando automaticamente o ponto de limiar através da modificação na frequência cardíaca.

O método de análise para determinação do limiar de anaerobiose utilizando o modelo matemático Heteroscedástico (E) é aplicado à variável FC para determinar o ponto de mudança da série de dados em cada variável e de cada voluntário.

Ao utilizar esta metodologia para identificar o LAn foram estabelecidos os valores da W (potência) e FC (bpm). O modelo Heteroscedástico possui regressão segmentada linear simples, segundo observações sequenciais $\left(y_{i}\right.$ e $\left.x_{i}\right)$ apresentada na figura 3 .

$$
y_{i}=\left\{\begin{array}{c}
\alpha_{1}+\beta_{1} x_{i}+\varepsilon_{i 1}, \text { se } i=1, \ldots, k, \\
\alpha_{2}+\beta_{2} x_{i}+\varepsilon_{i 2}, \quad \text { se } i=k+1, \ldots, n .
\end{array}\right.
$$

Figura 3: Equação de regressão segmentada linear simples, obtida no artigo de Pozzi (2006).

Os coeficientes desconhecidos e estimados pelo software são os alfas ( $\alpha$ ) e betas $(\beta)$, enquanto a variável dependente esta identificada como y e a fixa como x, sendo estimados 
também os erros aleatórios. De forma que através do auxílio de um engenheiro, criaram-se comandos específicos por meio do software MATLAB 8.3, 2014 (Mathworks, Natick), que determinava o ponto de limiar por meio do ponto da frequência cardíaca.

O processamento estatístico dos dados foi realizado pelo software Statistical Package for Social Science for Windows (SPSS), em diferentes condições as variáveis estudadas na análise de distribuição dos dados não possuíam distribuição normal. Assim, foram escolhidos testes estatísticos descritivos com uso de mínimo, média, máximo e desvio padrão para a comparação com a literatura.

Através da figura 4 observa-se que a sequência de atividades propostas para o desenvolvimento do trabalho foi alcançada, desde a primeira etapa de avaliação inicial até a terceira etapa de análise estatística e descrição dos resultados.

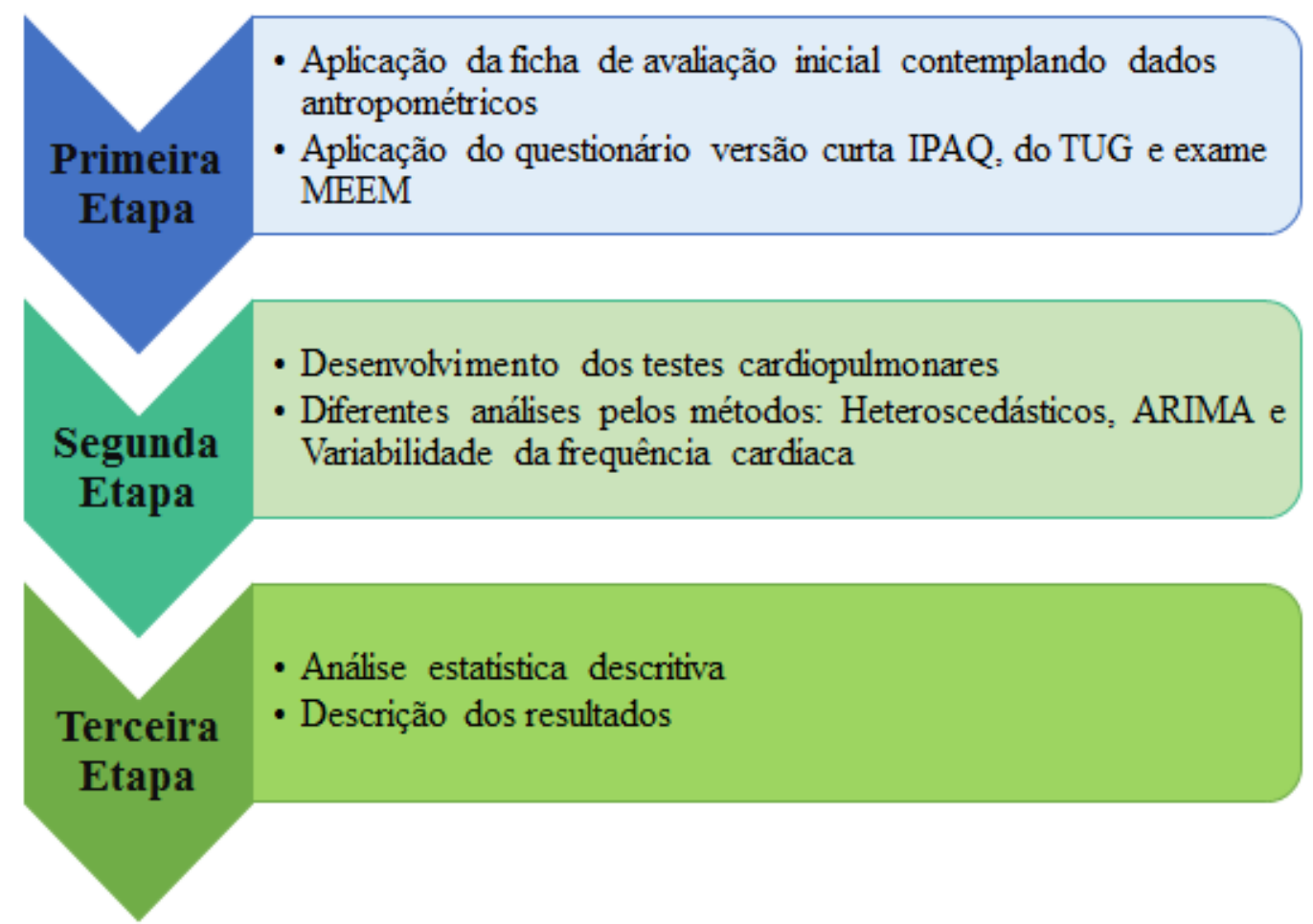

Figura 4: Sequência de atividades propostas para obtenção dos resultados. 


\section{RESULTADOS}

$\mathrm{Na}$ primeira etapa os voluntários foram classificados qualitativamente a respeito do nível de atividade física, através do questionário IPAQ em sua versão curta. Tendo em vista a intensidade, durabilidade e frequência de atividades físicas, dois voluntários foram classificados como muito ativos e um como ativo.

Estão descritos na tabela 1 as características da amostra estudada, levando em consideração a idade, peso e tempo de amputação.

Tabela 1: Características da amostra. Dados antropométricos descritivos de pacientes amputados transfemorais $(n=3)$.

\begin{tabular}{c|c|c|c|c|c}
\hline Voluntários & Altura & Peso & Idade & IMC & $\begin{array}{c}\text { Tempo de } \\
\text { amputação } \\
\text { (anos) }\end{array}$ \\
\hline COL & 1,78 & 65 & 32 & 20,51 & 10 \\
FBF & 1,79 & 80,8 & 30 & 25,21 & 8 \\
HSB & 1,76 & 56 & 27 & 18,07 & 3 \\
Média \pm DP & $1,77 \pm 0,015$ & $67,26 \pm 12,55$ & $29,66 \pm 2,51$ & $21,26 \pm 3,62$ & $7 \pm 3,60$ \\
\hline
\end{tabular}

IMC = Índice de massa corporal expresso em Kg/m, DP = Desvio Padrão.

Na figura 5 pode-se observar que os intervalos RR possuem estacionaridade nos 3 minutos iniciais do teste realizado por um indivíduo. Após este período há um declínio dos valores dos intervalos RR. Posteriormente os intervalos RR permanecem constantes até aproximadamente 7 minutos do teste cardiopulmonar, quando se pode observar um segundo ponto de mudança no padrão de resposta da curva dos intervalos RR. Tais pontos de mudanças podem indicar o limiar anaeróbio.

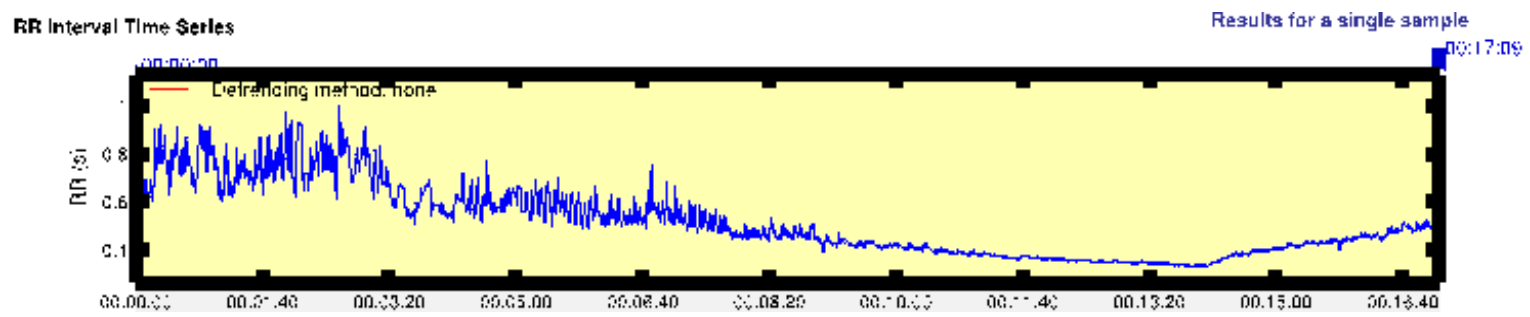

Figura 5: Dados coletados dos intervalos RR (inverso da frequência cardíaca) durante teste cardiopulmonar de um voluntário estudado.

A respeito do Mini Exame do Estado Mental (MEEM) todos os voluntários apresentaram pontuação máxima, representando ausência de comprometimento cognitivo. 
Durante a realização do Timed $U p$ and Go (TUG), todos os voluntários apresentaram valores médios de 10 segundos, ou seja, sem alterações, demonstrando que todos os voluntários poderiam ser submetidos a testes de esforço sem risco de quedas.

\subsection{LEVANTAMENTO DE REQUESITOS}

Todos os voluntários apresentaram teste de esforço submáximo, tendo como causa o desacoplamento da prótese, sendo este uma limitação do estudo. Acredita-se que outro tipo de soquete e/ou prótese possibilitaria testes com maior durabilidade e fadiga cardiorrespiratória.

Para obtenção dos resultados, este estudo apresentou como requisitos as análises através de três métodos sendo variabilidade da frequência cardíaca, e os modelos matemáticos Heteroscedásticos e ARIMA, e por fim sua análise estatística descritiva.

O primeiro método mensurado foi o modelo matemático Heteroscedásticos permitindo a visualização do momento em que a curva de frequência cardíaca pelo tempo apresenta a perda da linearidade marcada pela linha pontilhada vermelha, ambos os comandos específicos do MATLAB, sendo observada nas figuras 6, 7 e 8 o limiar de cada voluntário.

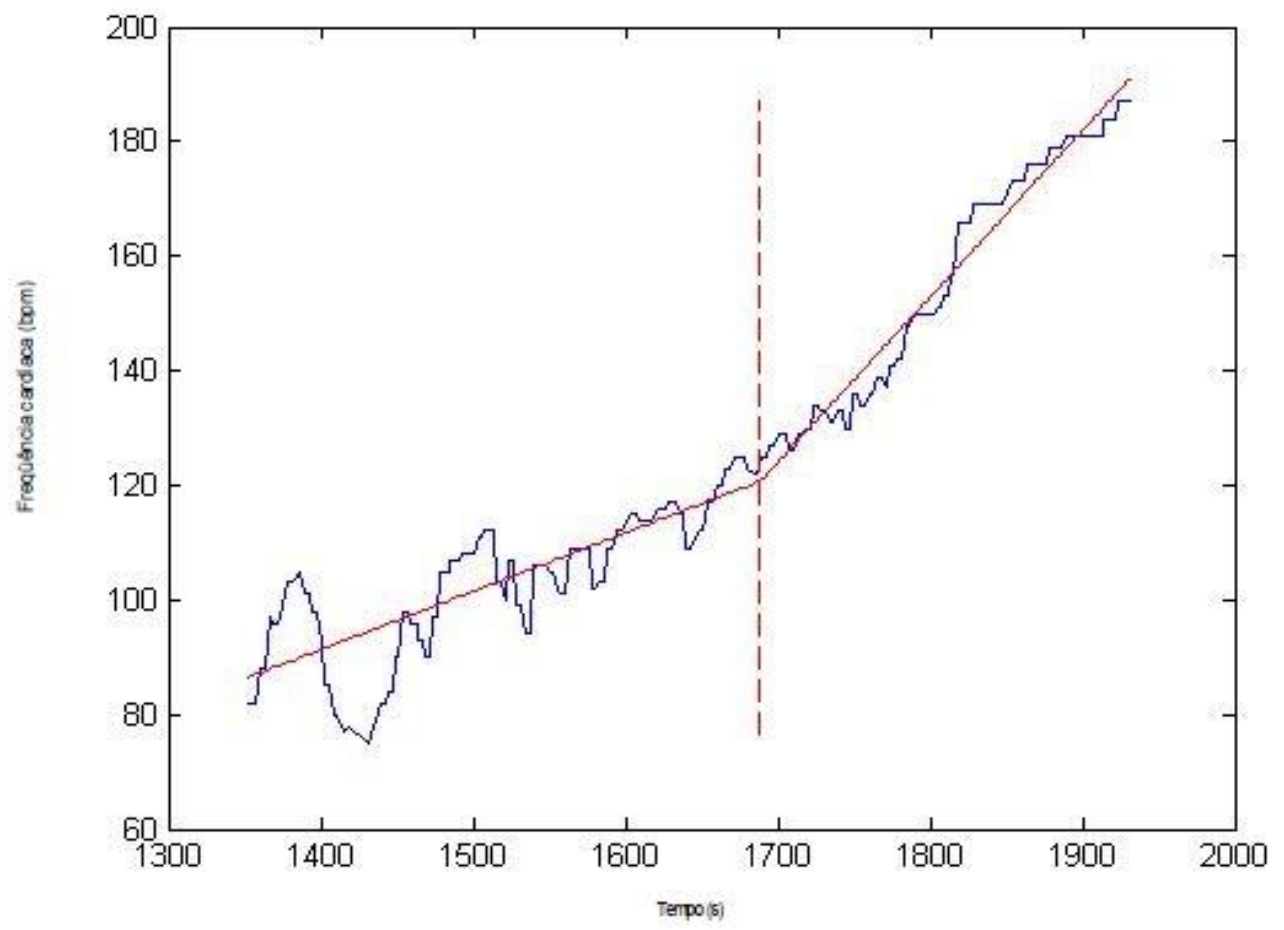

Figura 6: Frequência cardíaca expresso em batimentos por minutos, em função do tempo total de exercício (s), com análise por método matemático Heteroscedástico do voluntário COL. 


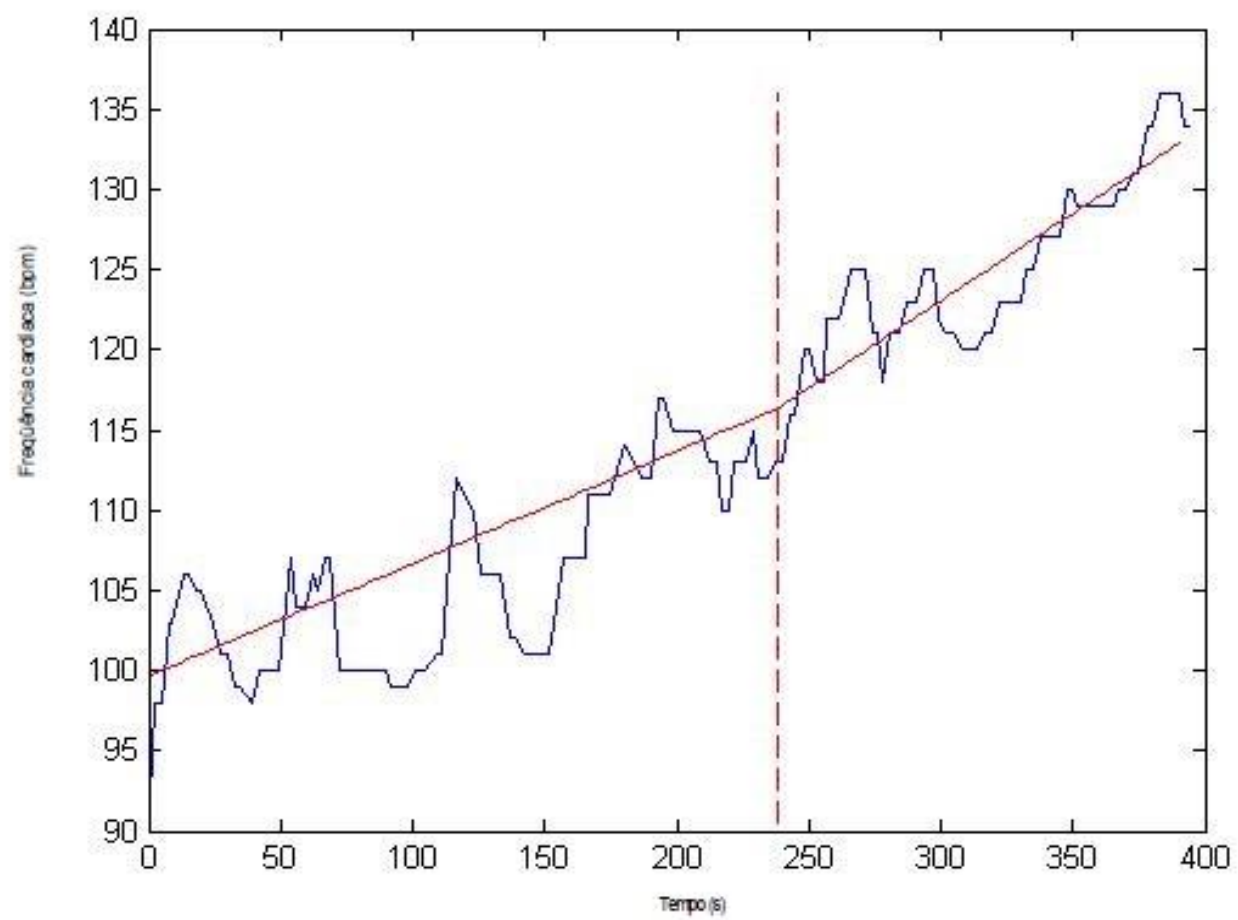

Figura 7: Frequência cardíaca expresso em batimentos por minutos, em função do tempo total de exercício (s), com análise por método matemático Heteroscedástico do voluntário FBF.

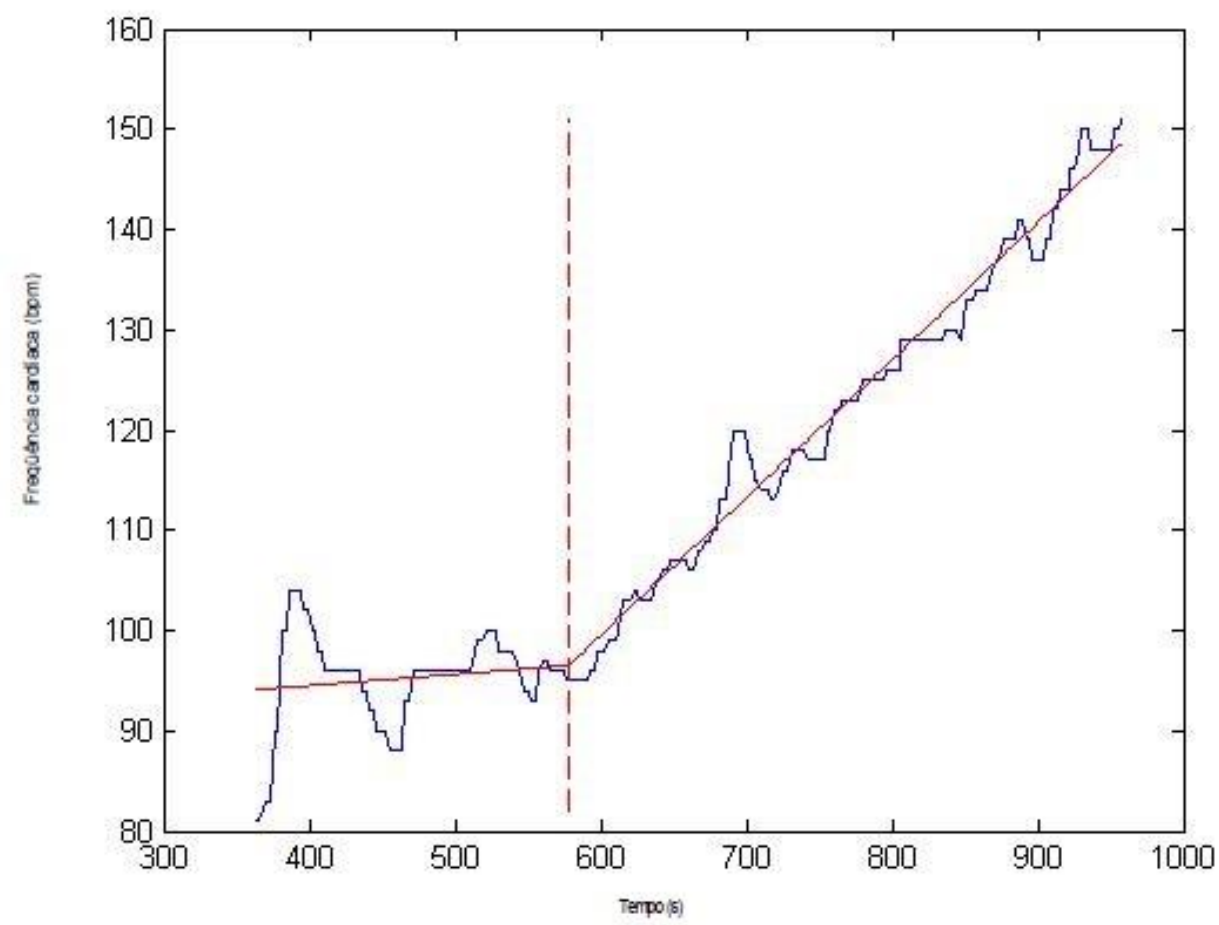

Figura 8: Frequência cardíaca expresso em batimentos por minutos, em função do tempo total de exercício (s), com análise por método matemático Heteroscedástico do voluntário HSB. 
Outra análise realizada fazendo uso da frequência cardíaca foi com o método ARIMA, de forma que o software apresenta a frequência cardíaca bruta (apresentada em azul) e a frequência cardíaca filtrada pelo modelo autoregressivo (apresentada em vermelho) e por fim, após comando específico ocorre a marcação do momento de limiar determinado pela linha preta no cursor, como apresentado nas figuras 9, 10 e 11.

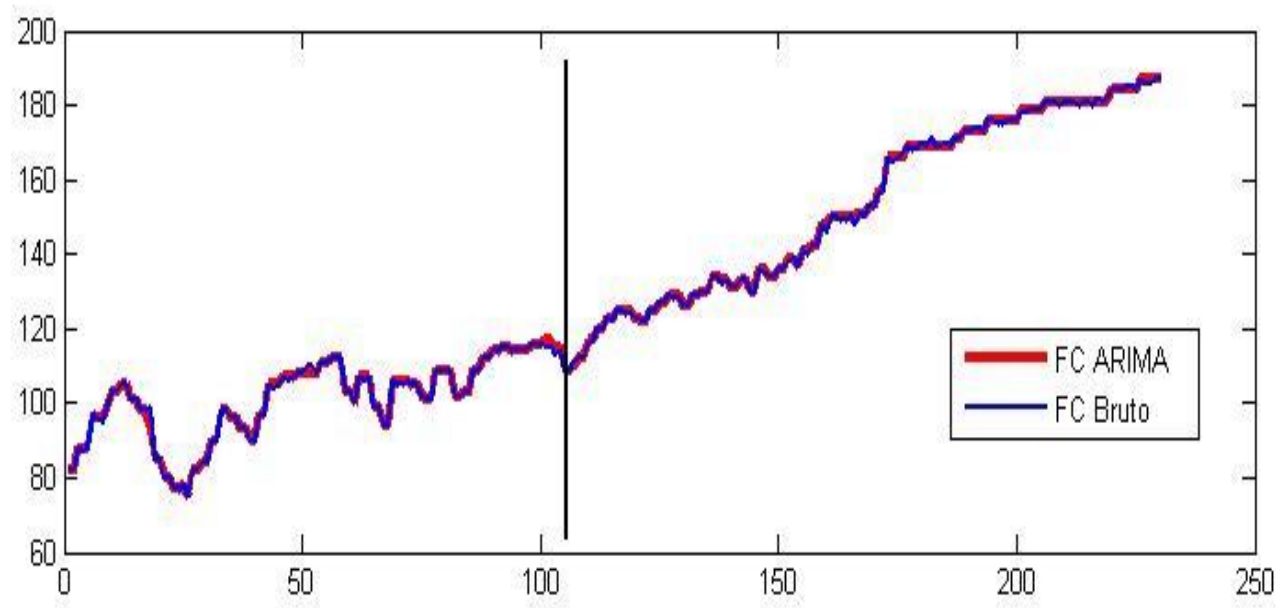

Figura 9: Representação do ajuste do modelo autoregressivo (ARIMA) aos dados de frequência cardíaca em batimentos por minuto em função do espaço de descrição do software, obtidos durante o teste de exercício físico do voluntário COL.

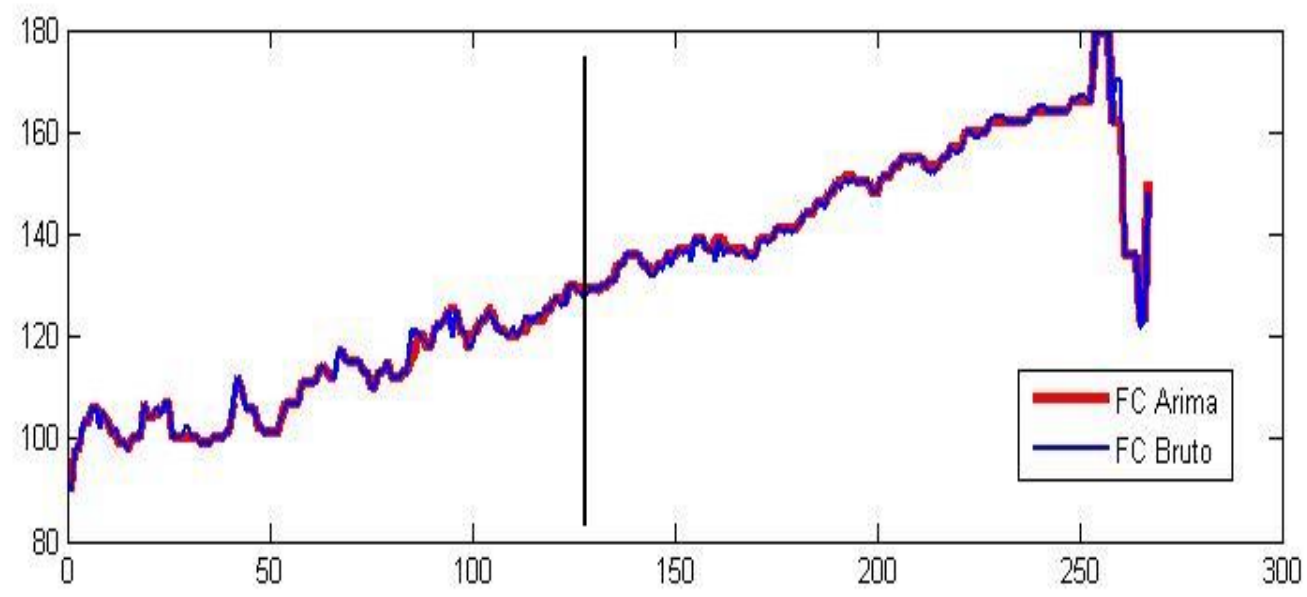

Figura 10: Representação do ajuste do modelo autoregressivo (ARIMA) aos dados de frequência cardíaca em batimentos por minuto em função do espaço de descrição do software, obtidos durante o teste de exercício físico do voluntário FBF. 


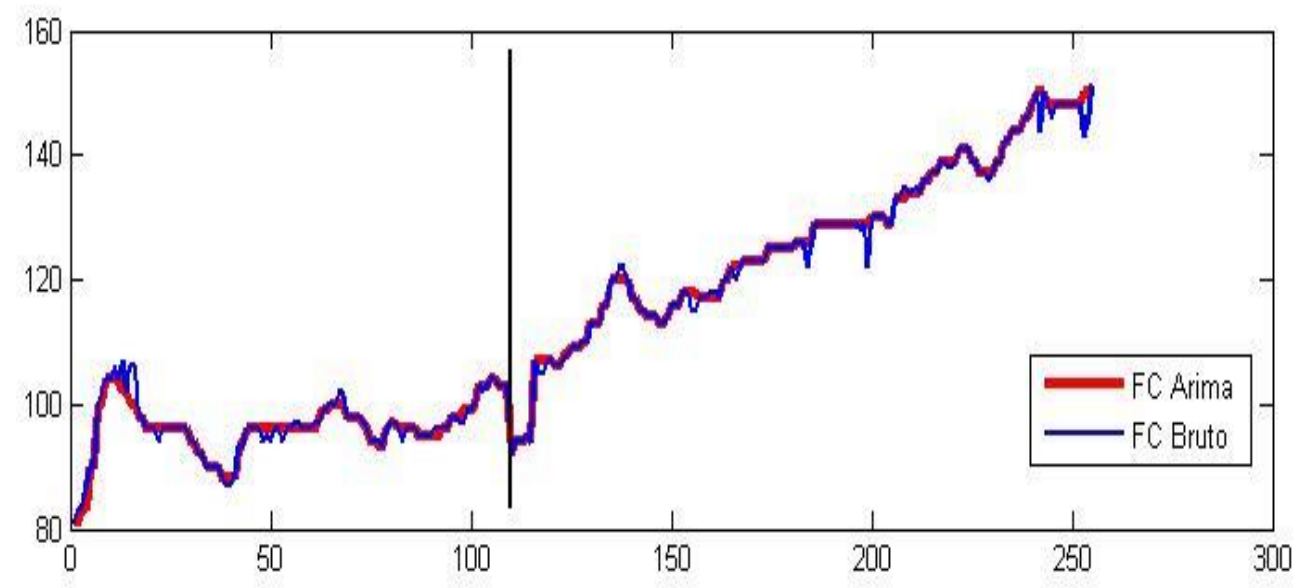

Figura 11: Representação do ajuste do modelo autoregressivo (ARIMA) aos dados de frequência cardíaca em batimentos por minuto em função do espaço de descrição do software, obtidos durante o teste de exercício físico do voluntário HSB.

Desta forma observou-se o momento em que instantaneamente a FC elevava-se e ocorriam alterações da VFC, sendo escolhido o RMSSD para análise por evidências demonstrando alta sensibilidade para identificação de mudanças da modulação autonômica no LAn, sendo apresentada na tabela 2 os valores mensurados pelos três métodos de forma detalhada de cada voluntário e na tabela 3 a análise estatística descritiva dos voluntários.

Tabela 2: Valores detalhados de RMSSD, FC método heteroscedástico e ARIMA no momento do limiar de anaerobiose.

\begin{tabular}{c|c|c|c|c}
\hline Voluntários & RMSSD & FC Heteroscedástico & FC ARIMA & POTÊNCIA \\
\hline COL & 33,963 & 117 & 115 & 69 \\
FBF & 19,627 & 116 & 121 & 12 \\
HSB & 7,904 & 92 & 94 & 40 \\
\hline
\end{tabular}

ARIMA: Modelos autorregressivos integrados médias móveis. FC: Frequência Cardíaca em (bpm). RMSSD: Raiz quadrada da média do quadrado das diferenças entre intervalos RR normais adjacentes, em ms. Potência expressa em Watts.

Tabela 3: Valores médios de RMSSD, FC método heteroscedástico e ARIMA no momento do limiar de anaerobiose.

\begin{tabular}{c|c|c|c|c}
\hline Variáveis & Mínimo & Máximo & Média & Desvio Padrão \\
\hline RMSSD LAn & 8 & 34 & 20,67 & $\pm 13,013$ \\
FC Heteroscedástico & 92 & 117 & 108,33 & $\pm 14,154$ \\
FC ARIMA & 94 & 121 & 110,00 & $\pm 14,177$ \\
Potência & 12 & 69 & 40,33 & 28,501 \\
\hline
\end{tabular}

ARIMA: Modelos autorregressivos integrados médias móveis. FC: Frequência Cardíaca em (bpm). RMSSD: Raiz quadrada da média do quadrado das diferenças entre intervalos RR normais adjacentes, em ms. Potência expressa em Watts, realizado pelo software Statistical Package for Social Science for Windows. 


\section{DISCUSSÃO E CONCLUSÃO}

Diversos fatores podem influenciar o organismo humano como: características antropométricas, envelhecimento, gênero, temperatura, fatores genéticos, hábitos de vida, condicionamento físico e de saúde e tantos outros. O presente estudo buscou padronizar as características dos voluntários selecionados e as condições ambientais da sala para o teste, a fim de evitar diferenças significantes quanto às características antropométricas e a idade.

Documentados na literatura os valores de FC média variam entre 60 e $100 \mathrm{bpm}$ e os valores da PA devem ser inferior a 130/85 mmHg (PASSARO, 1997). Os voluntários apresentaram valores médios da FC e PA normais para repouso (80 bpm e 120/80 mmHg) segundo a literatura. Durante o teste os voluntários apresentaram valor médio para o pico da FC de 109 bpm quando levado em consideração ambos os métodos.

Diversos métodos são descritos para a determinação do LAn sendo que os estudos que fazem uso de variáveis cardiovasculares como a frequência cardíaca, usam modelos matemáticos para obtenção do limiar, de forma que os modelos mais utilizados são o de Hinkley e ARIMA. O método Heteroscedástico e de Hinkley são os de maior descrição e reprodutibilidade para variáveis ventilatórias e principalmente FC (CRESCÊNCIO, 2002).

O modelo matemático Heteroscedástico é um método inovador, descrito na literatura por Pozzi (2006), sendo pioneiro como regressão segmentada linear simples, utilizada para aplicação da frequência cardíaca pelo tempo determinando o LAn. O presente estudo apresentou valores de mensuração semelhantes ao do método ARIMA, corroborando com os estudos que demonstram que modelos matemáticos são confiáveis para a determinação do LAn.

Pozzi (2006) afirma que a frequência cardíaca através do método Heteroscedástico em amputados transfemorais apresentou média de 108,33 bpm, enquanto no trabalho pioneiro os valores médios foram de $105 \mathrm{bpm}$, demonstrando que a frequência cardíaca de amputados transfemorais no momento de LAn pode ser maior em comparação a idosos ativos, sendo que a média de potência obtida no presente estudo (40 Watts) foi menor que a de idosas ativas (82 Watts).

O estudo de Lima (2012) realizou uma busca de estudos que fizessem uso de modelos matemáticos para determinação do LAn, sendo que obteve como resultado a respeito do 
Heteroscedástico somente o estudo de Pozzi (2006). Dessa forma, o único estudo que permite comparação metodológica é o estudo descrito acima.

A respeito do modelo autoregressivos-integrados-médias móveis, um estudo realizado em 2003 realizou teste de esforço cardiopulmonar em doze voluntários entre 40 e 50 anos ativos e saudáveis, fazendo uso do método ARIMA para determinação do limiar de anaerobiose, apresentando frequência média de $100 \mathrm{bpm}$ e potência de 60 Watts, em comparação aos voluntários do presente estudo observa-se que amputados apresentaram maior frequência cardíaca durante o limiar em menores potências (TEIXEIRA, 2003).

Desta forma, reafirma-se que os amputados apresentaram maiores valores de frequência cardíaca em menores potências, ou seja, atingindo o limiar mais rapidamente que idosos ativos e adultos ativos saudáveis, sugerindo que amputados transfemorais apresentem ajustes mitocondriais e cardiovasculares ocasionados pela perda parcial do membro (POZZI, 2006; TEIXEIRA, 2003).

Os estudos sobre as variáveis cardiovasculares, principalmente da VFC e FC pelo tempo são de extrema importância para determinação do LAn, devido à elevação da frequência cardíaca durante o exercício, como um ajuste cardiovascular agudo. A identificação precoce de alterações não esperadas na FC permite o diagnóstico de doenças isquêmicas e alterações no sistema cardiovascular (GUYTON, 2006).

Neste estudo observa-se uma elevação da FC acompanhando o acréscimo de carga, sendo que os voluntários alcançaram em torno de $90 \%$ da frequência cardíaca máxima prevista no método matemático Heteroscedástico e no método ARIMA, demonstrando boa atividade musculoesquelética, metabólica e cardiorrespiratória, e condicionamento aeróbio obtido pelas atividades físicas regulares (GUYTON, 2006; COUTO et al., 2013).

Nos últimos anos, os estudos com a VFC estão sendo muito descritos na literatura principalmente durante os testes de esforços, demonstrando as modulações simpáticas e parassimpáticas. Marães et al. (2015) em seu estudo com idosas ativas hipertensas e normotensas afirmaram que indivíduos submetidos a exercício físico de forma contínua com acréscimos de carga impactam na variabilidade da frequência cardíaca, ocasionadas pelos ajustes simpáticos e parassimpáticos.

Durante o incremento da potência acontecem modificações nos sistemas corporais, principalmente humoral, neural e metabólico, ocasionando modificações na FC permitindo 
a verificação do limiar pela perda da linearidade, de forma que essas alterações vão promover a redução significativa da VFC de forma progressiva até o momento do LAn, apresentando decréscimo dos valores em comparação ao estado de repouso, como demonstrado nesse estudo (MARÃES, 2003; ALONSO, 1998).

Um dos estudos clássicos sobre a VFC durante teste de esforço em cicloergômetro, desenvolvido com voluntários saudáveis do sexo masculino realizado em homens saudáveis apresentou que os valores de RMSSD diminuíram com o tempo de exercício e aumento da carga, ocasionados pela retirada vagal, corroborando com os resultados desse estudo (ALONSO, 1998).

Ainda legitimando os resultados apresentados, o estudo de Yamamoto et al., 1991 apresentou uma diminuição do controle parassimpático até o momento de limiar de anaerobiose, demonstrando que o mesmo ocorre com amputados transfemorais entretanto, em diferentes dimensões devido as alterações hemodinâmicas e autonômicas (NASCHITZ; LENGER, 2008).

Ademais sobre o RMSSD o trabalho desenvolvido com voluntários saudáveis sedentários em comparação a infartados ativos, apresentou que os índices de RMSSD correspondente ao índice temporal apresentou diminuição em seus valores durante o LAn em comparação aos valores basais, sendo que essas reduções aconteceram de forma progressiva durante o exercício (TAKAHASHI et al., 2005).

Em que as mensurações de RMSSD indivíduos saudáveis sedentários permitem comparação com os valores encontrados em amputados transfemorais ativos, durante LAn consecutivamente (5 a $7 \mathrm{~ms})$ e $(20,67 \pm 13,01 \mathrm{~ms})$. Expondo que amputados transfemorais ativos apresentam maiores índices de RMSSD do que indivíduos não amputados saudáveis sedentários.

A análise do conjunto de dados obtidos associados ao experimento empregado pode-se concluir:

- Durante o exercício físico as mudanças das variáveis cardiovasculares, hemodinâmicas e musculares ocorrem coincidentes com o LAn e reflete na interação dos sistemas orgânicos. O modelo matemático Heteroscedástico mostrou-se adequado na detecção da mudança de comportamento da FC, em que os métodos ARIMA e Heteroscedástico apresentaram valores muito próximos durante o limiar anaeróbio. 
- O limiar segundo a frequência cardíaca e potência apresenta valores maiores em idosos ativos e homens saudáveis ativos, entretanto em potências menores. De forma que segundo a variabilidade da frequência cardíaca observa-se uma retirada do tônus vagal durante o esforço físico no momento limiar, sugerindo que essas alterações são ocasionadas pela amputação associada à atividade física.

- A determinação do LAn é de extrema importância para evitar exercícios acima dos valores mensurados, para não promover eventos cardíacos e lesões osteomioarticulares.

Desta forma, no presente trabalho foi possível aplicar o teste cardiopulmonar em indivíduos amputados, analisar a curva de frequência cardíaca e identificar o limiar de anaerobiose dos voluntários estudados, contribuindo para melhor prescrição de exercício físico no protocolo de reabilitação de amputados transfemorais. 


\section{TRABALHOS FUTUROS}

Como trabalhos futuros sugerem-se estudos com um $\mathrm{n}$ amostral maior para melhor mensuração quantitativa e qualitativa. De forma que estudos comparativos permitam melhor identificação das alterações ocasionadas pela amputação assim sendo, acredita-se que uma comparação entre diferentes níveis de amputação possibilitaria observar as limitações associadas às alterações biomecânicas.

Ainda sobre uma análise comparativa é de extrema importância conferir entre indivíduos não amputados e amputados que fazem uso de prótese, se possível com diferentes materiais para observação de qual material acarreta maiores benefícios para amputados.

Quanto à validação do método matemático Heteroscedástico proposto por este estudo, espera-se que seja realizada com maior amostra comparativa e treinamento prévio para demais pesquisadores, afim de máximo domínio do software MATLAB. Será realizada no futuro a criação de um software específico para determinação do limiar de anaerobiose para quaisquer populações, utilizando maior número amostral. 


\section{REFERÊNCIAS BIBLIOGRÁFICAS}

ALEXANDRE, L. B. S. P (Org). Epidemiologia. São Paulo: Martinari, 2012.

ALONSO, D. O et al. Heart rate response and its variability during different phases of maximal graded exercise. Arquivos Brasileiros de Cardiologia, v. 71, n. 6, p. 787-792, 1998.

ARAKELIAN, V. M. Comparação do limiar anaeróbio e da carga crítica com relação aos parâmetros cardiorrespiratórios, metabólicos e eletromiográficos no exercício resistido de Leg Press $45^{\circ}$ em jovens e idosos. 2015. 91 f. Tese (Doutorado em Bioengenharia). Universidade de São Paulo, 2015.

ARAÚJO, C. G. S. Frequência cardíaca e exercício físico. Revista Ciência Hoje, v. 46, n. 271, p. 22-27, 2010.

BELLUSCI, S. M. Epidemiologia. São Paulo: Editora Senac, 1995.

BENETTI, M.; SANTOS, R. T.; CARVALHO, T. Cinética de lactato em diferentes intensidades de exercícios e concentrações de oxigênio. Revista Brasileira de Medicina do Esporte, Niterói, v. 6, n. 2, mar./abr. 2000.

BRASIL. Ministério da Saúde. Secretaria-Executiva. Área de Economia da Saúde e Desenvolvimento. Avaliação de tecnologias em saúde: ferramentas para a gestão do SUS / Ministério da Saúde, Secretaria-Executiva, Área de Economia da Saúde e Desenvolvimento. Brasília: Editora do Ministério da Saúde, 2009.

BRASILEIRO, T. V.; ARAÚJO, R. E. A aplicação da terapia manual em paciente diabético com amputação transfemoral usuário de prótese - relato de caso. Revista ConScientiae Saúde, São Paulo, v. 12, n. 4, p. 649-658, dez. 2013.

BRETAN, O. et al. Risco de queda em idosos da comunidade: avaliação com o teste Timed up and go. Brazilian Journal of Otorhinolaryngology, São Paulo, v. 79, n. 1, jan./fev. 2013.

CARUSO, F. C. R. et al. Determinação do limiar anaeróbio pela variabilidade da frequência cardíaca de pacientes com DPOC durante exercício em cicloergômetro. Revista Fisioterapia em Movimento, Curitiba, v. 25, n. 4, out./dez. 2012.

COUTO, P. G. et al . Pontos de transição da frequência cardíaca em teste progressivo máximo. Motriz: Revista de Educação Física, Rio Claro, v. 19, n. 2, p. 261-268, jun. 2013.

CRAIG, C. L. et al. International physical activity questionnaire: 12-country reliability and validity. Medicine and Science in Sports and Exercise, American College of Sports Medicine, v. 35, n. 8, p. 1381-1395. 2003.

CRESCENCIO, J. C. Determinação do limiar de anaerobiose ventilatório no exercício físico dinâmico em indivíduos sadios: comparação entre métodos obtidos por análise visual e modelos matemáticos. 2002. Dissertação (Mestrado em Clínica Médica) - Faculdade de 
Medicina de Ribeirão Preto, Universidade de São Paulo, Ribeirão Preto, 2002. doi:10.11606/D.17.2002.tde-05122002-094958. Acesso em: 18 dez. 2016.

FORJAZ, C. L. M.; TRICOLI, V. A fisiologia em educação física e esporte. Revista Brasileira de Educação Física e Esporte, São Paulo, v. 25, n. esp., dez. 2011.

GARTNER, L. P.; HIATT, J. L. Tratado de Histologia em Cores. 2. ed. Rio de Janeiro: Guanabara Koogan, 2003.

GOMES, C. J. Dinâmica cronotrópica pós-esforço e função autonômica cardíaca de repouso em praticantes de dança de salão. 2015. xiii, 126 f., il. Dissertação (Mestrado em Ciências Médicas) - Universidade de Brasília, Brasília, 2015.

GOMES, K. B. et al. Limiar anaeróbico ventilatório em adolescentes brasileiros de ambos os sexos. Revista Brasileira de Ciências do Esporte, Florianópolis, v. 35, n. 1, p. 65-80, jan./mar. 2013.

GUYTON, A. C. Tratado de fisiologia médica. 11. ed. Tradução: Bárbara de Alencar Martins... [et al.]. Rio de Janeiro: Elsevier, 2006.

HALLAL, P. C.; KNUTH, A. G. Epidemiologia da atividade física e a aproximação necessária com as pesquisas qualitativas. Revista Brasileira de Ciências do Esporte, Porto Alegre, v. 33, n. 1, mar. 2011.

HALLAL, P. C. et al. Evolução da pesquisa epidemiológica em atividade física no Brasil: revisão sistemática. Revista de Saúde Pública, São Paulo, v. 41, n. 3, jun. 2007.

IBGE. Instituto Brasileiro de Geografia e Estatística. Síntese de indicadores sociais: uma análise das condições de vida da população brasileira. Coordenação de População e Indicadores Sociais. Rio de Janeiro: IBGE, 2015.

JUNIOR, E. C. P. L. et al. Estudo comparativo do consumo de oxigênio e limiar anaeróbio em um teste de esforço progressivo entre atletas profissionais de futebol e futsal. Revista Brasileira de Medicina do Esporte, Niterói, v. 12, n. 6, nov./dez. 2006.

LEITE, P. H. et al. Resposta da frequência cardíaca durante o exercício isométrico de pacientes submetidos à reabilitação cardíaca fase III. Revista Brasileira de Fisioterapia, São Carlos, v. 14, n. 5, p. 383-9, set./out. 2010.

LIMA, C. R. Identificação do limiar anaeróbio através da variabilidade da frequência cardíaca durante a realização de exercício progressivo 2012. Dissertação (Mestrado em Fisioterapia), Universidade Federal de Minas Gerais, Belo Horizonte.

LOURENÇO, R. A.; VERAS, R. P. Mini-exame do estado mental: características psicométricas em idosos ambulatoriais. Revista de Saúde Pública, São Paulo, v. 40, n. 4, ago. 2006.

MARÃES, V. R. F. S.; SOUSA, B. S.; PAZ, L. P. Controle autonômico cardíaco de idosas hipertensas. Revista Brasileira de Hipertensão, v. 22, n.4, p. 139-45, 2015. 
MARÃES, V. R. F. S. et al. Determinação e validação do limiar de anaerobiose a partir de métodos de análise de frequência cardíaca e de sua variabilidade. Revista da Sociedade de Cardiologia do Estado de São Paulo, v.13, n.4, p. 1-16, 2003.

MARÃES, V. R. F. S. Frequência cardíaca e sua variabilidade: análises e aplicações. Revista Andaluza de Medicina del Deporte, Espanha, v. 3, n. 1, p. 33-42, mar. 2010.

MAROCOLO, M. et al. Análise da correlação entre o protocolo Polar Fitness Test ${ }^{\circledR}$ para predição de $\left(\mathrm{VO}_{2 \text { máx }}\right)$ e ergoespirometria. Revista Brasileira de Medicina do Esporte, São Paulo, v. 18, n. 3, maio/jun., 2012.

MATEUS, J. P. A. A atividade física em amputados transtibiais. 2012. Dissertação (Mestrado em Exercício e Bem-Estar) - Universidade Lusófona de humanidades e Tecnologias. Faculdade de Educação Física e Desporto, Lisboa, 2012.

MCARDLE, W. D.; KATCH, F. I.; KATCH, V. L. Fisiologia do exercício: nutrição, energia e desempenho humano. 7. ed. Tradução: Giuseppe Taranto. Rio de Janeiro: Guanabara Koogan, 2013.

MEDINA, M. N.; NISENBAUM, M. A. (2009). A primeira lei da termodinâmica. Disponível em: <http://web.ccead.pucrio.br/condigital/mvsl/Sala\%20de\%20Leitura/conteudos/A_primeira_lei_termodinamica.p df $>$ Acesso em: 18 mar. 2016.

MOORE, S. C. et al. Leisure time physical activity of moderate to vigorous intensity and mortality: a large pooled cohort analysis. PLOS Medicine, v. 9, n. 11. doi: 10.1371/journal.pmed.1001335. 2012.

NASCHITZ, J. E.; LENGER, R. Why traumaticleg amputees areatincreased risk for cardiovascular diseases. QJM: An International Journal of Medicine, v. 101, n. 4, p. 251259, 2008.

NEDER, J. A.; NERY, L. E. Fisiologia do exercício: teoria e prática. São Paulo: Artes Médicas, 2002.

NOGUEIRA, F. S.; POMPEU, F. A. M. S. Precisão da medida do limiar anaeróbio por meio do calorímetro portátil. Arquivos Brasileiros de Cardiologia, São Paulo, v. 95, n. 3, set. 2010.

NOGUEIRA, I. C. et al. Efeitos do exercício físico no controle da hipertensão arterial em idosos: uma revisão sistemática. Revista Brasileira de Geriatria e Gerontologia, Rio de Janeiro, v. 15, n. 3, jul./set. 2012.

OKANO, A. H. et al. Comparação entre limiar anaeróbio determinado por variáveis ventilatórias e pela resposta do lactato sanguíneo em ciclistas. Revista Brasileira de Medicina do Esporte, Niterói, v. 12, n. 1, jan./fev. 2006.

OMS. Organização Mundial da Saúde. Estatísticas da Saúde Mundial 2012. Geneva: OMS, 2012. 
PARREIRAS, L. P. Princípios do teste ergométrico: uma revisão. Revista EFDeports, Buenos Aires, ano 15, n. 143, abr. 2010.

PASSARO, Luiz Carlos. Resposta cardiovascular na prova de esforço: pressão arterial sistólica. Revista Brasileira de Medicina do Esporte, Niterói, v. 3, n. 1, p. 6-10, mar. 1997.

POLITO, M. D.; FARINATTI, P. T. V. Respostas de frequência cardíaca, pressão arterial e duplo- -produto ao exercício contra-resistência: uma revisão da literatura. Revista Portuguesa de Ciência do Desporto, 2003, v. 3, n. 1, p. 79-91.

POZZI, L. G. et al. Determinação do limiar de anaerobiose de idosos saudáveis: comparação entre diferentes métodos. Revista Brasileira de Fisioterapia, São Carlos , v. 10, n. 3, p. 333-338, set. 2006.

PRENTICE, W. E.; VOIGHT, M. L. Técnicas em reabilitação musculoesquelética. Tradução: Terezinha Oppido e Maria Alice Quartim Barbosa de Araújo. São Paulo: Artmed, 2007.

RODRIGUES, D. N.; MUSSI, R. F. F.; ALMEIDA, C. B. Atividade física na promoção da saúde de amputados. Revista EFDeportes, Buenos Aires, ano 19, n. 191, abr. 2014.

SADAVA, S. et al. Vida: a ciência da biologia. Tradução: Carla Denise Bonan [et al.]. 8. ed. Porto Alegre: Artmed, 2009.

SANDOVAL, A. E. P. Medicina do esporte: princípios e prática. Porto Alegre: Artmed, 2005.

SECOLI, S. R. et al. Avaliação de tecnologia em saúde: II. Análise de custo-efetividade. Arquivos de Gastroenterologia, São Paulo, v. 47, n. 4, out./dez. 2010.

SILVA, A. C. et al. Escalas de Borg e OMNI na prescrição de exercício em cicloergômetro. Revista Brasileira de Cineantropometria e Desempenho Humano, Florianópolis, v. 13, n. 2, mar./abr. 2011.

STEIN, R. Teste cardiopulmonar de exercício: noções básicas sobre o tema. Revista da Sociedade de Cardiologia do Rio Grande do Sul, Rio Grande do Sul, ano 15, n. 9, set./dez. 2006.

TAKAHASHI, A. C. M. et al. Avaliação do controle autonômico da frequência cardíaca e determinação do limiar de anaerobiose em homens saudáveis e coronariopatas. Revista Brasileira de Fisioterapia, v. 9, n. 2, p. 157-64, 2005.

TAVARES, A. C. et al. A meta-analysis of cardiopulmonary exercise testing in prepubertal healthy children produces new information. Medical Express, São Paulo, ano 3, n. 1, fev. 2016.

TEIXEIRA, L. C. A. Análises do padrão de resposta da frequência cardíaca pelos métodos de séries temporais e semiparamétrico e de sua variabilidade na determinação do limiar de anaerobiose. 2003. Dissertação (Mestrado em Bioengenharia) - Bioengenharia, 
Universidade de São Paulo, São Carlos, 2003. doi:10.11606/D.82.2003.tde-09092003100411.

UENO, D. T. et al. Efeitos de três modalidades de atividade física na capacidade funcional dos idosos. Revista Brasileira de Educação Física e Esporte, São Paulo, v. 26, n. 2, abr./jun. 2012.

UNESCO. Fisiologia do exercício. Fundação Vale. Cadernos de referência de esporte, 2. Brasília: UNESCO, 2013.

VANDERLEI, L. C. M. et al. Noções básicas de variabilidade da frequência cardíaca e sua aplicabilidade clínica. Revista Brasileira de Cirurgia Cardiovascular, São Paulo, v. 24, n. 2, p. 205-217, 2009.

VILLALBA, C. B.; GIL, D. B. Manual dell ciclo indoor avanzado. Barcelona: Paidotribo, 2007.

YAZBEK, J. P. et al. Ergoespirometria. Teste de esforço cardiopulmonar, metodologia e interpretação. Arquivos Brasileiros de Cardiologia, v.71, n.5, p.719-724, 1998.

YUE, A. (Coord.). Atlas de fisiologia humana. Tradução: Neila Freitas. Barueri, SP: Girassol; Firenze: Giunti Gruppo Editoriale, 2009. 
ANEXOS 
ANEXO 1: COMITÊ DE ÉTICA

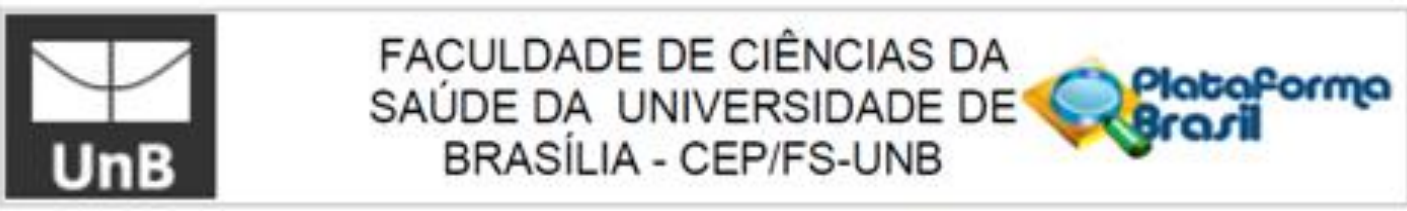

\section{PARECER CONSUBSTANCIADO DO CEP}

DADOS DO PROJETO DE PESQUISA

Titulo da Pesquisa: Desenvolvimento tecnológico e adaptaçăo de prótese ativa em amputados atletas

Pesquisador: Vera Regina Fernandes da Silva Marăes

Área Temática: Equipamentos e dispositivos terapéuticos, novos ou não registrados no Pais:

Versão: 6

CAAE: 38386714.8 .0000 .0030

Instituição Proponente: Faculdade de Ceiländia

Patrocinador Principal: FINANCIADORA DE ESTUDOS E PROJETOS - FINEP

FUNDACAO UNIVERSIDADE DE BRASILIA

\section{DADOS DO PARECER}

Número do Parecer: 1.446 .986

Situação do Parecer:

Aprovado

Necessita Apreciação da CONEP:

Năo

BRASILIA, 11 de Março de 2016

Assinado por:

Keila Elizabeth Fontana

(Coordenador)

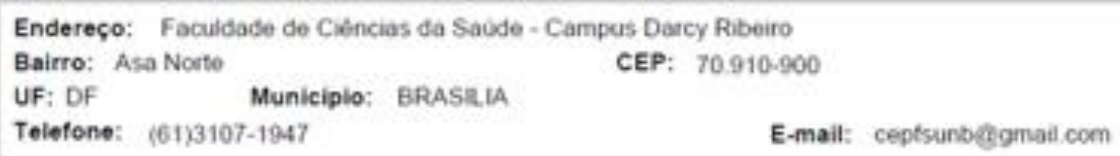




\title{
O CÂNCER DE MAMA NA PERCEPÇÃO DOS ALUNOS DE ENFERMAGEM: IMPLICAÇÕES NA PRÁTICA PROFISSIONAL
}

\author{
THE BREAST CANCER IN PERCEPTION OF NURSING STUDENTS: \\ IMPLICATIONS FOR PROFESSIONAL PRACTICE
}

\author{
Leandro Cardoso Xavier ${ }^{1 *}$; Elisângela de Andrade Aoyama ${ }^{1}$; Ludmila Rocha Lemos ${ }^{1}$; Rafael \\ Assunção Gomes de Souza ${ }^{3}$;Vera Regina Fernandes da Silva Marães ${ }^{1}$; Lourdes Mattos Brasil ${ }^{1}$. \\ ${ }^{1}$ Dep. Engenharia Biomédica - Universidade de Brasília - UNB \\ ${ }^{3}$ Centro Universitário de Desenvolvimento do Centro-Oeste - UNIDESC \\ *fiseandro@gmail.com
}

\section{Resumo}

A estratégia para o controle de câncer de mama, que promove a redução na mortalidade, é a prevenção secundária, por detectar e tratar precocemente. Trata-se de um estudo transversal de base populacional, com amostras entre homens e mulheres de 18 a 50 anos de idade. Foram entregues, por conveniência, 500 questionários para os discentes de enfermagem do primeiro ao sexto semestre. Os resultados mostraram que a maioria dos respondentes vê como principais fatores de risco para o câncer de mama a idade e o histórico familiar, no entanto, fatores como a hormonioterapia, a biópsia mamária prévia e o histórico prévio de câncer de mama, também são considerados relevantes.

\footnotetext{
Abstract

The strategy for breast cancer control, which promotes the reduction in mortality is secondary prevention, to detect and treat early. This is a prospective study of population-based sample of men and women 18-50 years old. Of the 500 questionnaires delivered randomly among the first nursing students to the sixth semester. The results showed that most respondents see as the biggest risk factors for breast cancer to age and family history, however, factors such as
}

hormone therapy, previous breast biopsy and the previous history of breast cancer, also are considered relevant. Moreover, students consider that both self-examination, such as mammogram is important in the prevention of disease.

\section{Introdução}

De acordo com o Instituto Nacional de Câncer (INCA), o câncer de mama é o segundo tipo de câncer mais frequente no mundo. Mais comum no sexo feminino, atinge $22 \%$ de indivíduos a cada ano e a estimativa para novos casos é de 57.120. Infelizmente, a taxa de mortalidade permanece alta, provavelmente devido a um diagnóstico tardio, uma vez que identificado e tratado precocemente tem um bom prognóstico ${ }^{1}$. Segundo o Sistema de Informação sobre Mortalidade (SIM) de 2011, o número de mortes chegou a 13.345 , sendo 120 homens e 13.225 mulheres $^{[2]}$.

No Brasil, o câncer de mama matou, segundo a localização primária do tumor, $15,59 \%$ no período de 2003 a 2007 , e $15,88 \%$ entre os anos de 2008 a 2012. Ao analisar a região centro-oeste, no mesmo período, o Distrito Federal registou um número de mortes de $16,73 \%$ e $16,54 \%$, respectivamente. Esses dados foram maiores do que o registrado nos estados de Goiás, Mato Grosso e Mato Grosso do Sul. Em relação à região Nordeste,

XI Congresso de Física Aplicada à Medicina 94 
o estado de Sergipe, no período de 2008 a 2012, registrou um índice maior do que o Distrito Federal, 17,21\%. A maior incidência de morte no Brasil foi registrada na região Sudeste, onde no estado do Rio de Janeiro o índice foi de $19,24 \%$, no período de 2003 2007 , e de $19,33 \%$, no período de 2008 $2012^{[1]}$.

A média mundial de sobrevida após cinco anos é de $61 \%^{[1]}$. Nos países desenvolvidos, nos últimos 40 anos, a sobrevida vem aumentando, $85 \%$ em cinco anos, e $50 \%$ e $60 \%$ em países em desenvolvimento, e neste último é a maior causa de morte por câncer. $\mathrm{O}$ envelhecimento, fatores relacionados à vida produtiva da mulher, consumo de álcool e fumo são alguns fatores de risco para o surgimento do câncer de mama. Sendo que a idade ainda é um dos fatores de risco mais importantes, observando que a incidência aumenta rapidamente até os 50 anos de idade $^{3}$. O que poderia explicar tal fato é o número de ciclos menstruais aumentados, que predispõe as mulheres a uma maior lesão do DNA no tecido ductal da mama em proliferação, podendo levar a mutações e resultando em câncer ${ }^{[4]}$.

Mulheres que fazem tratamento de reposição hormonal em um período de cinco anos tem cerca de 1,5 vez de desenvolver câncer de mama, e o risco se torna maior quando associado com estrogênio-progesterona do que a reposição somente com o estrogênio ${ }^{[4]}$.

$\mathrm{O}$ estilo de vida ocidental pode predispor as mulheres ao câncer, pois é caracterizado pela menarca precoce, menopausa tardia, maior idade ao engravidar ou a nuliparidade, obesidade, sedentarismo e reposição hormonal. Além disso, mulheres que consomem diversas bebidas alcoólicas têm maior risco de ter câncer de mama do que as abstêmicas, e o uso de anovulatórios orais o risco é mínimo, caso ocorra ${ }^{[4]}$.

Pacientes com história de câncer de mama na família tem maior risco de desenvolver a doença. A hereditariedade é responsável por $10 \%$ do total de casos, especialmente se uma ou mais parentes for mãe ou irmãs ${ }^{[5]}$. A maioria dessas pacientes apresentam mutações no gene BRCA1 e BRCA2 $2^{[4]}$. Esses genes são supressores de tumor $e$ seus produtos interagem com proteínas de reparo de DNA/recombinante para preservar a estrutura do cromossomo. Quando ocorrem mutações em BRCA1 e BRCA2 as células ficam sujeitas a maior risco de transformação maligna, pois causa uma instabilidade genética ${ }^{5}$. Ambos os genes são transmitidos de forma autossômica dominante, assim, uma portadora tem probabilidade de 50:50 de passar o gene a um filho ou filha. Mas é incerto se alguém com a mutação irá de fato desenvolver câncer de mama, e as manifestações dessas mutações podem parecer alternar gerações ${ }^{[6]}$.

Quando identificado que a mulher é portadora de mutação em BRCA1 ou BRCA2 indica-se o uso da mamografia a partir dos 25 anos. Nos programas de rastreamento, o uso da mamografia anual em mulheres entre 40 e 74 anos de idade ajuda a reduzir a probabilidade de óbito por câncer de mama entre 10 e $20 \%$. Aproximadamente de 15 a $25 \%$ dos tumores de mama palpável não são identificados pela mamografia, isso ocorre mais nas mulheres na pré-menopausa e naquelas que possuem as mamas mais densas ${ }^{[4]}$.

Segundo o INCA, o autoexame das mamas como método isolado de detecção precoce do câncer de mama não é seguro, pois não é eficiente e não contribui para a redução da mortalidade. Portanto, o autoexame não substitui o exame físico realizado por profissional de saúde (médico ou enfermeiro) qualificado para essa atividade ${ }^{[7]}$.

A estratégia para o controle de câncer de mama, que promove a redução na mortalidade, é a prevenção secundária, isso porque detecta precocemente e trata. A prevenção primária atua na identificação $e$ correção dos fatores de risco evitáveis e, a prevenção terciáriana reabilitação e nos cuidados paliativos ${ }^{[8]}$.

Mas nem sempre foi assim. Quando os primeiro mamógrafos chegaram ao Brasil, no início da década de 1970, a atenção para a saúde era individual e de caráter curativo. Com isso, o modelo daquela época era centrado na atenção hospitalar e os serviços dos prestadores privados eram comprados. Essa forma de atenção à saúde impossibilitava ações de prevenção de

XI Congresso de Física Aplicada à Medicina 95 
qualquer nível, assim como a detecção precoce. Ademais disso, a maior parte da população não tinha acesso à saúde ${ }^{[9]}$.

Com a implementação do Sistema Único de Saúde - SUS ${ }^{[1]}$ a partir da década de 1990 surge uma abordagem organizada dos cânceres femininos no Brasil, o programa "Viva Mulher". Esse projeto foi consolidado no período 1990/2000 com o monitoramento informatizado do câncer de colo do útero e, posteriormente, em 2009, o câncer de mama. A partir de 2004, o Ministério da Saúde produziu publicações técnicas para divulgação de programas de controle de câncer e instituiu ferramentas para apoio aos gestores municipais e estaduais ${ }^{[9]}$.

Apesar de toda a melhoria na saúde para o diagnóstico e tratamento do câncer de mama no Brasil, verificada desde a década de 70 , os casos registrados ainda estão aumentando em algumas regiões do país. Aliás, basta um nódulo no seio de uma mulher para que ela passe por dúvidas e incertezas que podem ou não ser abrandados por meio dos exames clínicos e radiológicos ${ }^{[10]}$. Acredita-se que a maioria das mulheres já possui a consciência do risco do câncer de mama, pois a sociedade civil organizada, assim como as ONGs relacionadas ao câncer de mama e a crescente divulgação de reportagens na mídia $^{[9]}$ ajudam na informação para a prevenção e o diagnóstico. A confirmação da doença desenvolvem conflitos nas pacientes, que são observados nas alterações psicológicas que podem durar deste a cirurgia até os tratamentos com a radioterapia, a quimioterapia, e a hormônioterapia ${ }^{[10]}$.

Para o atendimento dessas pacientes, fazemse necessárias ações por meio de uma equipe multidisciplinar. Segundo o INCA, essas ações devem ser conjuntas com todos os profissionais de saúde desde o momento do diagnóstico. O enfermeiro faz parte dessa equipe e atua no diagnóstico e antes da terapêutica. Sua atuação é relevante em diversas etapas do tratamento e vai além de cuidados com a ferida operatória. No caso, é esse profissional que orienta o paciente quanto aos cuidados seguintes à alta hospitalar, que auxilia grupos de apoio interdisciplinar no exame de questões educativas, sociais e emocionais voltados à reintegração desse indivíduo em suas atividades $^{[11]}$. Por isso, aliás, o paciente pode e deve construir um elo com esse profissional. Por esta razão, esse trabalho tem por finalidade analisar as percepções dos alunos de enfermagem sobre o câncer de mama, enquanto profissionais da saúde, para identificar o nível de conhecimento.

\section{Materiais e métodos}

Estudo transversal de base populacional na Faculdade Juscelino Kubitschek na cidade do Gama, DF, em 2014, com amostras entre homens e mulheres de 18 a 50 anos de idade. Foram entregues 500 questionários, por conveniência, entre os discentes de enfermagem do primeiro ao sexto semestre. Após três dias da entrega foi realizado reforço sobre a importância do levantamento de dados e entregue laços rosa, símbolo mundial na luta contra o câncer de mama, conhecida por "Outubro Rosa".

Os questionários foram estruturados de maneira a permitir o preenchimento sem grande dispêndio de tempo, para evitar o desinteresse dos respondentes. Foram divididos em duas partes: a primeira contendo dados pessoais (sexo, idade e profissão); a segunda contendo perguntas dicotômicas, com respostas do tipo Sim/Não. Estas perguntas pertenciam a três grupos que buscavam: 1- Identificar a percepção dos alunos sobre o tema "Câncer de mama"; 2Identificar a percepção sobre as condutas em relação ao câncer de mama; 3- Identificar as concepções e interpretações no enfrentamento do câncer de mama.

O critério de inclusão foi ser aluno da Instituição de Ensino Superior, supracitada e estar cursando a graduação em Bacharelado em Enfermagem. A organização dos dados não permitia a identificação do autor das respostas. Para levantamento estatístico, tabulação das respostas e resgate dos resultados, foi utilizado o programa de software excel. Os questionários foram entregues no mês de outubro de 2014 e o

XI Congresso de Física Aplicada à Medicina 96 
período de espera pelas respostas se deu até três dias após a entrega.

\section{Resultados e discussão}

Dos 500 questionários aplicados, 81 (16,2\%) foram devolvidos em branco e $43(8,6 \%)$ não devolvidos por motivos alheios. Ao todo retornaram 376 questionários respondidos, $17,8 \%(n=67)$ destinaram aos discentes do sexo masculino e $81,6 \%(n=307)$ as discentes do sexo feminino. Quanto ao sexo $0,6 \%$ $(n=02)$ deixaram de responder, perfazendo uma taxa de retorno de $75,2 \%$.

Respostas referentes aos dados pessoais: Sexo masculino: $17,8 \%(n=67)$ e para o sexo feminino: $81,6 \%(n=307)$. Idade variou de 18 a 50 anos, com média de 29,8 anos (desviopadrão $=7,8$ anos), moda prevaleceu em 21,2 anos e mediana $=29,1$. Dentre as profissões mais exercidas citaram estudantes $(21,3 \%)$, seguida por área da saúde $(21 \%)$, grande variabilidade do comércio $(3,2 \%)$, outros $(42 \%)$ e deixaram em branco $(12,5 \%)$.

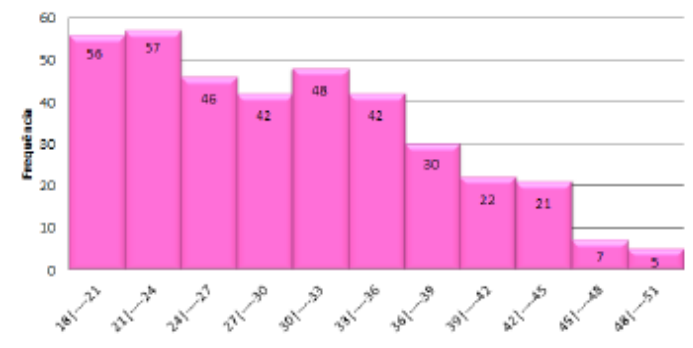

Figura 1 - Faixa etária dos discentes que participaram da pesquisa.

As respostas às perguntas relativas à percepção, condutas, concepções e interpretações dos discentes sobre o tema câncer de mama estão dispostas nas Tabelas de 1 a 6 .
Tabela 1 - Capacidade de reconhecimento dos fatores de risco para câncer de mama.

\begin{tabular}{lcccc}
\hline & \multicolumn{2}{c}{ SIM } & \multicolumn{2}{c}{ NÄ0 } \\
Idade & n & $\%$ & n & $\%$ \\
História faniliar & 278 & 73,9 & 98 & 21,1 \\
Hormonioterapia & 263 & 69,9 & 113 & 30,1 \\
Biópsia mamária prévia & 188 & 50,0 & 188 & 50,0 \\
História prévia de câncer de mama & 217 & 57,7 & 159 & 42,3 \\
\hline
\end{tabular}

Um dos objetivos desta investigação era identificar a percepção de estudantes de enfermagem sobre o Câncer de mama. Os dados coletados por meio da aplicação de um questionário semiestruturado com perguntas fechadas foram tabulados e analisados estatisticamente. Os resultados da Tabela 1 mostram que a maioria dos respondentes vê como principais fatores de risco para o câncer de mama a idade $(73,9 \%)$ e o histórico familiar $(69,9 \%)$, no entanto, fatores como a hormonioterapia, a biópsia mamária prévia e o histórico prévio de câncer de mama, também são considerados relevantes.

Tabela 2 - Crenças e opiniões sobre câncer de mama

\begin{tabular}{lccccc}
\hline & \multicolumn{2}{c}{ SIM } & \multicolumn{2}{c}{ NÁ0 } \\
& n & $\%$ & n & $\%$ \\
Autoexame mamírio é importante? & 371 & 98,7 & 05 & 1,3 \\
Mamografia é importante? & 372 & 98,9 & 04 & 1,1 \\
Mamografia reduz a mortalidade? & 308 & 81,9 & 68 & 18,1 \\
A mamografia melhora o prognóstico do càncer de mama? & 318 & 84,6 & 58 & 15,4 \\
Mamografia confere proteçầ legal? & 242 & 64,4 & 134 & 35,6 \\
\hline
\end{tabular}

A Tabela 2 traz os dados sobre as crenças e opiniões que os estudantes têm sobre o câncer de mama. Os resultados permitem inferir que os estudantes consideram que tanto o autoexame $(98,7 \%)$, como o exame de mamografia $(98,9 \%)$ são importantes na prevenção da enfermidade. No entanto, também acreditam que a mamografia não reduz a mortalidade (81,9\%). Esses dados mostram um bom esclarecimento dos consultados sobre as formas de prevenção do câncer de mama $o$ que permite um diagnóstico prévio e consequentemente um tratamento mais eficaz, o que reduz os números de óbitos causados pelo câncer de mama.

XI Congresso de Física Aplicada à Medicina 97 
Tabela 3 - Detectando análises

\begin{tabular}{|c|c|c|c|c|}
\hline & \multicolumn{2}{|c|}{ SIM } & \multicolumn{2}{|c|}{ NÁO } \\
\hline & n & $\%$ & $\mathrm{n}$ & $\%$ \\
\hline Na sua familia algıém já teve câncer de mama? & $6 ?$ & 178 & 309 & 82,2 \\
\hline $\begin{array}{l}\text { Conhece alguém que teve diagnóstico positivo de câncer } \\
\text { de mama no último ano? }\end{array}$ & 205 & 54,5 & 171 & 45,5 \\
\hline $\begin{array}{l}\text { Caso simpara as perguntas anteriores, a paciente fez ou } \\
\text { faz tratamento médico? }\end{array}$ & 241 & 64,1 & 135 & 35,9 \\
\hline $\begin{array}{l}\text { O nivel socioeconónico é unn dos mais importantes fatores } \\
\text { deteminartes da maior ou menor fealizaçăo das condutas } \\
\text { preventivas para o cáncer de mama? }\end{array}$ & 258 & 68,6 & 118 & 31,4 \\
\hline $\begin{array}{l}\text { E provável que estimulo dirigido às mulheres, por } \\
\text { campanhas especificas, aumentou o nimero de exames } \\
\text { elinicos de mamas? }\end{array}$ & 355 & 94,4 & 21 & 5,6 \\
\hline
\end{tabular}

Com relação à deteç̧ão, descrita na Tabela 3 , os participantes da pesquisa consideram que as campanhas publicitárias contribuem enormemente para estimularem a procura pelos exames clínicos de mama. Cerca de $17,8 \%$ dos respondentes tiveram casos de câncer de mama na família e $54,5 \%$, conhece alguém que tem ou já teve. Dos 376 consultados, 258 avaliam que o nível socioeconômico é um fator preponderante para uma maior prevenção do câncer de mama, como indicam os dados publicados na Tabela 3. A falta de recursos adequados na rede pública torna mais difícil para as pacientes de classes sociais menos favorecidas economicamente a se prevenirem de forma adequada.

Tabela 4 - Idade atribuída à maior índice de câncer de mama

\begin{tabular}{lccccc}
\hline & \multicolumn{3}{c}{ SIM } & \multicolumn{2}{c}{ NÁ0 } \\
& n & $\%$ & n1 & $\%$ \\
Menores ou iguala 35 anos & 79 & 21,0 & 297 & 79 \\
Entre 36 e 49 anos & 262 & 69,7 & 114 & 30,3 \\
Maiores ou igual a 50 ancos & 47 & 12,5 & 329 & 87,5 \\
\hline
\end{tabular}

A idade é apontada como um dos fatores que influenciam no surgimento do câncer de mama. Como mostram os dados plotados na Tabela 4 , os estudantes consultados $(69,7 \%)$ sopesam que a faixa etária de maior incidência da enfermidade é entre 36 e 49 anos.
Tabela 5 - Atividades educativas exercidas

\begin{tabular}{|c|c|c|c|c|}
\hline & \multicolumn{2}{|c|}{ SIM } & \multicolumn{2}{|c|}{$\mathrm{NÄO}$} \\
\hline & $\mathrm{n}$ & $\%$ & $\mathrm{n}$ & $\%$ \\
\hline Costuma ler informaçōes sobre câncer de mama? & 277 & 73,7 & 99 & 26,3 \\
\hline Sabe fazer o autoexame mamário? & 286 & 76,1 & 90 & 23,9 \\
\hline $\begin{array}{l}\text { Tem orientaçäo que a mulher deve fazer o autoexame } \\
\text { mamário a partir dos } 20 \text { anos? }\end{array}$ & 277 & 73,7 & 99 & 26,3 \\
\hline $\begin{array}{l}\text { Tem orientaçäo que as mulheres com idades entre } 20 \text { e } 39 \\
\text { anos devem submeter-se ao exame clinico das mamas } \\
\text { trienalmente? }\end{array}$ & 224 & 59,6 & 152 & 40,4 \\
\hline $\begin{array}{l}\text { Tem orientação que as multheres devem realizar o exame } \\
\text { clinico das mamas anualmente após os } 40 \text { anos? }\end{array}$ & 332 & 88,3 & 44 & 11,7 \\
\hline
\end{tabular}

Os dados descritos na Tabela 5 estão relacionados com as condutas que os respondentes têm em relação ao câncer, sobre os quais podemos inferir que uma grande maioria $(73,7 \%)$ costuma ler informações sobre câncer de mama. O autoexame mamário é realizado por $76,1 \%$ da amostra, revelando um alto grau de esclarecimento. A maioria dos consultados também tem conhecimento sobre a faixa etária de maior incidência do câncer de mama e da idade que deve ser realizado o exame clínico. O nível de informação dos estudantes sobre o câncer de mama pode ser considerado muito bom o que permite inferir que como profissionais da área da saúde tenham os pré-requisitos necessários para disseminar o conhecimento sobre a doença entre os pacientes e evitando um diagnóstico tardio.

Tabela 6 - Concepções e interpretações no enfrentamento do câncer de mama

\begin{tabular}{|c|c|c|c|c|}
\hline & \multicolumn{2}{|c|}{ SLM } & \multicolumn{2}{|c|}{ NÁO } \\
\hline & $\mathrm{n}$ & $\%$ & $\mathrm{n}$ & $\%$ \\
\hline $\begin{array}{l}\text { A causa estaria relacionada justamente coma contenç̧̄o do } \\
\text { desejo ou nảo expressividade das emoçōes? }\end{array}$ & 168 & 44,7 & 208 & 55,3 \\
\hline $\begin{array}{l}\text { O enfrentameato, alteraçōes da rotina familiar e emoçōes } \\
\text { experimentadas após o diagnóstico de cáncer, referem-se } \\
\text { ao medo e a dor, rodeados de estigmas e preconceitos? }\end{array}$ & 330 & 87,8 & 46 & 12,2 \\
\hline $\begin{array}{l}\text { Acredita que estratégias adotadas para lidar com o } \\
\text { diagnóstico tratamento do cincere expectativas quanto ao } \\
\text { tratamento estão acentuados na religifo fé? }\end{array}$ & 254 & 67,6 & 122 & 32,4 \\
\hline $\begin{array}{l}\text { Devido a dore ao sofrimento gerados pela quimioterapia e } \\
\text { a mastectomia repercute a autoimagem da mulher? }\end{array}$ & 337 & 89,6 & 39 & 10,4 \\
\hline $\begin{array}{l}\text { A familia possui papel primordial no enfrentamento e } \\
\text { reorganizaça logo após um diagnóstico positivo da } \\
\text { doença? }\end{array}$ & 363 & 96,5 & 13 & 3,5 \\
\hline
\end{tabular}

As concepções e interpretações sobre o câncer de mama dos estudantes participantes da pesquisa estão relacionadas na Tabela 6 , cuja análise revela que $96,5 \%$ da amostra acreditam que a família possui um papel

XI Congresso de Física Aplicada à Medicina 98 
primordial no enfrentamento e reorganização logo após um diagnóstico positivo da doença. É o apoio da família o principal fator no enfrentamento do câncer de mama, contribuindo para o aumento da autoestima e das condições psicológicas do paciente.

\section{Conclusão}

Os resultados da análise de dados da pesquisa, realizada com alunos de enfermagem, a respeito de sua percepção sobre o câncer de mama, revelam que esta enfermidade ainda é uma das doenças que mais leva mulheres a óbito. Embora os avanços tecnológicos promovam maior conhecimento sobre a enfermidade, a cura ainda parece distante.

O número de mulheres diagnosticadas com câncer de mama aumenta a cada ano e mostra que não só as mulheres mais velhas estão sujeitas a essa doença, mas, um grande número de mulheres jovens já é diagnosticado com a enfermidade.

A percepção dos futuros profissionais de saúde sobre o câncer de mama é privilegiada, levando em conta não só a literatura existente, como as informações vinculadas nos meios de comunicação. Os resultados apontam que os mesmos tem um nivel de informação considerável, o que pode contribuir de forma positiva na sua atuação profissional, como enfermeiros oncológicos especialistas em câncer de mama, com visão humanizada.

\section{Referências}

[1] INCA. Atlas On-line de Mortalidade. Distribuição proporcional do total de mortes por câncer, segundo localização primária do tumor, por sexo, localidade, por período selecionado [acesso 2014 out 28]. Disponível em: <https://mortalidade.inca.gov.br/Mortalida deWeb/pages/Modelo02/consultar.xhtml>.

[2] INCA. Câncer: tipos de câncer- mama [acesso 2014 out 27]. Disponível em: <http://www2.inca.gov.br/wps/wcm/connect/tip osdecancer/site/home/mama/cancer_mama>

[3] INCA. Estimativa 2014: incidência de câncer no Brasil [acesso 2014 out 28]. Disponivel em: <http://www.inca.gov.br/ esti mativa/2014/sintese-de-resultados-comenta rios.asp>

[4] Goldman, L. Ausiello, D. Cecil, tratado de medicina interna. Tradução de Ana Kemperet al. Rio de Janeiro: Elsevier, 2005. 1424-30p.

[5] Schaffer, J. L. Hoffman, B. L. Schorge, J. O. Ginecologia de Williams. $2^{\circ}$ ed. Tradução Ademar Valadares Fonseca et al. Rio de Janeiro: Artmed, 2014. 854p.

[6] INCA. Detecção precoce [acesso 2014 nov. 19]. Disponível em:<http://www2.inca. gov.br/wps/wcm/connect/tiposdecancer/ site/home/mama/deteccao_precoce>.

[7] INCA. Prevenção [acesso 2014 nov. 21]. Disponivel em: < http://www2.inca.gov.br/wps/ wcm/connect/tiposdecancer/site/ home/mama + /prevencao+>.

[8] Silva, R. C. F. Evidências científicas e análise comparada de programas de rastreamento: elementos para a discussão de pré-requisitos ao rastreamento organizado de câncer de mama no Brasil [Tese]. Revista de Brasileira de Cancerologia 2003; 59 (3): 467.

[9] Porto, M. A.; Teixeira, L. A. S. Aspectos Históricos do Controle do Câncer de Mama no Brasil. Revista Brasileira de Cancerologia 2013; 59(3): 331-39 [acesso 2014 out 30]. Disponivel em: <http://www1 inca.gov.br/rbc/n _59/v03/pdf/03-artigo-aspectos-historicoscontrole-cancer-mama-brasil.pdf>.

[10] Maluf, M. F. M.;Mori, L. J.; Barros, A. C. S. D. O impacto psicológico do câncer de mama. Revista Brasileira de Cancerologia 2005; 51(2): 149-54 [acesso 2014 nov 03]. Disponivel em:<http://www.inca.gov.br/rbc/n _51/v02/pdf/revisao1.pdf>.

[11] Brasil. Ministério da Saúde. Instituto Nacional de Câncer. Controle do câncer de

XI Congresso de Física Aplicada à Medicina 99 
mama: documento de consenso. Rio de Janeiro: CONPREV; 2004 [acesso 2014 nov 03]. Disponível em: <http://www.inca.gov.br/pu blicacoes/consensointegra.pdf> 


\title{
AVALIAÇÃO DA RESPOSTA DA FREQUÊNCIA CARDÍACA DE ADULTOS DURANTE TESTE CARDIOPULMONAR
}

\author{
E. A. Aoyama*, L. R. Lemos", V. R. F. S. Paz*, M. M. Gomes*, R. A. G. Souza ${ }^{* *}$, E. R. S. \\ Assunção ${ }^{* * *}$ \\ *Universidade de Brasília, Brasília, Brasil \\ ${ }^{* *}$ Centro Universitário de Desenvolvimento do Centro-Oeste, Luziânia, Brasil \\ ${ }^{* * *}$ Universidade Norte do Paraná, Paraná, Brasil \\ elisangelaaoyama@gmail.com
}

\begin{abstract}
Resumo: A resposta da frequência cardíaca é considerada o melhor parâmetro para monitorar a intensidade do trabalho do coração, tornando-se ferramenta indispensável na prescrição individualizada do exercício físico e para a clínica, com intuito de elucidar as causas e os riscos de morbimortalidade desencadeados por sua oscilação caracterizada por arritmias fatais. $O$ teste de exercício máximo ou teste ergométrico é utilizado para avaliar possíveis alterações cardiovasculares e identificar vários marcadores metabólicos. Este teste associado a um ergoespirômetro permite coletar e analisar os gases inspirados e expirados e obter importantes marcadores metabólicos como o limiar anaeróbio e o ponto de compensação ventilatória. Estes limiares podem ser identificadostambém por meio da análise da resposta da frequência cardíaca durante o exercício físico, tornandose um método mais prático e menos dispendioso comparativamente a ergoespirometria. Este trabalho apresenta como objetivos identificar mudanças na curva de resposta da frequência cardíaca de adultos, durante teste cardiopulmonar e identificar o limiar anaeróbio e o ponto de compensação ventilatória, empregando ferramenta estatística. Os dados para análise foram obtidos por meio da aplicação do teste cardiopulmonar, realizado em dois homens, na faixa etária entre 40 e 60 anos. Primeiramente estes voluntários foram submetidos a uma avaliação e anamnese, para estimar a função cognitiva, risco para queda, capacidade física e funcional, os níveis de atividade física e grau de dependência. Os dados resultantes da aplicação dos testesserão compilados e analisados utilizando modelagem estatística, para a verificação de curva de frequência cardíaca em adultos durante teste cardiopulmonar.
\end{abstract}

Palavras-chave: Exercício Físico, Frequência Cardíaca, Limiar Anaeróbio, Teste de esforço.

Abstract:The heart rate response is considered the best parameter to monitor the intensity of work of heart, becoming indispensable tool in individualized prescription of physical exercise and the clinic, in order to elucidate the causes and risks of morbidity and mortality triggered by its oscillation characterized in fatal arrhythmias. The maximal exercise test or treadmill test is used to evaluate cardiovascular abnormalities and identify various metabolic markers. This test associated with aergospirometer lets you collect and analyze the inspired and expired gases and obtain important metabolic markers such as anaerobic threshold and the respiratory compensation point. These thresholds may also be identified through the analysis of heart rate response during exercise, making it a more practical and less expensive method compared to spirometry. This work has the objective to identify changes in the response curve of heart rate in adults during cardiopulmonary exercise testing and identify the anaerobic threshold and the respiratory compensation point, using statistical tool. The data for analysis were obtained through the application of cardiopulmonary exercise testing, carried out in two men, aged between 40 and 60 years. First these volunteers were submitted to an evaluation and history to estimate the cognitive function, risk to fall, physical and functional capacity, physical activity levels and degree of dependency. Data from tests of the application will be compiled and analyzed using statistical modeling for checking heart rate curve in adults during cardiopulmonary exercise testing.

Keywords: Physical Exercise, Heart Rate, Anaerobic Threshold, Stress Test.

Introdução

As necessidades corporais são reguladas pelos neurônios do centro vasomotor, adaptados por atividade dos neurônios do simpático, assim, se a pressão arterial aumenta, receptores específicos (barorreceptores) enviam sinais ao centro cardiorregulador e ao vasomotor A pressão nas artérias depende de parâmetros físicos, distensibilidade, resistência ao fluxo por parte dos vasos, viscosidade do sangue e ejeção da frequência cardíaca, e cada uma destas variáveis serão diretamente influenciadas pelo sistema nervoso autônomo (SNA) [1]

A frequência cardíaca $(\mathrm{FC})$ é caracterizada pelo número de vezes que o coração contrai e relaxa, ou seja, os batimentos por minuto. Reconhecidamente é o melhor parâmetro de monitoramento da atividade física, para determinar o limiar anaeróbio [2]. A FC é uma informação importante sobre o estado de saúde de uma pessoa e um excelente indicador sobre o nível de intensidade de trabalho do coração, principalmente para 
avaliar diferentes variáveis fisiológicas. O músculo cardíaco responde às necessidades de oxigênio e fluxo sanguíneo do organismo, em diferentes momentos [3].

Ao iniciar o exercício físico a FC aumenta de acordo a intensidade do exercício e a capacidade fisica atual do indivíduo. Há correlação direta entre a frequência cardíaca máxima $\left(\mathrm{FC}_{\max }\right)$ e o consumo máximo de oxigênio $\left(\dot{V} O_{2 m a ́ x .}\right)$ durante o exercício, tanto para a população em geral, quanto para esportista [3]. Muitos fatores afetam a FC durante o exercício, sendo os principais: temperatura, umidade, horário, posição, ingestão de alimentos e uso de medicamentos.Aplicando-se modelos estatísticos tanto aos dados da produção de dióxido de carbono $\left(\dot{V} \mathrm{CO}_{2}\right)$, quanto aos dados da $\mathrm{FC}$, é possível configurar importantes estratégias de avaliação e capacidade funcional.

Quando se pedala ou anda a pé o corpo promove movimentos complexos e afetam todos os sistemas do organismo. Enquanto se faz exercício várias vezes semanalmente o corpo adapta-se, fazendo de forma mais eficiente. Durante a prática de exercício o coração pode atingir 150 batimentos por minuto (bpm) ou mais, duplicando o valor habitual em repouso, para a maioria das pessoas situa-se em torno de 60 a $80 \mathrm{bpm}$. Este aumento permite ao coração bombear até 20 litros de sangue por minuto, quadruplicando o habitual em repouso [4].

Omecanismo que gera energia durante o exercício físico provém da complexa e sofisticada integração entre os sistemas cardiovascular, respiratório e muscular [5]. O limiar de anaerobiose ou limiar anaeróbio (LAn) é considerado um importante marcador metabólico e é um índice para mensurar o desempenho aeróbio durante o exercício físico. Em teste cardiopulmonar (TCP) é possível analisar as respostas ventilatórias e metabólicas sendo refletidas, mesmo com atraso, na respiração celular dos músculos periféricos. Existem vários fatores de risco cardiovascular e utilizar a FC como valiosa ferramenta possibilita ampliar perspectivas para a aplicação clínica. Diversos estudos apresentam a modificação da FC durante exercício físico e a alteração do balanço simpático-vagal cardíaco [1].

A prática da atividade física regular e sistematizada influencia no desempenho funcional, preservando a independência e autonomia das pessoas. As tecnologias em saúde incluem os equipamentos, medicamentos, procedimentos e sistemas organizacionais e de suporte, com intuito de promover os cuidados com a saúde [6]. Primariamente a tecnologia biomédica, avaliada de senso comum, oferece tecnologia aos equipamentos e medicamentos, interatuando diretamente com os pacientes [7]

Para determinar o LAn utiliza-se o método ventilatório, de caráter não invasivo e consideravelmente prático, mas que infelizmente possui acesso restrito, por envolver equipamentos caros, ainda que seja em laboratórios específicos, como o de físiologia do esforço [1].Para o desenvolvimento de novos aparelhos criados por engenheiros biomédicos os dados da pesquisa iniciam uma discussão sobre as possibilidades de aprimoramento,já que muitas vezes as análises dessa variável, frequência cardíaca, na identificação do limiar de anaerobiose e do ponto de compensação ventilatória são feitas visualmente. Agregada ao estudo estatístico essa inovação tecnológica possibilitará encontrar pontos de mudança na curva da FC (intervalos RR) correspondente ao LAn do indivíduo e ao ponto de compensação ventilatória, ferramenta importante para a prescrição adequada de exercício fisico.

\section{Materiais e métodos}

O estudo foi realizado no laboratório de Biofisica e de Fisiologia do Exercício da Universidade de Brasília $(\mathrm{UnB})$ - Faculdade de Ceilândia (FCE), em laboratório climatizado artificialmente,para controle da temperatura e umidade.

Repassadas orientações sobre a participação no estudo, aos dois voluntários, com idades entre 40 e 60 anos, de não ingerir bebidas alcoólicas, café e/ou outras bebidas estimulantes, não praticar atividade física 24 horas antes do teste ergoespirométrico e tão pouco realizarem o teste em jejum, estes assinaram o Termo de Consentimento Livre e Esclarecido, aprovado pelo Comitê de Ética em Pesquisa (Parecer n ${ }^{\circ} 1.166 .770$ ).

Previamente foram apresentadas todas as informações relativas ao teste e orientações para que os voluntários respirassem espontaneamente e não conversassem durante oteste cardiopulmonar. Os voluntários foram treinadospor 14 minutos, em média,e utilizaram a Escala de Borg como indicador de sua percepção de esforço físico.Os critérios de exclusão para participar da pesquisa: alterações metabólicas associadas, déficit de equilibrio, etilistas, fumantes, instabilidade da marcha, problema musculoesquelético que inviabilize praticar exercício físico, uso de medicamento betabloqueador, por interferir nas variáveis.

A primeira etapa foiconstituída por umaavaliação e anamnese, a qual os voluntários foram submetidos à aferição da $\mathrm{FC}$, da pressão arterial $(\mathrm{PA})$ em repouso, das medidas da massa corporal e estatura, do cálculo do índice de massa corpórea (IMC) e ainda dos seguintes instrumentos: Questionário Internacional de Atividade Física (IPAQ), Escala de Borg, Mini Exame do Estado Mental (MEEM), Timed Up and Go (TUG).

$\mathrm{Na}$ segunda etapa foi realizado um eletrocardiograma (ECG) e um teste cardiopulmonar (Vmax Care Fusion) utilizando bicicleta ergométrica para registro da variabilidade da frequência cardíaca (intervalos RR) durante o exercício físico.

Os métodos de análise da frequência cardíaca podem ocorrer nos domínios do tempo, da frequência e ainda com aplicação de modelos estatísticos que podem descrever o comportamento da frequência cardíaca ao longo do tempo e do exercício realizado [1][5]. Baseado em cálculos estatísticos simples é possível analisar o comportamento da $\mathrm{FC}$ ou dos intervalos $\mathrm{RR}$, utilizando 
índices temporais estatísticos paramétricos e não paramétricos, empregando média, mediana, desvio padrão, quartis e diferença entre os intervalos $R R$ máximo e $R R$ mínimo e ainda modelos estatísticos. $O$ estudo do padrão de resposta da frequência cardíaca pode trazer informações fisiológicas e metabólicas relevantes do indivíduo submetido a um estresse fisico [1].

\section{Resultados}

Os modelos estatísticos dos dados foram analisados para que possibilitem traçar o ponto de mudança da FC e de compensação ventilatória.

Na figura 1 pode-se observar que os intervalos $R R$ possuem estacionaridade nos 3 minutos iniciais do teste realizado por um indivíduo. Após este período há um declínio dos valores dos intervalos RR. Posteriormente os intervalos $R R$ permanecem constantes até aproximadamente 7 minutos do teste cardiopulmonar, quando pode-se observar um segundo ponto de mudança no padrão de resposta da curva dos intervalos $R R$. Tais pontos de mudanças podem indicar o LAn e o ponto de compensação ventilatório, respectivamente.

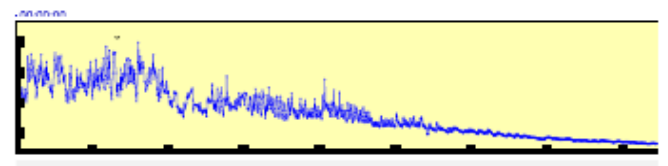

Figura 1: Dados coletados dos intervalos $R R$ (inverso da frequência cardiaca) durante teste cardiopulmonar de um voluntário estudado.

Em concordância à análise de gases expirados, variáveis respiratórias e oximetria, a ergoespirometria é um procedimento não invasivo que avalia $o$ desempenho fisico e a capacidade funcional da pessoa [8]. É útil para determinar os fatores que indicam o desempenho

\section{Discussão}

O teste cardiopulmonar é uma ferramenta indispensável para tomada de decisão em situações clínicas. Sendo a combinação do teste ergométrico, saturação de $O_{2}$ e medidas das trocas ventilatórias. Associado a oximetria de pulso para quantificar a saturação das hemoglobinas e a bicicleta ergométrica, por possuir vantagens, independente do peso do indivíduo, fornece ampla gama de aplicações para exames de exercícios, detectando os valores iniciais e de pico, o que melhora e reduz o tempo de processamento de relatórios

Utilizado na prática clínica tanto para avaliação quanto para treinamento o LAn é a transição entre o metabolismo aeróbio para o anaeróbio, sinalizando a aptidão fisica. Quando caracterizado apenas em função das trocas respiratórias o limiar anaeróbio é denominado limiar ventilatório, estabelecido pela intensidade de esforço, superando a remoção de ácido láctico, que acarreta na hiperventilação.

O escopoajusta um modelo estatístico, que possa substituir a análise visual, à curva dos intervalos $R R$ de dois voluntários do sexo masculino, sedentários e com idades que variam entre 40 e 60 anos. 0 método de avaliação será utilizado para descrever a curva de resposta da frequência cardíaca.

\section{Conclusão}

Ao encontrar os pontos de mudança que podem ter relação com o limiar de anaerobiose e ponto de compensação ventilatória, será possível utilizar os métodos estatísticos paraindicaros padrões de mudança na resposta dos intervalos RR, ou seja,da FC.O estudo está em andamento e a próxima etapa é a análise dos dados. Essa inovação tecnológica é de suma importância para configurar estratégias de avaliação e capacidade funcional, como para ampliar perspectivas para a aplicação clínica.

\section{Referências}

[1] Marães VRFS. Frequência cardíaca e sua variabilidade: análises e aplicações. Revista Andaluza de Medicina Del Deporte, v. 3, n. 1, p. 33-42. Espanha, mar. 2010.

[2] Caruso FCR, et al. Determinação do limiar anaeróbio pela variabilidade da frequência cardíaca de pacientes com DPOC durante exercício em cicloergômetro. Fisioterapia em movimento, v. 25 , n. 4. Curitiba, out./dez. 2012.

[3] Sandoval AEP. Medicina do esporte: princípios e prática. Porto Alegre: Artmed, 2005.

[4] Polito MD, Farinatti PTV. Respostas de frequência cardíaca, pressão arterial e duplo- -produto ao exercício contra-resistência: uma revisão da literatura. Revista Portuguesa de Ciências do Desporto, 2003, v. 3, n. 1, p. $79-91$.

[5] Gomes CJ. Dinâmica cronotrópica pós-esforço e função autonômica cardíaca de repouso em praticantes de dança de salão. 2015. xiii, 126 f., il. Universidade de Brasília, Brasília, 2015.

[6] Brasil. Ministério da Saúde. Secretaria-Executiva Área de Economia da Saúde e Desenvolvimento Avaliação de tecnologias em saúde: ferramentas para a gestão do SUS / Ministério da Saúde, Secretaria-Executiva, Área de Economia da Saúde e Desenvolvimento. Brasilia: Editora do Ministério da Saúde, 2009

[7] Secoli SR, et al. Avaliação de tecnologia em saúde: II. Análise de custo-efetividade. Arquivos de Gastroenterologia, v. 47, n. 4. São Paulo, out./dez. 2010.

[8] Junior ECPL, et al. Estudo comparativo do consumo de oxigênio e limiar anaeróbio em um teste de esforço progressivo entre atletas profissionais de futebol e futsal. Rev. Bras. Med. Esporte, v. 12, n. 6. Niterói, nov./dez. 2006. 


\title{
HOMEOPATIA: UMA TECNOLOGIA EM SAÚDE
}

\author{
R. L. Ludmila, R. F. S. M. Vera, M. F. G. Marilia e A. A. Elisângela \\ Universidade Federal de Brasília (Unb), Brasília, Brasil \\ e-mail: ludymilarocha@hotmail.com
}

\begin{abstract}
Resumo: Toda medicação homeopática é uma apresentação farmacêutica obtida pelo método de diluições seguidas de agitação. Pouco se sabe sobre o processo de dinamização e a dinâmica da água, o que dificulta a consolidação da homeopatia como ciência nos parâmetros tradicionais. Vários estudos publicados analisaram a água homeopática utilizando técnicas sensiveis como a termoluminescência, a espectroscopia de Raman, a calorimetria de fluxo, a condutividade elétrica, e a impedância elétrica. Esse estudo tem um caráter interdisciplinar, em busca de evidências científicas e informações relevantes acerca do estudo da homeopatia dentro do campo da engenharia biomédica. Palavras-chave: Engenharia Biomédica, Homeopatia, Tecnologia em saúde.
\end{abstract}

Abstract: Every homeopathic medication is a pharmaceutical presentation obtained by the methods of dilutions followed by agitation. Little is known about the process of dynamization and water dynamics, which makes it difficult for homeopathy to consolidate as a science in the traditional parameters. Many published studies have analised homeopathic water using the sensitive techniques, such as thermoluminescence, Raman spectroscopy, heat flow calorimetry, electrical conductivity and electrical impedance. This study has interdisciplinary nature seeking scientific evidence and relevant information about the homeopathy study within the field of Biomedical Engineering.

Keywords: Biomedical Engineering, Health technology, Homeopathy.

\section{Introdução}

Em todas as civilizações a doença esteve presente, e cada uma delas compreendia e as tratavam de formas diversas. Por exemplo, a medicina da época préhistórica atribuía o adoecimento a uma fraqueza frente a uma força mais forte, feitiçaria ou possessão por um espírito do mal. Hipócrates (cerca de 460-377 a.C.) se opôs a esse antigo foco no misticismo e na superstição. Foi o primeiro a afirmar que a doença era um fenômeno natural e que suas causas poderiam ser conhecidas e mereciam estudos sérios. Assim, constituiu as primeiras bases para uma abordagem científica da cura [1]. Escreveu vários tratados sistematizando e dando um caráter mais científico, tornando-se dessa forma, figura principal nos primeiros estágios da medicina e da ciência [2]

A homeopatia surge no século XVIII, onde o capitalismo valorizava o trabalho no sentido de fornecer produtos, causando mudanças nas relações entre a filosofia e a ciência, o trabalho manual e o intelectual, a teoria e a técnica, resultando no abandono da concepção de ciência como verdade desinteressada em benefício das coisas necessárias à vida [3]. A homeopatia vai de encontro a Hipócrates ao considerar não somente as alterações fisiológicas, mas, sobretudo as emoções e os pensamentos das pessoas e a escolha da medicação segue o princípio da lei dos semelhantes.

A homeopatia foi desenvolvida pelo médico alemão Christian Frederick Samuel Hahnemann. Ela é uma terapia que se baseia no princípio similia similibus curantur (semelhante cura-se pelo semelhante), ao contrário da alopatia, segundo a qual os contrários são curados pelos contrários. Então, os pacientes tratados com homeopatia receberam remédios que, num indivíduo sadio, produzem os mesmos sintomas que se pretende curar no doente [4].

Toda medicação homeopática é uma apresentação farmacêutica obtida pelo método de diluições seguidas de agitação [5]. Esse processo de dinamização tem sido sugerido por alguns autores como sendo capaz de alterar as propriedades físicas e químicas da água. Pouco se sabe sobre o processo de dinamização e a dinâmica da água, o que dificulta a consolidação da homeopatia como ciência nos parâmetros tradicionais [6].

$\mathrm{Na}$ comunidade científica muitos consideram a homeopatia como uma pseudociência, pois alegam não haver princípio ativo na água devido às diluições. Além disso, argumentam não haver estudo estatístico publicado que mostre os efeitos da medicação homeopática. Chegam até a chamar as terapias alternativas de "medicina dos ignorantes do método cientifico" [7]

A engenharia biomédica tem uma natureza multidisciplinar [8] o que possibilita enormes oportunidades para inovações no campo de estudos na homeopatia, na área de tecnologia em saúde.

Tecnologia em saúde não se refere somente a medicamentos, a equipamentos e a procedimentos utilizados na assistência à saúde, refere-se também a todas as formas de conhecimento que podem ser aplicadas para a solução ou a redução dos problemas de saúde de indivíduos ou populações [9]. De acordo com a hierarquia de tecnologia proposto por Liaropoulos, citado na avaliação de tecnologias em saúde do Ministério da Saúde, as tecnologias biomédicas incluem as medicações e os equipamentos, o que é considerado pela maioria das pessoas tecnologia na área da saúde [9] 
A homeopatia enquadra-se na tecnologia biomédica e, segundo a Política Nacional de Práticas Integrativas e Complementares (PNPIC) no Sistema Único de Saúde SUS - é considerada um sistema médico complexo que aborda o pacientes de forma integral e dinâmica no processo saúde-doença. Além disso, atua no campo da prevenção de agravos, promoção e recuperação da saúde [10].

Com isso, fortalece um modelo centrado na saúde, observando a pessoa como um todo, em dimensões físicas, psicológicas, sociais e culturais. Também corrobora na redução do uso de medicamentos alopáticos. Esse recurso permite ao terapeuta trabalhar em vários níveis de atenção à pessoa, por meio de ações de prevenção de doenças, promoção e recuperação da saúde. Assim, a homeopatia é incorporada em vários setores como emergências, unidades de terapia intensiva, centros de cuidados paliativos e em enfermarias hospitalares. Portanto, complementa e contribui para a maior resolubilidade da atenção [10].

O sistema de saúde aponta para uma grande diversidade no que se refere à incorporação de tecnologia, dificultando a escolha da melhor intervenção ao usuário. Tendo ainda que considerar os custos, a capacidade de recursos humanos, as necessidades de atualização dos instrumentos de regulação e certificação, e aos investimentos na infraestrutura física. Em decorrência dessa dificuldade surge a Avaliação em Tecnologia em Saúde (ATS) para auxiliar as decisões políticas quanto ao impacto da tecnologia em saúde. É um processo interdisciplinar sistemático baseado em evidência científica e outros tipos de informação [9]

Apesar do SUS oferecer a homeopatia aos usuários, muitos gestores apresentam resistência à sua utilização devido a não compreensão da ação das ultradiluições, pois não apresenta a mesma explicação farmacológica para a ação das substâncias que utiliza. Ainda há muitas dificuldades na comprovação científica de sua ação. Como não compreendem a ação da homeopatia, atribuem sua ação como geral e inespecífica, não direcionada a um determinado distúrbio, sendo então uma medicina incapaz de dar respostas imediatas às doenças agudas e graves, ao contrário da biomedicina, que atende a exigência, resolvendo $o$ problema rapidamente. Assim, alguns gestores afirmam que as dificuldades e as resistências são em decorrências da falta de esclarecimento sobre os procedimentos homeopáticos, o que gera insegurança [11].

Nessa perspectiva, e em consonância com a ATS, que afirma a necessidade da avaliação tecnológica pelo estudo sistematizado, este trabalho tem como objetivo identificar estudos que constataram alteração na água homeopática e que contribuíram para o conhecimento da homeopatia como uma tecnologia em saúde.

\section{Materiais e métodos}

A pesquisa bibliográfica considerou estudos que analisaram a água homeopática utilizando aparelhos com o objetivo de identificar alterações na estrutura molecular da água, ou seja, da mediação homeopática. O banco de dados utilizado foi o National Center for Biotechnology Information (NCBI) e publicações dos últimos 8 anos.

O NCBI é um banco de dados que fornece informações de novas tecnologias de informação para ajudar na compreensão dos processos moleculares e genéticas fundamentais que controlam a saúde e a doença. A pesquisa realizada resultou em trabalhos no PubMed e na Pub Med Central (PMC). As palavras chaves e a quantidade de artigos encontrados estão na Tabela 1.

Tabela 1: Resultado da quantidade de artigos encontrados na pesquisa bibliográfica.

\begin{tabular}{ccccc}
\hline NCBI & Palavra chave & Total & Seletos & Relevantes \\
\hline PubMed & $\begin{array}{c}\text { Homeopathy } \\
\text { evidence } \\
\text { Homeopathy } \\
\text { tecnology, }\end{array}$ & 712 & 34 & 0 \\
& $\begin{array}{c}\text { Homeopathy } \\
\text { spectrometry }\end{array}$ & 39 & 16 & 5 \\
PMC & $\begin{array}{c}\text { Homeopathy } \\
\text { ultraviot }\end{array}$ & 41 & 3 & 3 \\
\hline
\end{tabular}

O critério de inclusão foi selecionar artigos que realizaram experimentos com a água homeopática. Como critério de exclusão optou-se por não utilizar trabalhos que descreviam estudos clínicos e homeopatias glóbulos.

\section{Resultados}

Vários estudos publicados analisaram a água homeopática utilizando técnicas sensíveis como a termoluminescência, a espectroscopia de Raman, a calorimetria de fluxo, a condutividade elétrica, e a impedância elétrica [6].

Estudos analisaram a água homeopática após a exposição a fatores físicos (luz ultravioleta, incubadora e aquecimento a $90^{\circ} \mathrm{C}$ ). $\mathrm{O}$ espectrômetro de infravermelho detectou que as águas homeopáticas tiveram suas propriedades alteradas em comparação ao controle [12]. Em outro trabalho investigou as propriedades físicas das medicações homeopáticas do sulfato de cobre, enxofre e quartzo. Também houve diferenças significativas nas medicações após análise no espectrômetro de infravermelho [13]. As homeopatias pesquisadas após a exposição a fatores externos, como altas temperaturas, não são inertes, apresentando diferenças significativas em comparação ao controle [14].

Análise de dispersão dielétrica apresenta informações relevantes para se estabelecer o valor medicinal da homeopatia. $\mathrm{O}$ autor perscrutou a hipótese de que o efeito da medicação homeopática se deve a codificação estrutural dos átomos e moléculas do veículo que criam um tipo de macromoléculas peculiares. Análise da água homeopática utilizando um 
instrumento desenvolvido pelo autor, anômala detector de dispersão dielétrica, mostrou que a frequência de ressonância da água sem a mediação homeopática é sempre maior do que a água com a homeopatia. Isso sugere que a molécula de água contendo homeopatia é mais organizada [15].

A microscopia eletrônica de transmissão de alta resolução também foi utilizada para analisar os medicamentos homeopáticos derivados de sais inorgânicos e metais. Identificou-se partículas à escala nanométrica nos medicamentos, mesmo em potência mais altas, ou seja, ultra diluídas [16]. Outra pesquisa constatou a presença de estruturas supramoleculares na água homeopática, além disso, as diluições homeopáticas foram fisicamente distinguívies dos seus solventes [17]

\section{Discussão}

Apesar das tentativas para explicar os mecanismos de ação das medições homeopáticas, ainda a natureza de um princípio ativo na homeopatia esta longe de ser esclarecido. Mas há evidências que apoiam fortemente que a estruturação da água e seus solutos desempenham um papel fundamental [18]

$\mathrm{O}$ espectrômetro analisa a estrutura das moléculas, geralmente com base nas diferenças de absorção de radiação eletromagnética. Há vários tipos de espectroscopia, entre elas a espectroscopia de ultravioleta, a espectroscopia de ressonância magnética nuclear, a espectroscopia de infravermelho e a espectrometria de massas [19]. A espectroscopia parece demonstrar alterações nas propriedades fisicas nas homeopatias [12, 13, 14 15, 18], independente do tipo de medicação, sendo uma simples ferramenta útil para tal identificação

As preparações homeopáticas quando foram expostas a fatores externos apresentaram valores de transmissão no espectrômetro de infravermelho inferior em comparação aos controles. Isso significa que uma quantidade maior de luz foi absorvida pelas preparações homeopáticas. Esse resultado pode ser em decorrência de um estado molecular menos estruturado ou mais dinâmico da amostra $[12,13,14]$

A técnica experimental baseada na dispersão dielétrica sugere que nas medicações homeopáticas ocorrem alterações nas dimensões das estruturas de água. A explicação da ação da medicação altamente diluída pode estar na codificação estrutural dos átomos e das moléculas do veículo e do tipo específico de macromoléculas peculiares na substância original, bem como o grau de diluição da medicação. Esses achados fortalecem a hipótese proposta pelo autor de que a ação da homeopatia se deve a essas alterações estruturais [15].

Provavelmente essas moléculas agem como centros de nucleação, ampliando a formação de estruturas supramoleculares e transmitindo ao solvente. Busca-se explicar esse acontecimento pelo clusters da água, pela eletrodinâmica quântica ou pela formação de nanopartículas de soluto original adicionados ao componentes dos solventes. Apesar da dificuldade para o esclarecimento da natureza físico-química das medicações homeopáticas, estudos atuais apoiam-se fortemente na alteração estrutural da água e seus solutos em nanoescalas, assim, desempenhando um papel fundamental nas investigações [18]

\section{Conclusão}

Uma recente avaliação de tecnologia em saúde relata que a eficácia clínica da homeopatia é apoiada por evidência [13], mas é necessário que haja mais estudos no campo da homeopatia para o entendimento de suas propriedades físico-químico.

Estudos nesse sentido encontram-se atualmente em desenvolvimento na Universidade de Brasília (Unb) no Mestrado de Engenharia Biomédica. A pesquisa visa analisar as propriedades fisicas da medicação homeopática no espectrofotômetro de infravermelho e no equipamento de espalhamento dinâmico de luz Nano-Zetasizer da Malvern Instruments.

\section{Agradecimentos}

Agradecemos a Dra. Claure Nain Lunardi Gomes, graduada em química e professora da Unb, pelo auxílio aos estudos em andamento no laboratório de fotoquímica e nanobiotecnologia da Faculdade de Ceilândia, Distrito Federal.

\section{Referências}

[1] Straub RO. Psicologia da Saúde: uma abordagem biopsicossocial. 3a ed. Porto Alegre: Artmed; 2014. p. $02-11$.

[2] Santos R, SÁ FMP. Homeopatia: histórico e fundamentos. Revista Científica da Faculdade de Educação e Meio Ambiente [internete]. 2014 JanJun [acesso 26 Jul 15]; 5(1):60-78. Disponível em http://www.faema.edu.br/revistas/index.php/RevistaFAEMA/article/view/206/166

[3] Mota A, Noveas HMMD, Scharaiber LB. In: Escola Politécnica de Saúde Joaquim Venâncio - EPSJV. (Org.). Dicionário da educação profissional em saúde. 1a ed. Rio de Janeiro - RJ: Fiocruz/EPSJV, [internete]. 2006 [acesso 01 Nov 15]: 248-257. Disponível em: $\mathrm{http}: / /$ www.sites.epsjv.fiocruz.br/dicionario/verbetes /tecsau.html\#topo.

[4] Gonsalves PE. Medicinas Alternativas: Os tratamentos não-convencionais. 3a ed. São Paulo: Ed. IBRASA, 1999. p.194-204.

[5] Fontes OL, et al. Farmácia homeopática: teoria e prática. 4a ed. Rev. e atual. Barueri, SP: Manole, 2014. p. 389.

[6] Holandino C. A Homeopatia e os Modelos Experimentais para a Compreensão das Propriedades Físico-Químicas e Biológicas dos Sistemas Dinamizados. Revista de Homeopatia. 2009 Jan [acesso 16 Ago 15]; 72(3/4):15-17. Disponível em: https://www.researchgate.net/publication/228498270 
A Homeopatia e os Modelos Experimentais par a a Compreensao das Propriedades FisicoQuimicas_e_Biologicas_dos_Sistemas_Dinamizado S.

[7] Young P. La farsa de la homeopatía. Rev. méd. Chile, Santiago [internete]. $2014 \mathrm{Feb}$ [Acesso 24 Set 15]; 142(2):272-3. Disponível em: http://www.scielo.cl/scielo.php?script=sci arttext\&p id $=$ S0034-98872014000200021\&lng=es \&nrm=iso

[8] Possa PRC, Andrighetto E, Santos FC, Rathke JE, Adur R, Argoud FIM, Ojeda R, Azevedo FM Marino-Neto J. A inserção da Engenharia Biomédica nos cursos de graduação em Engenharia Elétrica no Brasil. Revista Brasileira de Engenharia Biomédica. 2008 Ago [acesso 18 Set 15]; 24(2):123-130 Disponível em: $\mathrm{http}: / /$ www.rbejournal.org/files/v24n2/v24n2a3.pdf

[9] Brasil. Ministério da Saúde. Secretaria-Executiva. Area de Economia da Saúde e Desenvolvimento. Avaliação de tecnologias em saúde: ferramentas para a gestão do SUS / Ministério da Saúde, Secretaria-Executiva, Área de Economia da Saúde e Desenvolvimento. - Brasilia: Editora do Ministério da Saúde, [internete] 2009. 110 p. : il. - (Série A Normas e Manuais Técnicos). [acesso 22 Abr 16] Disponível em http://bvsms.saude.gov.br/bvs/publicacoes/avaliacao tecnologias saude ferramentas gestao.pdf.

[10] Brasil. Ministério da Saúde. Portaria do Gabinete do Ministro n.971, de 03 de maio de 2006. Aprova a Política Nacional de Práticas Integrativas e Complementares (PNPIC) no Sistema Único de Saúde. [acesso 14 Out 14]. Disponível em http://bvsms.saude.gov.br/bvs/saudelegis/gm/2012/p rt0971 1505 2012.html.

[11] Salles SAC, Schraiber LB. Gestores do SUS: apoio e resistências à Homeopatia. Cadernos de Saúde Pública (FIOCRUZ) [internete]. 2009 Jan [acesso 30 Abr 16]; 25 (1):195-202. Disponível em http://www.scielo.br/scielo.php?script=sci arttext\&p id=S0102-311X2009000100021.

[12] Marschollek B, Nelle M, Wolf M, Baumgartner S, Heusser P, Wolf U. Effects of exposure to physical factors on homeopathic preparations as determined by ultraviolet light spectroscopy TheScientificWorldJournal. [internte]. 2010 Jan [acesso 30 Abr 16]; 10: 49-61. doi 10.1100/tsw.2010.15. Disponível em http://www.ncbi.nlm.nih.gov/pubmed/2006295.

[13]Wolf U, Wolf M, Heusser P, Thurneysen A, Baumgartner, S. Homeopathic preparations of quartz, sulfur, and copper sulfate assessed by UVspectroscopy. Evid. Based Complement. Alternat. Med., in press [internete]. 2009 Jun [acesso $27 \mathrm{Abr}$ 16]. Disponível em: http://www.ncbi.nlm.nih.gov/pubmed/19474239

[14] Klein SD, Sandig A, Baumgartner S, Wolf U. Differences in Median Ultraviolet Light Transmissions of Serial Homeopathic Dilutions of Copper Sulfate, Hypericum perforatum, and Sulfur,
Evidence-Based Complementary and Alternative Medicine [internete]. 2013 Nov [acesso 27 Abr 16] Disponível em http://www.hindawi.com/journals/ecam/2013/37060 9/citations/.

[15] Mahata CR. Dielectric dispersion studies of some potentised homeopathic medicines reveal structured vehicle - Homeopathy [internete]. 2013 Oct [acesso 29 Abr 16]; 102(4):262-7. Disponível em http://www.homeopathyjournal.net/article/S14754916(13)00063-5/abstract.

[16] Temgire, MK, et al. Establishing the interfacial nano-structure and elemental composition of homeopathic medicines based on inorganic salts: a scientific approach. Homeopathy, Volume 105, Issue $2,160-172$. [acesso $29 \mathrm{Abr} 16$ ]. Disponível em

http://www.homeopathyjournal.net/article/S1475 4916(15)00074-0/abstract.

[17]Demangeat JL. Gas nanobubbles and aqueous nanostructures: the crucial role of dynamization. Homeopathy, Volume 104 , Issue 2, $101-115$. [acesso 29 Abr 16]. Disónível em http://www.homeopathyjournal.net/article/S14754916(15)00004-1/fulltext.

[18]Bellavite1 P, Marzotto1 M, Olioso1 D, Morattil E, Conforti A. High-dilution effects revisited. 1. Physicochemical aspects. Homeopathy [internte]. 2014 Jan [acesso 7 Jan 16]; 103(1):4-21. Disponível em: http://www.homeopathyjournal.net/article/S1475 4916(13)00063-5/abstract.

[19] Vollhardt KPC, Shore NE. Química Orgânica Estrutura e Função. 6a ed. Porto Alegre: Bookman; 2013. p 388-390 


\section{ANEXO 3: FICHAS DE AVALIAÇÃO}

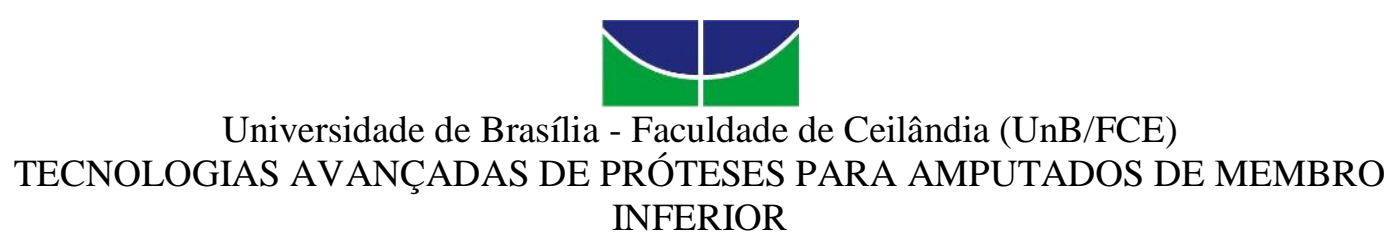

FICHA DE AVALIAÇÃO - $1^{\circ}$ DIA

Data: I

Avaliador:

Local:

Nome:

Idade: Data de nascimento: Raça:

Tipo de amputação: Causa: Tempo:

Profissão atual:

Local de trabalho:

Escolaridade: Estado Civil:

Queixa:

\section{1- HÁBITOS DE VIDA:}

FUMANTE: ( ) SIM ( ) NÃO

OBSERVAÇÕES:

INGERE BEBIDAS ALCOÓLICAS: ( ) SIM ( ) NÃO

OBSERVAÇÕES:

ATIVIDADE FÍSICA: ( ) SIM ( ) NÃO QUAL:

QUANTAS VEZES/SEMANA: DURAÇÃO:

OBSERVAÇÕES:

APRESENTA ALGUM DISTÚRBIO DE SONO:

( ) SIM

( ) NÃO

OBSERVAÇÕES: 


\section{2- ANTECEDENTES FAMILIARES:}

APRESENTA ANTECEDENTES FAMILIARES DAS DOENÇAS ABAIXO:

\begin{tabular}{|l|l|l|}
\hline CATEGORIA & PARENTESCO & HÁ QUANTO TEMPO \\
\hline ALTERAÇÃO DA TIREÓIDE & & \\
\hline DIABETES & & \\
\hline DISLIPIDEMIA & & \\
\hline OBESIDADE & & \\
\hline RENAIS & & \\
\hline PULMONARES & & \\
\hline CARDIOVASCULAR & & \\
\hline
\end{tabular}

OBSERVAÇÕES:

\section{3- HISTÓRIA PREGRESSA E ATUAL DE DOENÇAS:}

3.1- APRESENTA OU APRESENTOU ALGUMA DAS DOENÇAS ABAIXO:

\begin{tabular}{|l|l|l|l|l|}
\hline DOENÇAS & SIM & NÃO & TIPO & QUANTO TEMPO \\
\hline ALTERAÇÃO DA TIREÓIDE & & & & \\
\hline DIABETES & & & & \\
\hline DESLIPIDEMIA & & & & \\
\hline OBESIDADE & & & & \\
\hline RENAIS & & & & \\
\hline PULMONARES & & & & \\
\hline ESCLERODERMIA & & & & \\
\hline ESPASMO ESOFÁGICO & & & & \\
\hline ÚLCERA PEPTOCA & & & & \\
\hline EPILEPSIA & & & & \\
\hline CARDIOVASCULAR & & & & \\
\hline RESPIRATÓRIA & & & & \\
\hline
\end{tabular}


OBSERVAÇÕES:
3.2- COSTUMA SENTIR FALTA DE AR/DISPNÉIA:
( ) SIM
( ) NÃO

3.3- APRESENTA OUTROS SINTOMAS?

3.4- FAZ USO DE MEDICAMENTOS: ( ) SIM ( ) NÃO

ESPECIFICAR:

\section{4- EXAME FÍSICO}

\section{2- COMPOSIÇÃO CORPORAL}

$\operatorname{MASSA}(\mathrm{Kg})$ : ALTURA:

$\operatorname{IMC}\left(\mathrm{Kg} / \mathrm{m}^{2}\right)$ :

PERÍMETRO QUADRIL:

CINTURA:

RCQ:

ABDOMINAL: $(\mathrm{H}<94)$

COXA: D E

PREGAS CUTÂNEAS: (H- TR+ TO+ SB)

\section{3- AVALIAÇÃO DO COTO}

CONDIÇÕES DA PELE:

( ) FINA ( ) ESPESSA ( ) NORMAL ( ) DESIDRATADA

( ) TEMPERATURA NORMAL ( ) ALTERADA

( ) ALTERAÇÕES DE UNHAS E PELOS.

Obs:

COLORAÇÃO: ( ) NORMAL ( ) PÁLIDO ( cIANÓTICO

SENSIBILIDADE: ( ) NORMAL ( ) PARESIA ( ) HIPOESTESIA ( ) ANESTESIA DEFORMIDADES: ( ) SIM ( ) NÃO Obs:

CONDIÇÕES: ( ) FIRME; ADERÊNCIAS CICATRICIAIS ( ); NEUROMAS ( ); EDEMA ( ); DOR FANTASMA ( ).

Obs: 


\section{AVALIAÇÃO DO EQUILÍBRIO}

\section{Posição Tandem (pé não dominante à frente - $\mathbf{1 0}$ segundos)}

( ) Negativo

( ) Estratégia de equilíbrio de tornozelo (+)

( ) Estratégia de equilíbrio de quadril (+)

( ) Estratégia de equilíbrio do passo (+)

( ) Reflexo de proteção (+)

\section{Timed Get Up and Go Test:}

( )10 segundos ou menos ( sem alterações)

( ) 20 segundos ( independência para atividades básicas)

( )10 segundos ou mais ( dependentes na mobilidade)

\section{Alcance Funcional - Reach test}

Primeira tentativa: $\mathrm{cm}$

Segunda tentativa: $\mathrm{cm}$

Terceira tentativa: $\mathrm{cm}$

Média: $\mathrm{cm}(<17 \mathrm{~cm}=$ risco de queda $)$

\section{4- TESTE DE CAMINHADA DE 6 MINUTOS:}

\begin{tabular}{|l|l|l|}
\hline \multicolumn{1}{|c|}{ DADOS } & INÍCIO & FIM \\
\hline FC & & \\
\hline PA & & \\
\hline \multicolumn{2}{|l}{ DISTÂNCIA PERCORRIDA: }
\end{tabular}


HORÁRIO:

OBSERVAÇÕES:

\section{5- OUTRAS INFORMAÇÕES}

5.1NÍVEL DE AMPUTAÇÃO:

5.2 TEMPO DE AMPUTAÇÃO:

5.3 TEMPO DE USO DA PRÓTESE:

5.4 FABRICANTE E MODELO DA PRÓTESE:

6- COLETA DA VFC (POLAR):

\begin{tabular}{|l|l|l|l|l|l|}
\hline Posição & Horário & FC inicial & PA inicial & FC final & PA final \\
\hline Supino & & & & & \\
\hline Sentado & & & & & \\
\hline Em pé & & & & & \\
\hline $\begin{array}{l}\text { Teste de } \\
\text { caminhada }\end{array}$ & & & & & \\
\hline
\end{tabular}




\title{
ANEXO 4: TERMO DE CONSENTIMENTO LIVRE E ESCLARECIDO (TCLE)
}

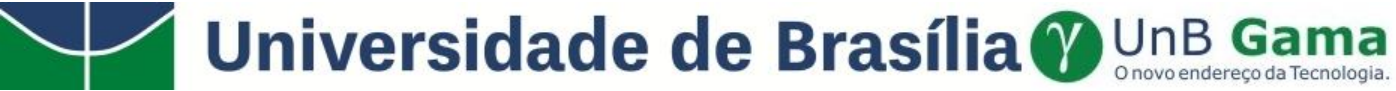

\author{
Termo de Consentimento Livre e Esclarecido - TCLE
}

O (a) Senhor(a) está sendo convidado(a) a participar do projeto: Desenvolvimento tecnológico $e$ adaptação de prótese ativa em amputados atletas

O objetivo desta pesquisa é: avaliar a sua condição física e se o nosso equipamento é válido para analisar pacientes com amputação abaixo do joelho!

$\mathrm{O}$ (a) senhor(a) receberá todos os esclarecimentos necessários antes e no decorrer da pesquisa e lhe asseguramos que seu nome não aparecerá, sendo mantido o mais rigoroso sigilo através da omissão total de quaisquer informações que permitam identificá-lo(a).

A sua participação será através de uma série de avaliações que o(a) senhor(a) deverá participar no setor de fisioterapia da Faculdade de Ceilândia na data combinada com tempo estimado para sua realização. Será respeitado o tempo de cada um para respondê-lo. Informamos que o(a) Senhor(a) pode se recusar a responder qualquer questão que lhe traga constrangimento, podendo desistir de participar da pesquisa em qualquer momento sem nenhum prejuízo para o(a) senhor(a).

As etapas a que o senhor (a) se submeterá são:

1. Avaliação: coleta de dados pessoais, hábitos de vida e alimentar, antecedentes familiares, história atual e pregressa de doenças.

2. Captação da frequência cardíaca batimento a batimento na condição de repouso deitado e sentado por 10 min e caminhando durante 6 minutos.

3. Teste isocinético: Avaliação da força muscular

4. Teste Ergoespirométrico: Avaliação da condição física

5. Captação de sinais biológicos: Avaliação da ativação muscular

a. Experimentação dos eletrodos em matriz

b. Experimentação do socket no membro amputado

É possível que durante os testes, o senhor tenha sintomas como falta de ar, visão escurecida, tontura, mal estar e até mesmo dores no peito. Mas não se preocupe! O teste será interrompido imediatamente e a equipe de pesquisa estará te acompanhando durante todo o processo e bem atenta a esses sinais. Além disso, somos treinados para atendimento de primeiro socorros e em caso de persistirem os sintomas o atendimento de urgência local será contatado.

É também garantido ao senhor e ao seu acompanhante, o reembolso de gastos adicionais que o senhor possa ter para comparecer ao nosso ambiente de pesquisa, assim como indenização quando houver algum tipo de dano em virtude da nossa pesquisa. 
Nós acreditamos que nossa pesquisa pode beneficiar várias pessoas com amputação de membro inferior! É nossa meta entender melhor como o seu corpo se adaptou a perda da perna e assim contribuir para um tratamento mais específico e completo.

O equipamento que será desenvolvido aqui tem também é um pequeno passo para a melhoria de próteses. Através dos sinais originados na etapa número 5 (Captação de sinais biológicos) poderemos determinar os pontos de maior ativação muscular da coxa e a partir deles projetar uma malha de material elástico especial para captar esses pontos e possivelmente controlar uma prótese de joelho.

Você tem direito à assistência integral gratuita em virtude de danos diretos/ indiretos e imediatos/ tardios, pelo tempo que for necessário. Além disso, os testes aqui fornecidos são importantes para a sua saúde e você poderá levar todos eles e apresentar ao seu médico de rotina.

Os resultados da pesquisa serão divulgados na Instituição Universidade de Brasília - UnB podendo ser publicados posteriormente. Os dados e materiais utilizados na pesquisa ficarão sobre a guarda do pesquisador e poderão ser acessados por você a qualquer tempo, sempre que solicitado.

Se o(a) Senhor(a) tiver qualquer dúvida em relação à pesquisa, por favor telefone para: Dr(a). Vera Regina, na instituição Faculdade de Ceilândia telefone: 3377-0615 ou 8228-3700.

O Comitê de ética em pesquisa da Faculdade de Saúde da UnB é a autoridade responsável pela regulamentação e fiscalização dos projetos de pesquisa. As dúvidas com relação à assinatura desse termo ou dos seus direitos dentro da pesquisa podem ser obtidas através do telefone: (61) 3107-1918, indo até a Faculdade de Ciências da Saúde (FS) no Campus Darcy Ribeiro (Asa norte, via L4) em horário comercial ou ainda através do endereço eletrônico cepfs@ unb.br! Este projeto foi Aprovado pelo Comitê de Ética em Pesquisa da FS/DF.

Este documento foi elaborado em duas vias, uma ficará com o pesquisador responsável e a outra com o sujeito da pesquisa. TODAS as vias devem ser rubricadas por nós e por você.

Nome / assinatura

Pesquisador Responsável 